The history of Finnish Lapland is a history of labor migration. First, in the late 19th Century, people travelled from the South to Lapland in search of work in the timber industry. A hundred years later, in the 1960s and 70s, many of their grandchildren's generation took the same journey in reverse in search of work in southern Finland, Sweden, or across the oceans in the New World.

This book is about the everyday lives of those migrant workers in Lapland and in Sweden. The primary source for this book is the narratives of the migrant workers. They tell their own story.

Hanna Snellman is a Research Fellow of the Academy of Finland, and this book is part of her study of the resilience of migrants.

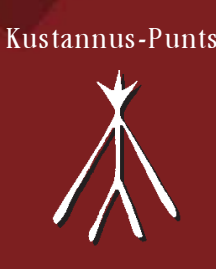

Inari 2005
点

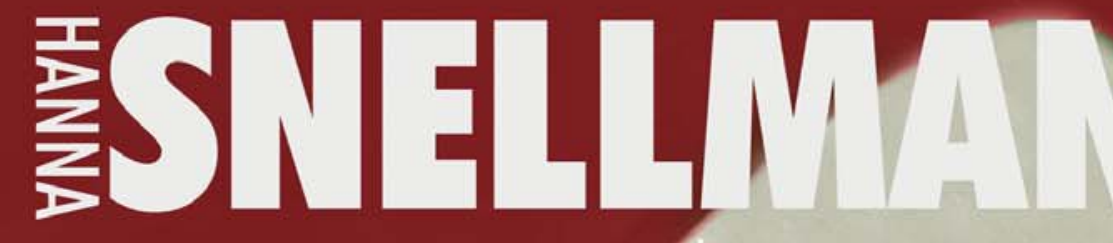

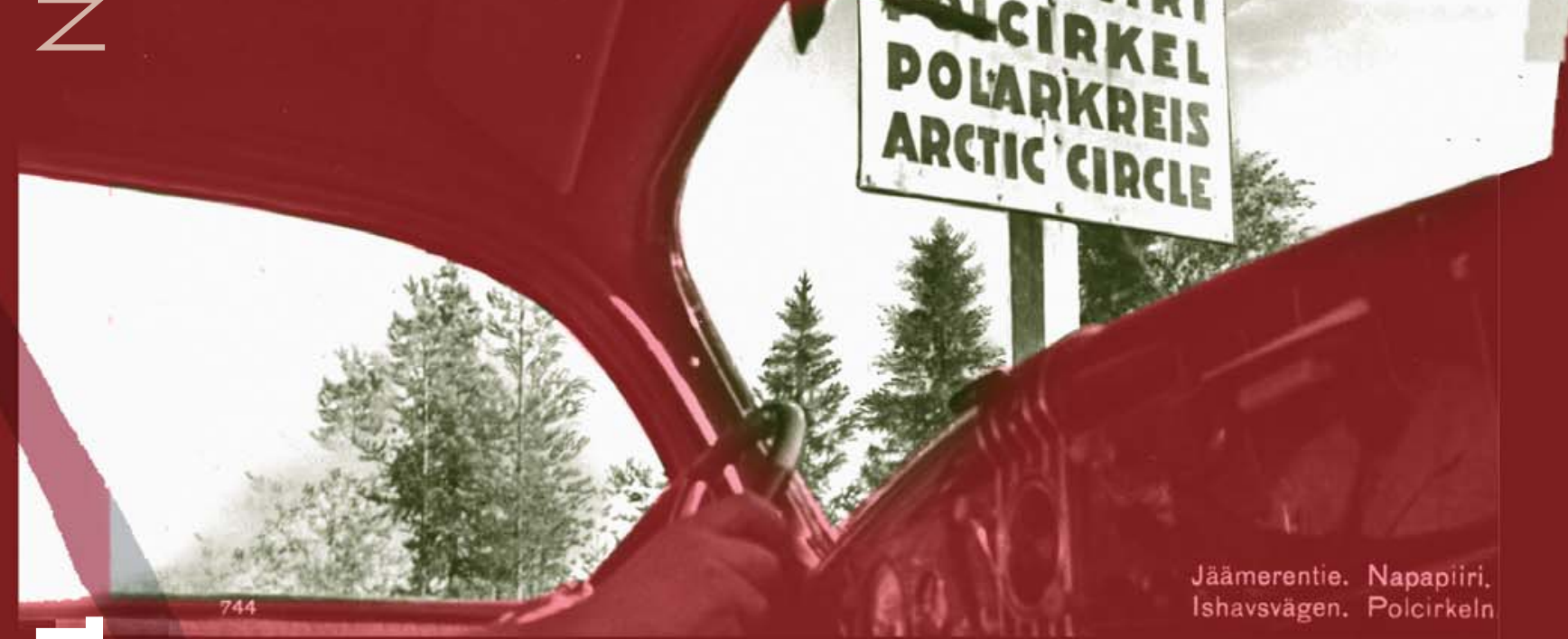

8

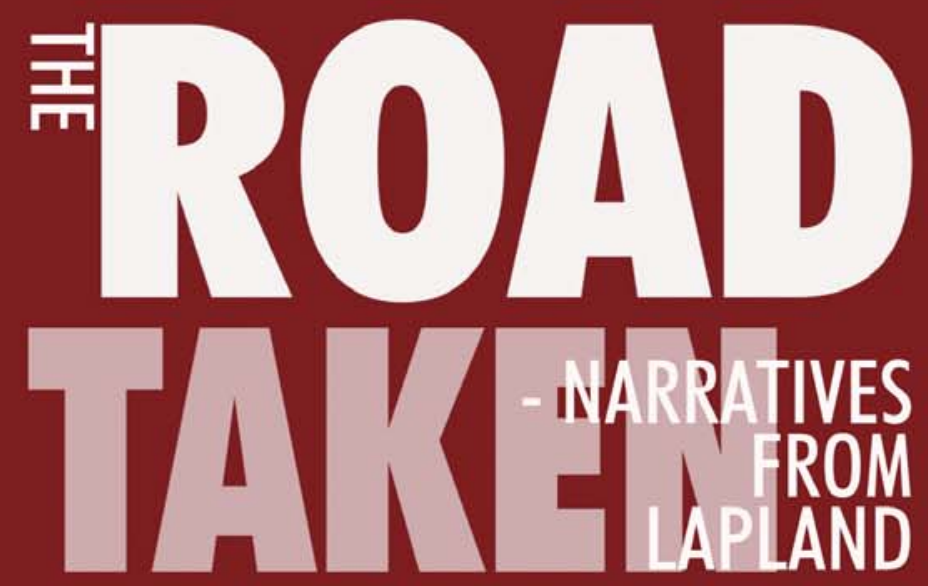


<smiles>[C]1C=C[Te]1</smiles> 
(C) Hanna Snellman

Editor: Kaisa Voutila

Layout and cover: Matjas Jumisko

Original cover photo by Fred Runeberg, The Arctic Circle. The National Board of Antiquities

Kustannus-Puntsi Inari

WWW.PUNTSI.FI

ISBN 952-5343-26-X

Gummerus Kirjapaino Oy

Saarijärvi 2005 


\section{THE ROAD TAKEN}



HANNA SNELLMAN

\section{THE ROAD TAKEN}

NARRATIVES FROM LAPLAND 
FOR THE ROAD

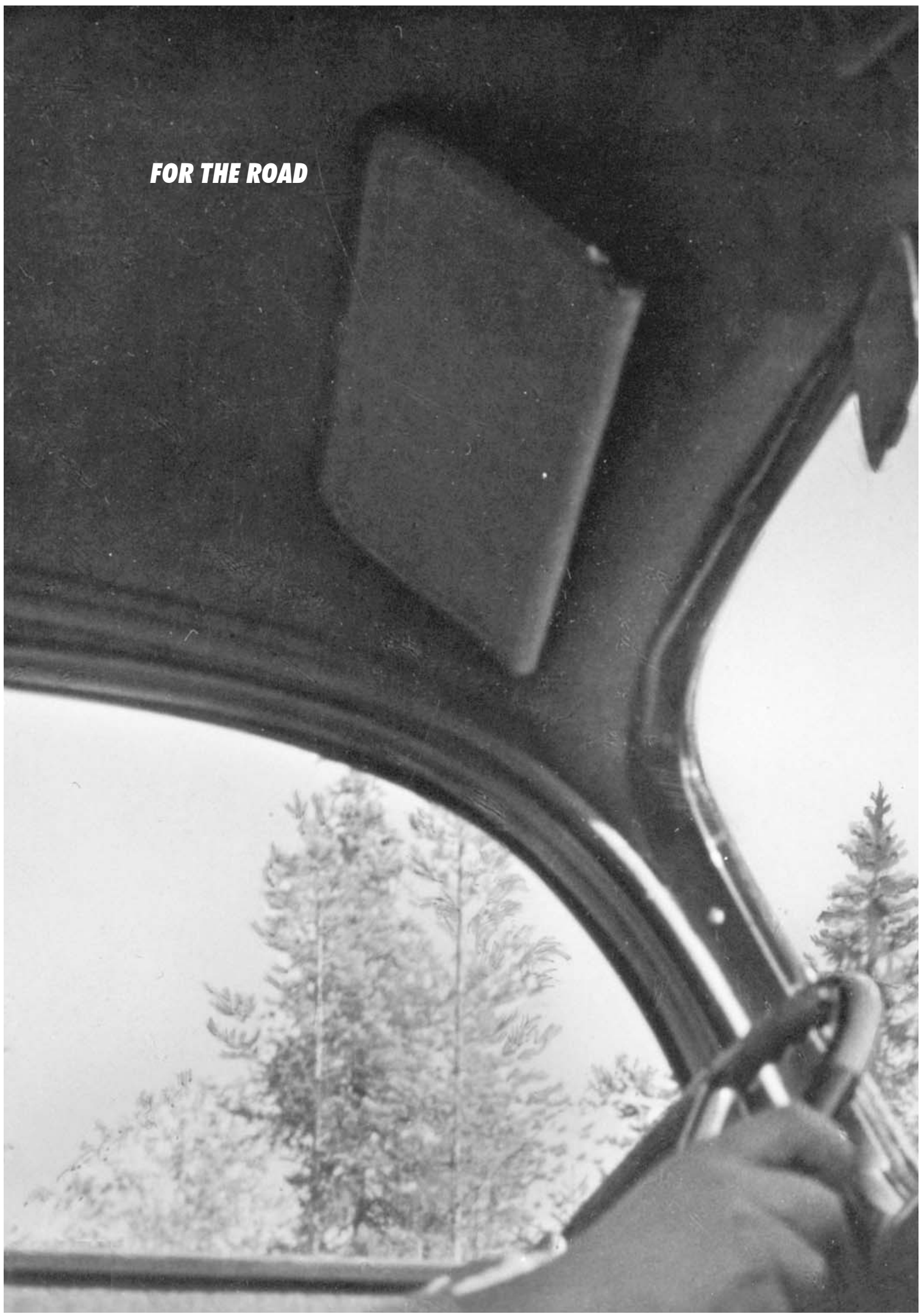




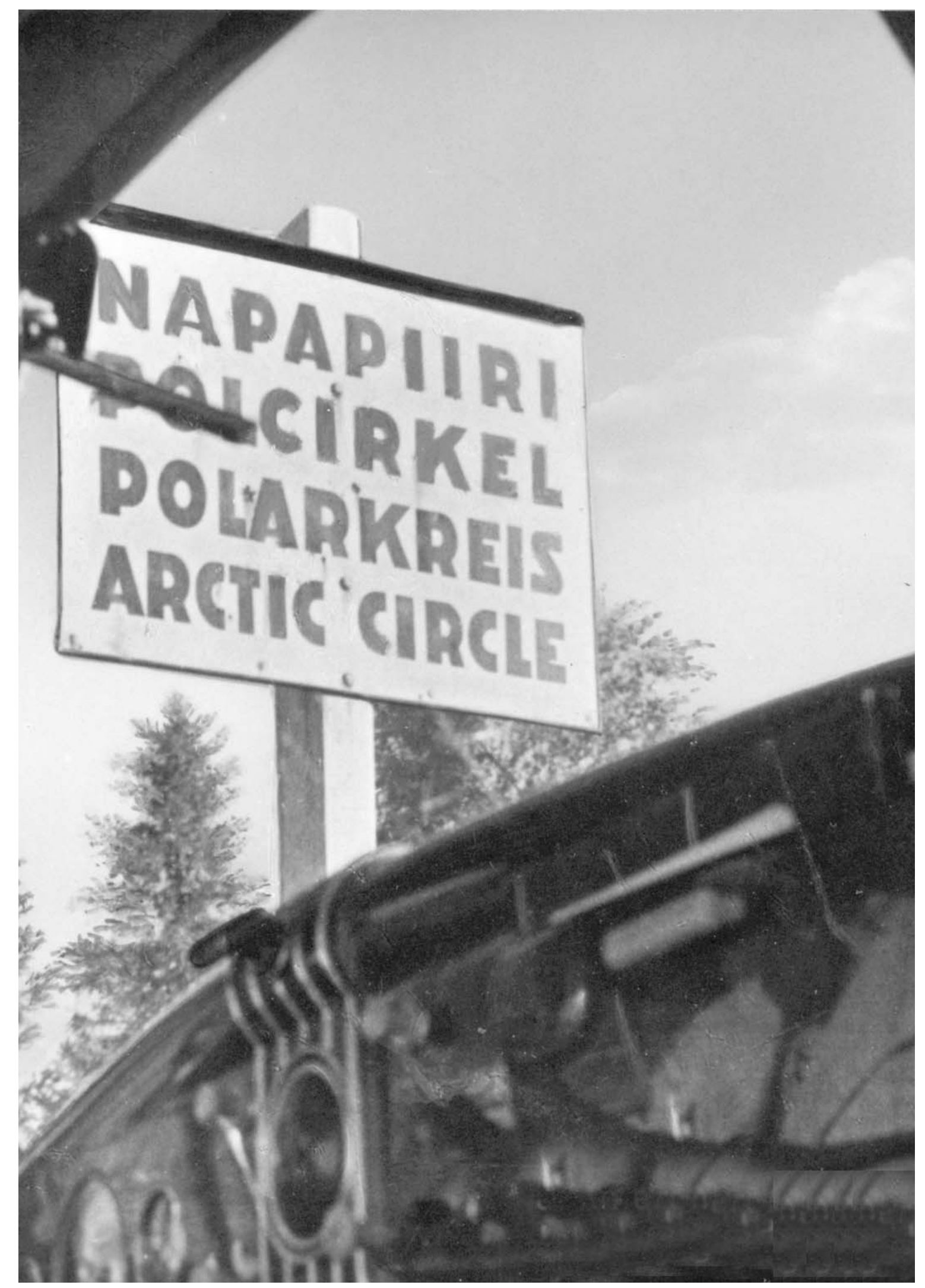




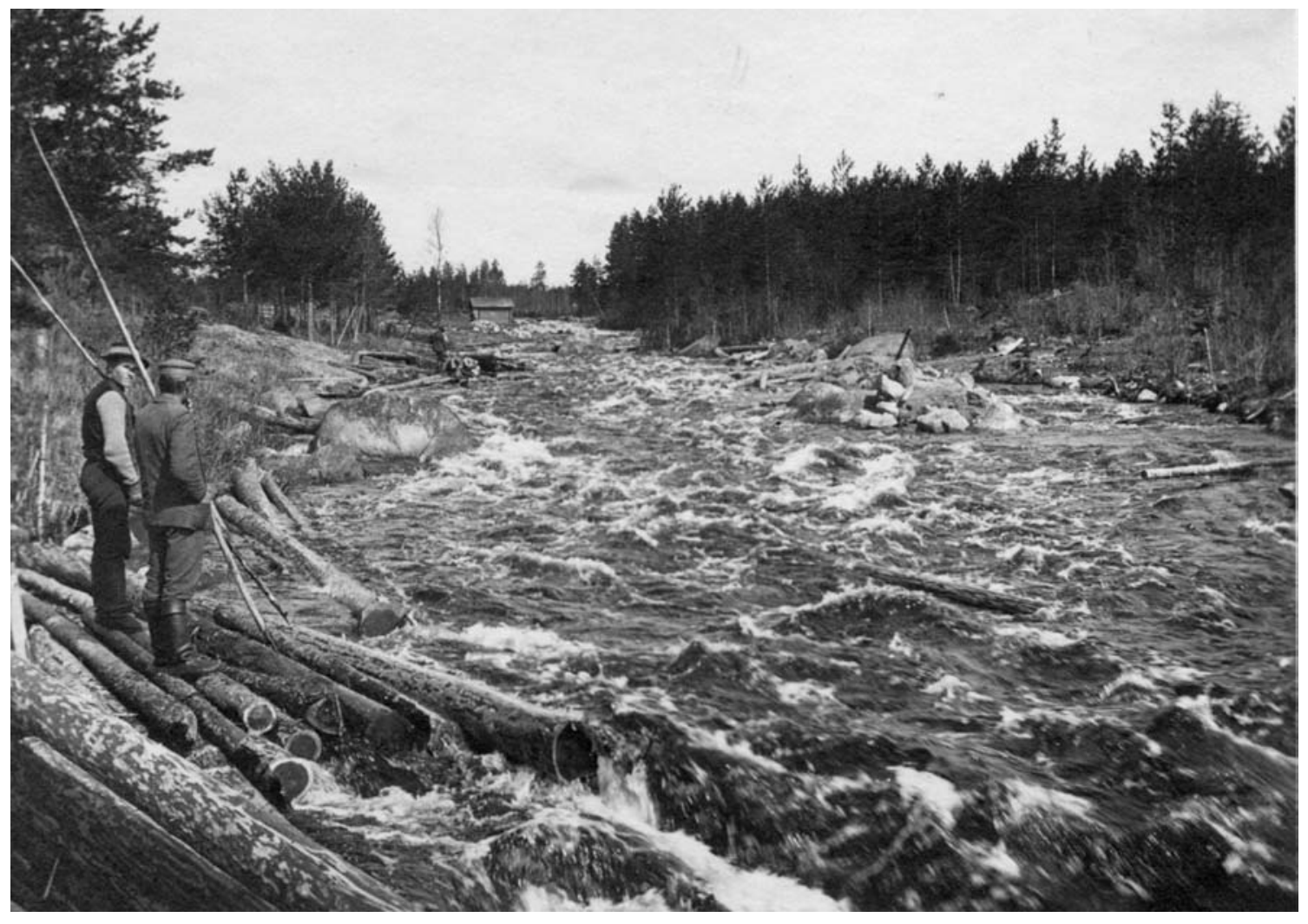


The landscape of twentieth century

Lapland is a landscape of logging

and river driving.

The life history approach arrived in Finnish ethnology in the 1970s when scholars became interested in the life styles of industrial workers and the history of occupations. It was typical to start an interview with biographical questions in order to shed light on the informant's family history, career history, and the history of their residence. Ethnologists were taught that it would be easier to conduct an interview when the interviewer knew approximately the "time table" of the informant's life. In fact, it was merely a question of timing, rather than obtaining a thorough picture of someone's life. At that time the ethnologist's task was to find details and in addition, to put a time or date to certain events. Furthermore life history was seen as a key to opening up historical sources. If you knew someone's name, date and place of birth you could easily increase your knowledge of that person's life with information from for example census lists, inventories and other records.

As ethnologists became more interested in the lives of industrial workers, they became increasingly fascinated by sociology and social politics as disciplines. ${ }^{1}$ A pioneer in this field in Finland, was Professor Ilmar Talve from the University of Turku who was actually invited to Finland from Sweden by a professor in sociology, Esko Aaltonen. ${ }^{2}$ Another professor in sociology, Heikki Waris, was an important figure, and his $\mathrm{PhD}$ thesis on workers in Helsinki at the end of the 1800s also provided a model for ethnological research on urban workers. 
Heikki Waris for one was inspired by the Chicago school. As is wellknown, the life history method was crucial to the Chicago school. The first sociological use of the technique had taken place immediately before the First World War. The life history method employed in Chicago had connections with Europe through the collection of "pamietniki", written autobiographies or memoirs usually solicited through competitions run by newspapers. Znaniecki, one of the authors of the Chicago school classic "The Polish Peasant in Europe and America", organized the first "pamietniki" competition in Poland in $1921 .^{3}$

In sociology there was a lively methodological debate between the life history or "case study" method and the "statistical method" between the two World Wars. Gradually the overwhelming dominance of quantitative methods of research resulted in life history methods and other qualitative methods fading into the background. ${ }^{4}$ But not for long. The 1960s are known for the rise of countercultures, civil rights movements, protest against the war in Vietnam and the events of $1968 .{ }^{5}$ This all had an effect on research methodology: biographical methods provided a means of conducting research that gave voice to the socially excluded. The work of Oscar Lewis was particularly influential. In 1970, Lewis wrote that "one of the major objectives of my recent work has been to give a voice to people who are rarely heard and to provide readers with an inside view of a style of life which is common in many of the deprived and marginal groups of our society". This declaration 
has been repeated constantly in research conducted in the spirit of oral history. The task is to give people whose voice has not been heard, at least not so far, a voice. Through biographical and other qualitative research methods, faceless cases can attain an identity that quantitative analysis has denied them. ${ }^{6}$

Åke Daun's study “Upp till kamp i Båtskärsnäs. En etnologisk studie av ett samhälle inför industrinedläggelse" published in 1969 pioneered a new way of conducting ethnological research. Båtskärsnäs is something of a symbol of change in ethnology and in post-war rural Sweden. Daun did his fieldwork in a small sawmill community near the Finnish border in northern Sweden. The employees of the sawmill had came together to prevent the closing down of the sawmill, because they did not want to move to factories in Southern Sweden, preferring instead to stay in the north in the area where they had lived all their lives. Ake Daun himself recalls the end of the 1960s as an inspiring time. ${ }^{7}$

In Finnish ethnology, the use of quantitative methods reached its peak in the 1970s with almost comical results - it is difficult to measure a way of life using quantity - and vanished from the text books during the same decade. By the 1980s, Finnish ethnologists - with the exception of a few old-timers - had said farewell to evolutionism, diffusionism, and functionalism and had welcomed cultural analysis. ${ }^{8}$ The latter was, however, only slowly accepted by Finnish ethnologists. Often cultural analysis was disguised as biographical study. 
It has been argued that the origins of the new interest in biography lay in the "qualitative backlash" against the dominance of the quantitative approach." That is perfectly true in ethnology, but the concept of biography can be replaced by the concept of cultural analysis. ${ }^{10}$

What might now be called the biographical perspective has since become established in ethnology. However, biographical data is not collected in order to be able to find clues to other sources. Narrative accounts of careers and life stories have value in themselves, especially when the focus is on the history of mentalities.

Personally, I became interested in life histories in the 1980s when I was writing my master's thesis on bakers. Thinking back it is obvious that the scientific discussion of that time had an effect on my interests. ${ }^{11}$ I soon found Daniel Bertaux's studies on bakers, ${ }^{12}$ and since then oral history has been a beacon in my research work. I have attended several international oral history conferences (Great Britain 1987, Sweden 1996, Holland 1998, and South-Africa 2002) and given papers based on oral history material to other conferences as well. The first paper I presented was in 1987 in Oxford, Great Britain and the last in 2004 in Minneapolis, USA. Papers given at these conferences form the contents of this book. Some of the articles have been published earlier. ${ }^{13}$

John Van Maanen has written that writing ethnography "is an isolated 


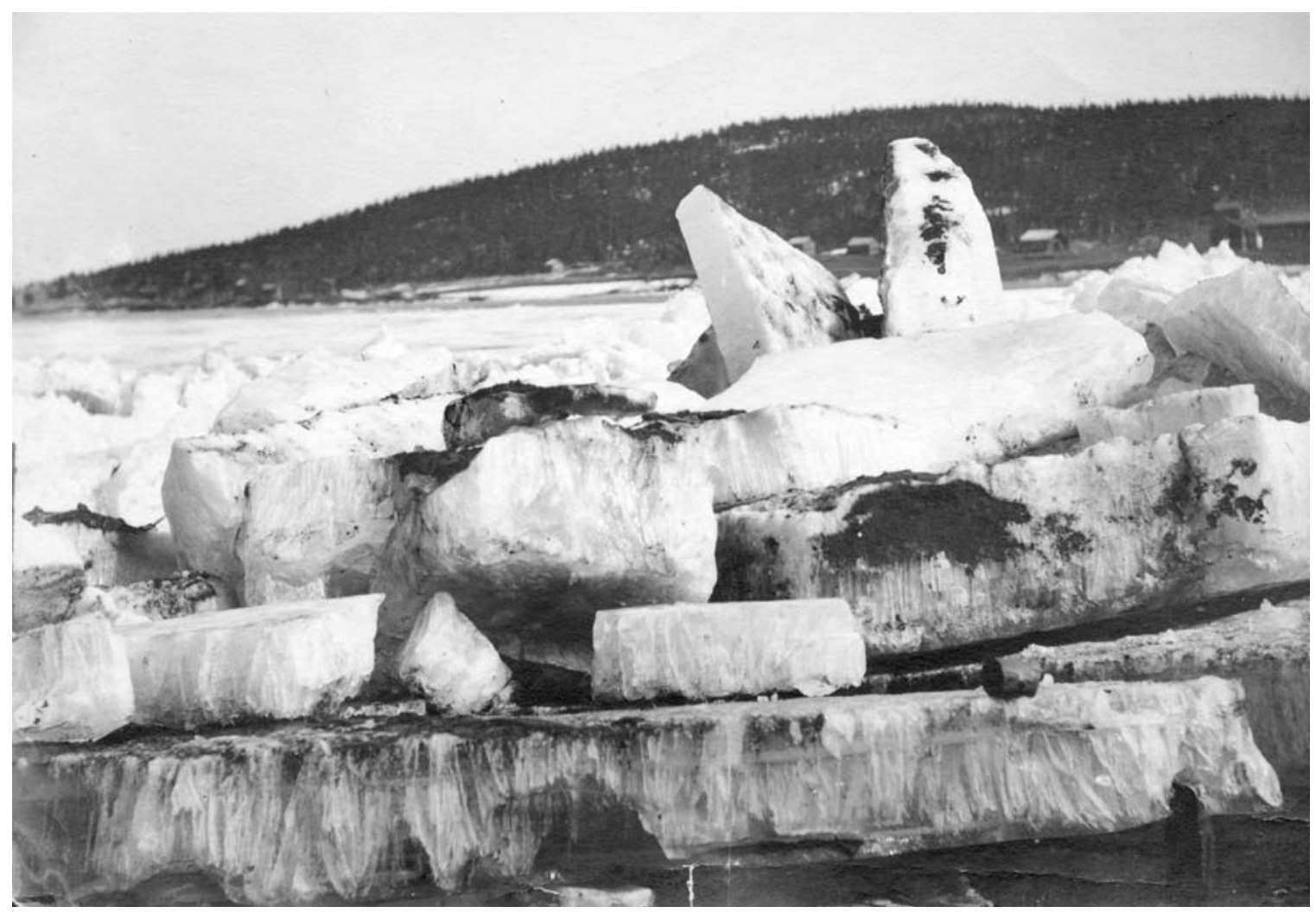

FOR THE ROAD 


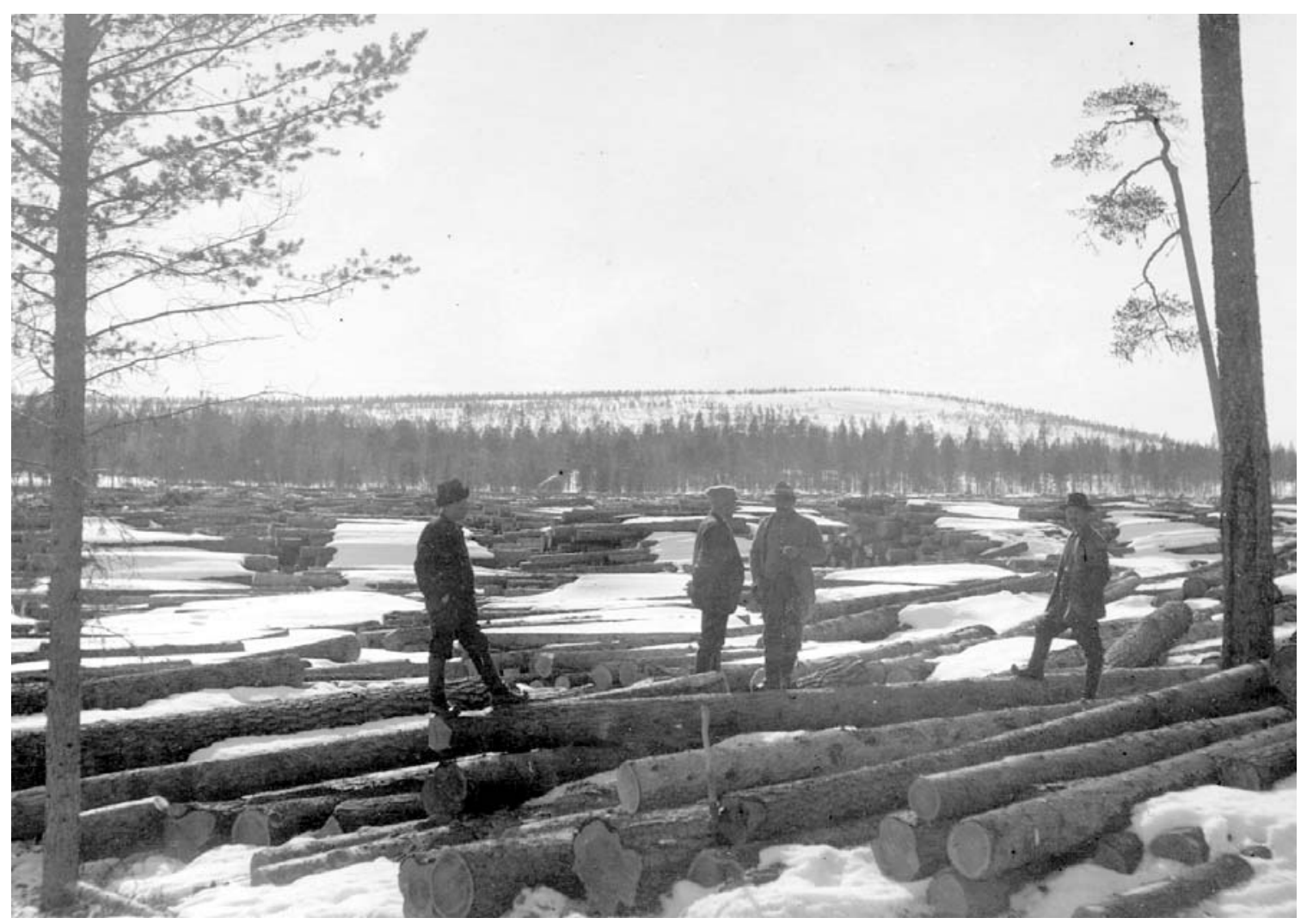


and highly personal business and those who discuss it in print are certain to discover that their best examples must be their own". ${ }^{14}$ The title of this book, "The Road Taken", indicates that my career as an ethnologist, from the end of the 1980s up to now has been like a trip on a road from the woods of Lapland to the Swedish cities of Gothenburg and Västerås. A trip from the woods to cities has also been the path Finns in general have taken since the Second World War. This book sheds light on that phenomenon. In addition, this collection of articles will hopefully shed light on how narratives as such have been treated in ethnological research.

Articles on floating workers' dwellings and migrants living off forests were typical representatives of Finnish ethnology in the 1980s. The approach is antiquarian and focused - whenever possible - on artifacts. You can sense echoes of diffusionism in them. ${ }^{15}$ Even though fieldwork is mentioned as providing source material it is not discussed in these articles. The aim of the fieldwork has been to collect facts, and only facts. The approach is "over realist" in its search for objective truth. For my first paper on oral history given at an international oral history conference in Oxford in 1987, and presented here with the title "Reality and Romance as Historical Portrayals", I discussed source material about lumberjacks in a somewhat different way. However, the first time I actually attempted the narrative approach was almost ten years later, in my paper given, again, at an oral history conference, this time in Gothenburg in 1996. I gave a paper "A Girl from the Univer- 
sity: An Ethnological Fieldworker In Focus" where I discussed how my personal background; that is being born in the area the study was about, being young and female in a male setting, and being the child of the parents I had, affected my fieldwork. I saw the fieldwork itself as an ongoing project, an interplay between the interviewer and interviewee. The paper presented here with the title "Doing fieldwork", was a typical "confession tale"16 of that time inspired by Lena Gerholm's book "Etnologiska visioner".

Lena Gerholm’s book “Etnologiska visioner”, which was published in 1993, triggered a revolution in Finnish ethnology. For her book, Gerholm invited leading Swedish ethnologists to reminisce about how they became ethnologists and what motivated them in their work. ${ }^{17}$ The result is fascinating. The book shows how similar the reasons for choosing ethnology as their discipline were, and, even more interestingly, how often the researcher's family background had an effect on the topics they studied. ${ }^{18}$ Up until the beginning of the 1990s, Finnish ethnologists had hidden their past in the acknowledgements section of their books, and had tried to hide their actual sources of interest. ${ }^{19}$ After the publication of Gerholm's book, Finnish ethnologists started to reveal more about themselves and tell academia their position regarding the subject of their research. Of course, this would have happened even without Gerholm's book. However, it was very easy for a Finnish ethnologist to adopt the ideas of self-reflection that Gerholm had presented in her book, because all the authors were 


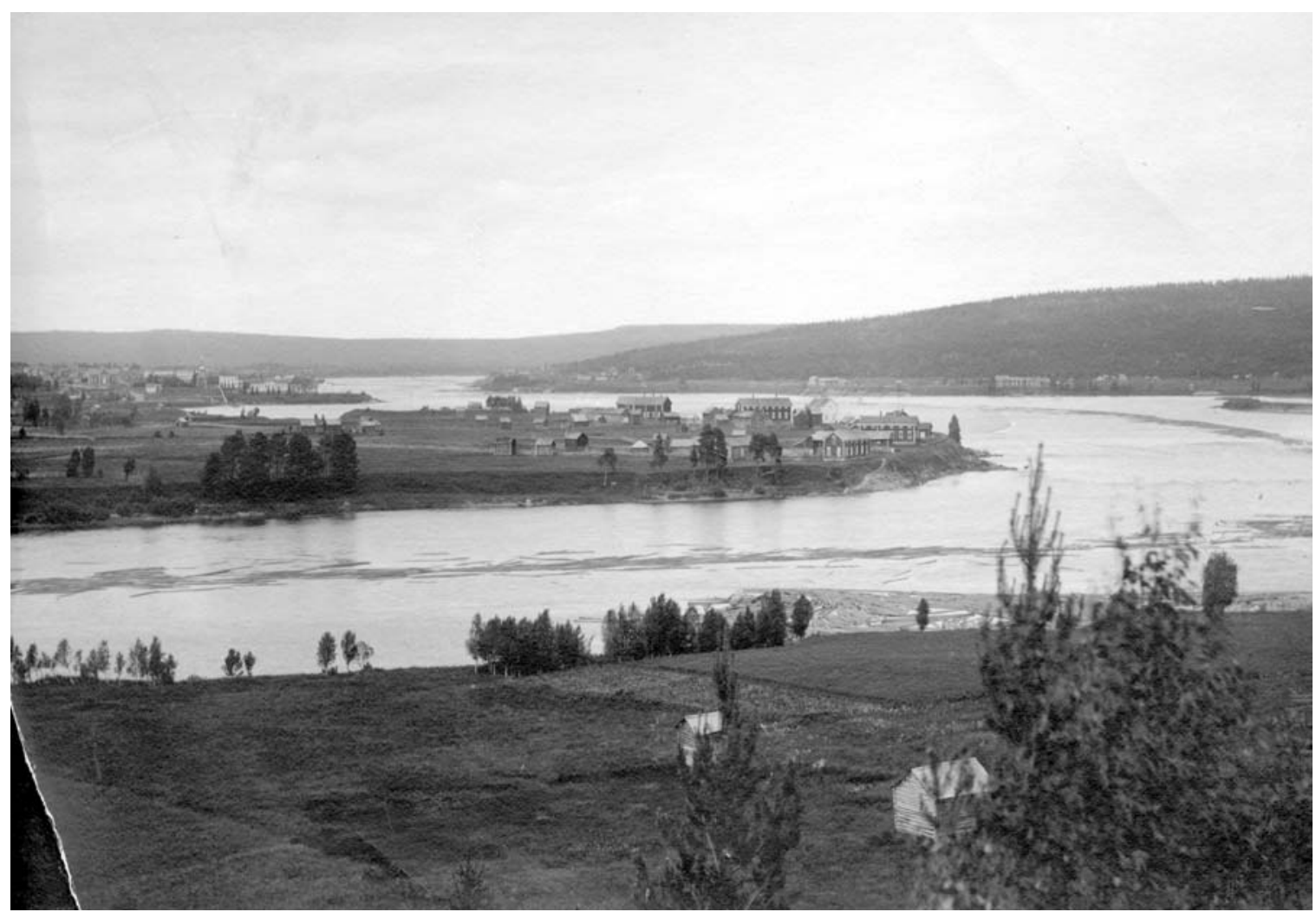




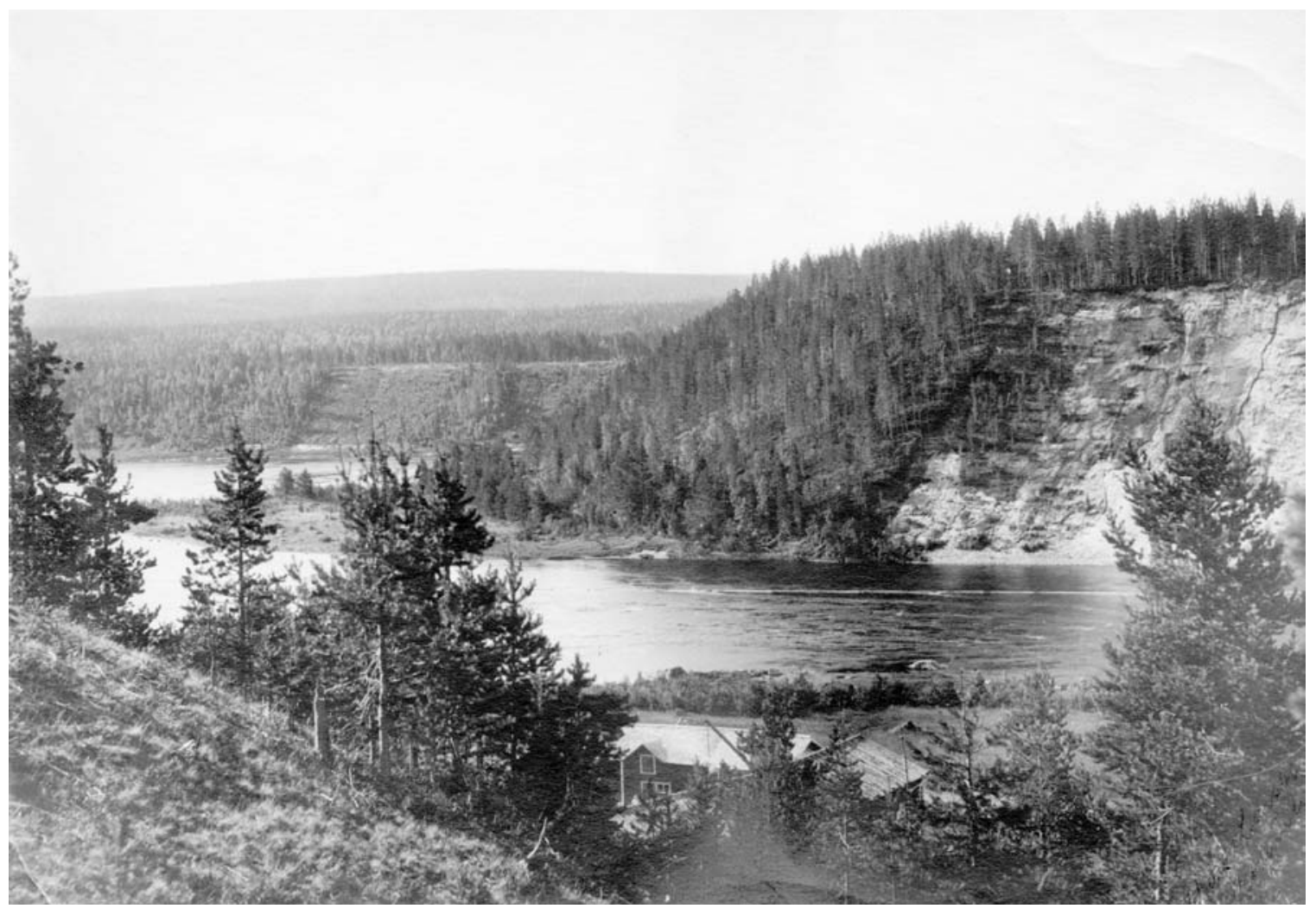


familiar from their scientific work. Reading Gerholm's book is not far from voyeurism!

In the 1980s there had already been discussions about how ethnologists should treat the unpleasant sides of life. Ethnology was criticized for making life seem too nice and happy. ${ }^{20}$ The articles "The Challenge of Differences" and "Sad Histories" on prostitutes and the social hierarchies of lumber camps were reactions to that discussion. An interest in the oral history approach to research is obvious: my aim was definitely to give a voice to the socially excluded, prostitutes, and hobos.

The article "Telling Migrations" is based on a paper given at another international oral history conference, this time in South-Africa in 2002. It was the first time my aim had not been to find the objective truth. The way I had collected the life stories was similar to the narrative approach. Reality was seen to be situational and fluid, jointly constructed by the interview partnership during the conduct of the interview. ${ }^{21}$ Then again, the approaches overlap as Robert Miller has observed. The realist approach is so deep in Finnish ethnology (and me) that it is also present.

The results of my current research on first generation Finns in Swe$\operatorname{den}^{22}$ are presented in the last four articles and also include features typical of the realist approach. The interviews were as undirected and unfocused as 
possible. The aim was to get virtually a monologue from the interviewee. As Miller has observed: "The endpoint of a stage of analysis begins to come into view as the researcher approaches 'saturation'. At some point the collection of new empirical material does not add significantly to the process of concept generation. The new material slots into the existing conceptual frameworks, validating them but not throwing up anomalous instances. Since new empirical material ceases to challenge the existing conceptual frameworks, its collection does not spur further development but rather can be seen as 'variations on (pre)existing themes'. At this point the data can be said to be 'saturated' and the further collection of information is no longer necessary". ${ }^{23}$ When these stories became familiar to me, 'saturation' was reached.

A change has taken place. Ethnologists are no longer looking for the objective truth, but the subjective truth. "False" information no longer irritates the researcher; it is not something to be eliminated, but is actually something of interest.

"Fieldwork at forty" compared to "fieldwork at twenty" is an issue worth discussing. ${ }^{24}$ The joys and sorrows of life that are usually familiar by the time you reach your 40s teach us certain facts of life that are extremely helpful in fieldwork. For example, you can more easily relate to childbirth, the death and sickness of loved ones, and the difficulties of combining family life with a career as you grow older. Yet, by one's 40s one is also lazier 
and more shy in making social contacts, which makes it difficult to knock on strangers' doors and start inquiring about their lives. I envy the enthusiasm I had doing interviews with lumberjacks in Lapland in the 1980s. Yet I know that my interviews with their children (metaphorically speaking) in Sweden in the 2000s have been far more intimate and real. Then again, without the fieldwork I had done among the lumberjacks I would not have understood a lot of things concerning the migrants in Sweden. The key word, after all, is labor migration. First, labor migrants and their children in Lapland for the first half of the $20^{\text {th }}$ century, and then labor migration to Sweden for the other half.

A grant from the Metsämiesten Säätiö Foundation made publication of this book possible. A student of ethnology, Kaisa Voutila, has edited the material. Over the years, many colleagues have joined me at conferences and made them a lot of fun. My sister, Outi Snellman, has helped me with formal academic English. I thank you all. I dedicate this book to my parents Toini and Erkki Snellman.

Helsinki May 19, 2005

Hanna Snellman 


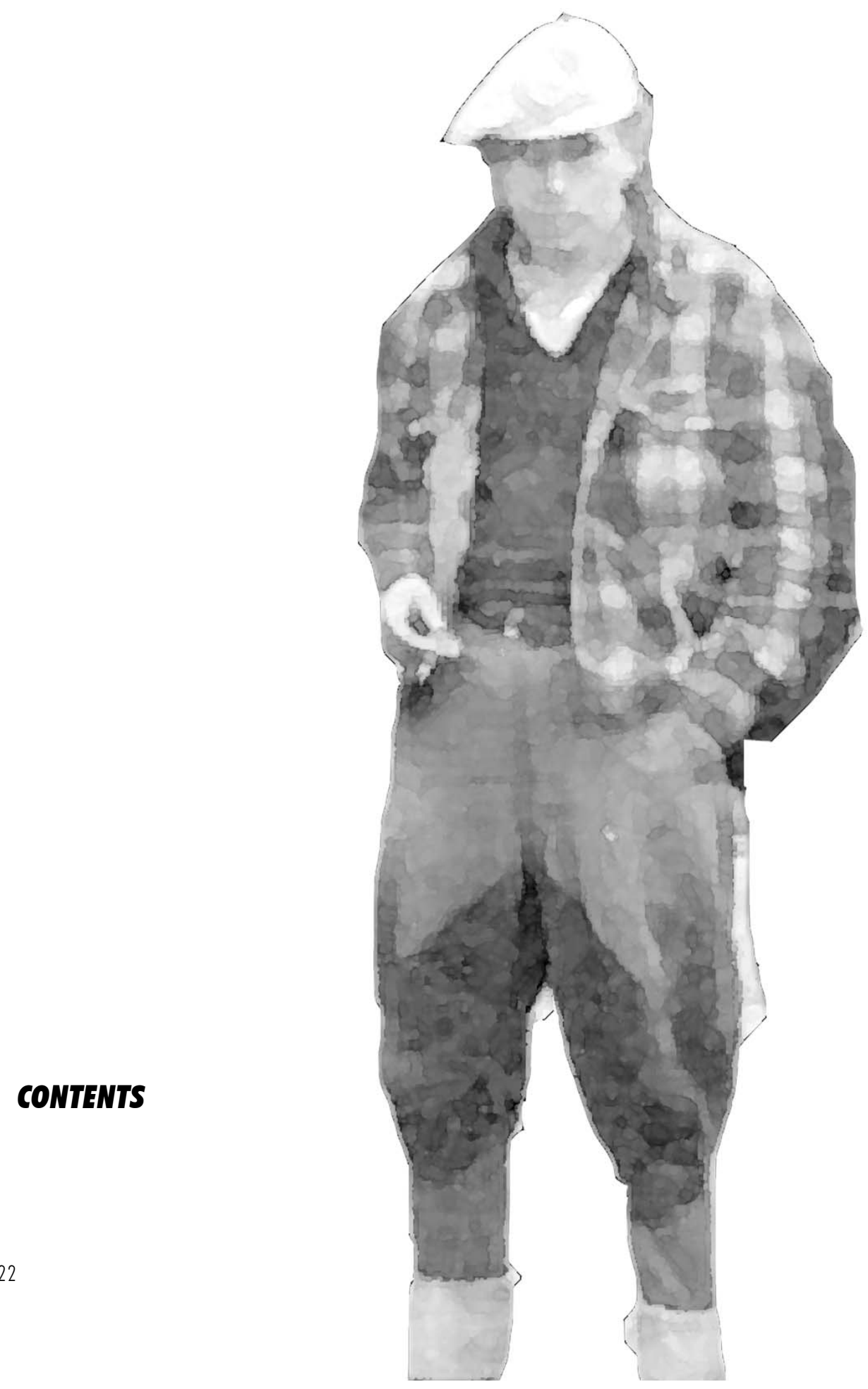


Reality and Romance as Historical Portrayals

Symbols of Power and Nostalgia

The Surprise of Similarities

The Challenge of Differences

Sad Histories

Doing Fieldwork

Telling Migrations

The Finnish Worker in Sweden

Longing for Home

A Thousand Life Stories

Notes

Sources

Bibliography 


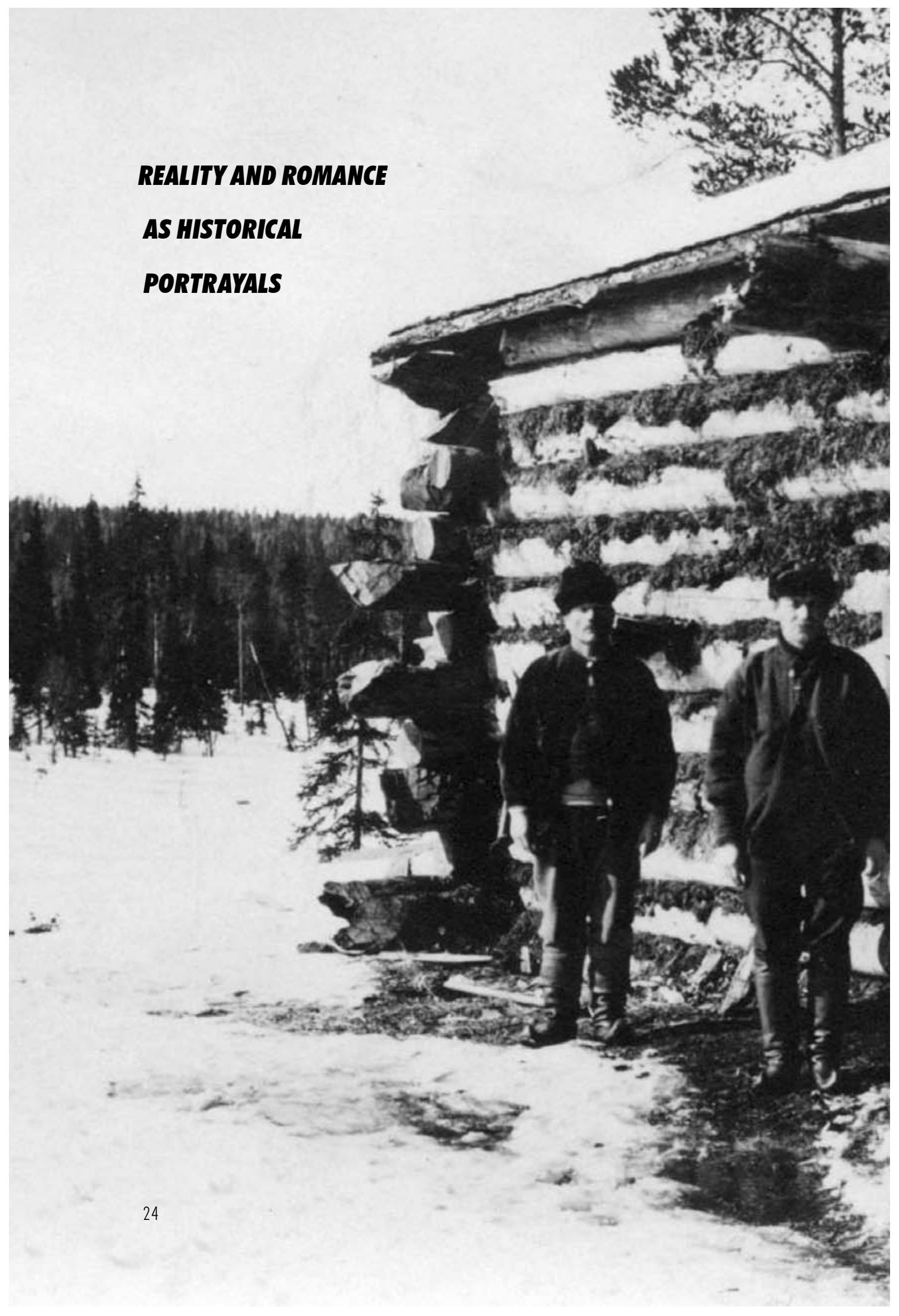




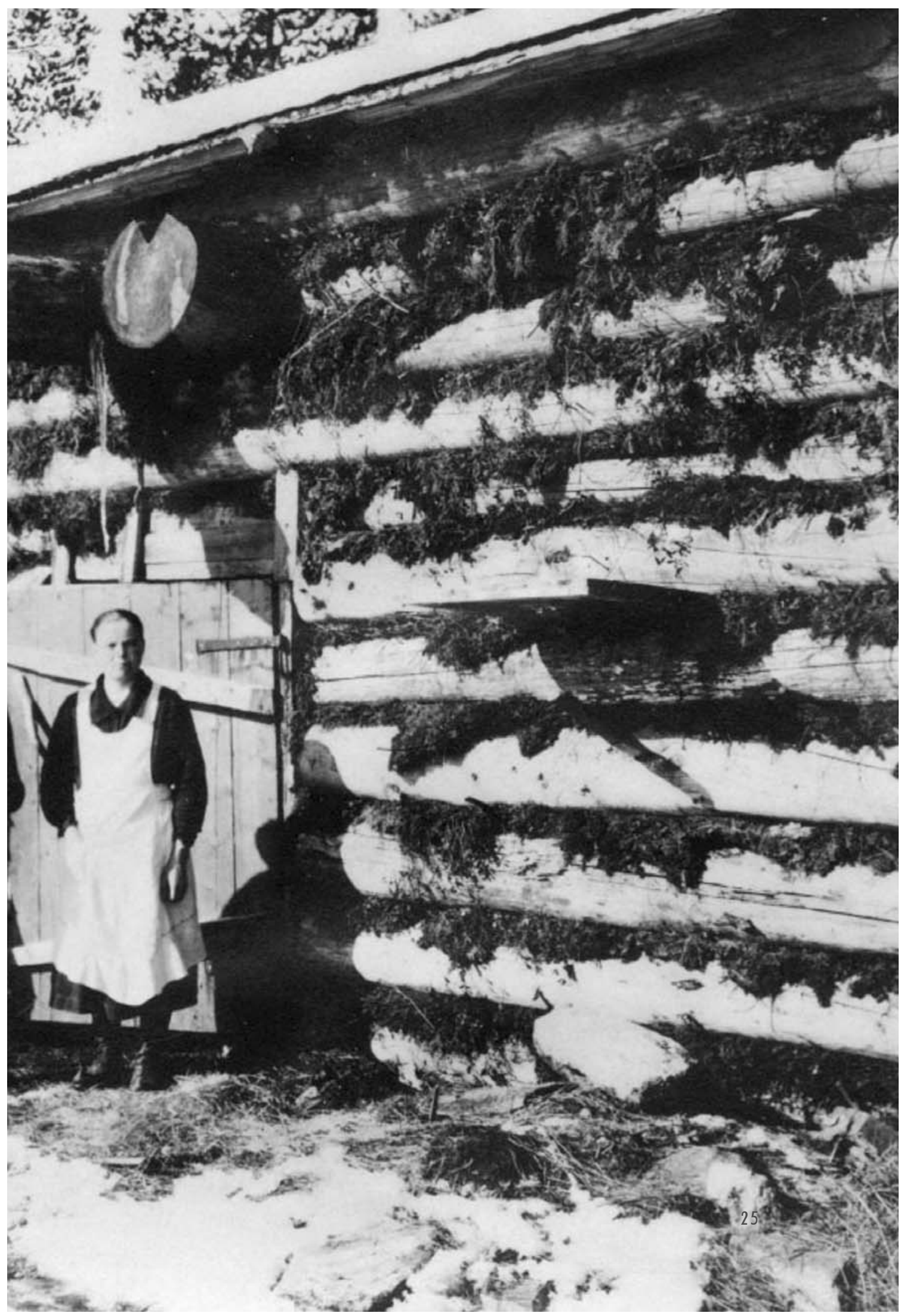


From the 1870 s to the 1950 s the forests of Lapland attracted lumberjacks who did the heavy work of felling trees and transporting logs to sawmills and factories. Since about 1900, interestingly, the popular image of these lumberjacks has been a highly romanticized picture of their lives. A contrary portrayal emerges from the life stories and oral history reminiscences of the lumberjacks themselves. This article begins with a brief account of how lumbering developed in Lapland, next focuses on the first-person narratives of the lumberjacks themselves, and then recounts how the romanticized view of the lumberjacks has evolved and persisted. A brief conclusion suggests how popular stereotypes in conflict with authentic experiences can be explored by utilizing the recollections of obscure but important figures in the historical actualities being studied. 


\section{Labor in the Lapland Forests}

The abolition of import duties in England marked a turning point for the European wood market in the 1840s. Industrialists became interested in the vast untouched forest areas in Lapland and the opportunities they offered for a steam-driven sawmill industry on the coast of the Gulf of Bothnia. Lumberjacks were needed to fell trees and transport the lumber to sawmills. Until the change in the 1950s from manual lumbering to more mechanized felling and transport, the woodsmen toppled trees in the winter and floated logs to their destinations in summer. ${ }^{1}$ The lumber was floated either in big rafts or loose. The latter method became the dominant floating method during the 1900s in the Kemijoki water system, the most important floating channel in Lapland. ${ }^{2}$

Earlier, in the times of water-driven sawmills, local farmers had performed the modest lumbering and floating tasks. It became obvious during the first great period of lumbering in the 1870s that Lapland lacked enough skilled labor to carry out extensive lumbering. At first labor was recruited from neighboring communities, but soon men had to be brought in from southern and eastern Finland and from Ostrobothnia. ${ }^{3}$ Originally the workers came to Lapland only for short periods to work at lumbering sites, but gradually much of the mobile labor settled down permanently in Lapland. Although labor was recruited from other parts of the country, the core of the working team consisted of locals who worked near their homes for the additional income. ${ }^{4}$

Due partly to fragmentary payroll accounting and partly to the use of 
temporary labor, the exact number of lumberjacks in this labor force is unknown, but estimates range up to 10,000 men in the late 1930 s. ${ }^{5}$ The majority of workers were landless men who earned their living in lumbering. Furthermore, quite a few of the landowners and tenant farmers in Lapland worked outside their home districts for the additional income.

Studies have shown that the lumberjacks' social conditions were poor. Strikes by lumberjacks occurred frequently. The first big strike took place in 1906. In their meeting the workers had agreed on a list of shortcomings in their working conditions. On the basis of this list they made the following demands that fairly well illustrate their living conditions in 1906:

The company must raise wages. The company must pay each working team for building a log barrack. The company must sell unspoiled food in the store. The company store must use a checked set of weights for weighing. The black list system must be abolished. The company must pay for the doctor when somebody falls ill in the forest. The working day must not be longer than 10 hours and overtime compensation must be paid for any overtime work. Overtime must not exceed four hours per day. Working on Sundays and holidays must be stopped. The fines (20\% of the salary) for gambling and drinking must be abolished. Workers must be given full right of assembly. Workers must be treated justly by their foremen.

\section{Lumberjacks' Narratives}

The lives of lumberjacks can be studied through oral history materials collected at the Finnish Literature Society Tradition Archive. One of the pioneers of ethnology in Scandinavia, the Finnish Literature Society started its collection of oral history material in the nineteenth century. National romanticism stirred interest in folklore and ethnology. First, between 1845 and 1861, university students went about the country collecting material. The second phase started in 1883 with a request in newspapers to send material about the past to the Finnish Literature Society. ${ }^{7}$ Since then it has been customary for the collection of tradition material to use a permanent network of voluntary informants, to publish questionnaires about chosen 
The lumberjacks of the early 1900s lived in flimsy logging camps during winter and on the bare ground in the summer. From the 1940s onwards they had their meals prepared by female camp cooks.

The photos of this article taken in the 1920s are by Aarne Snellman, 1950s, by Erkeki Snellman, and, 1980s, by Hanna Snellman.

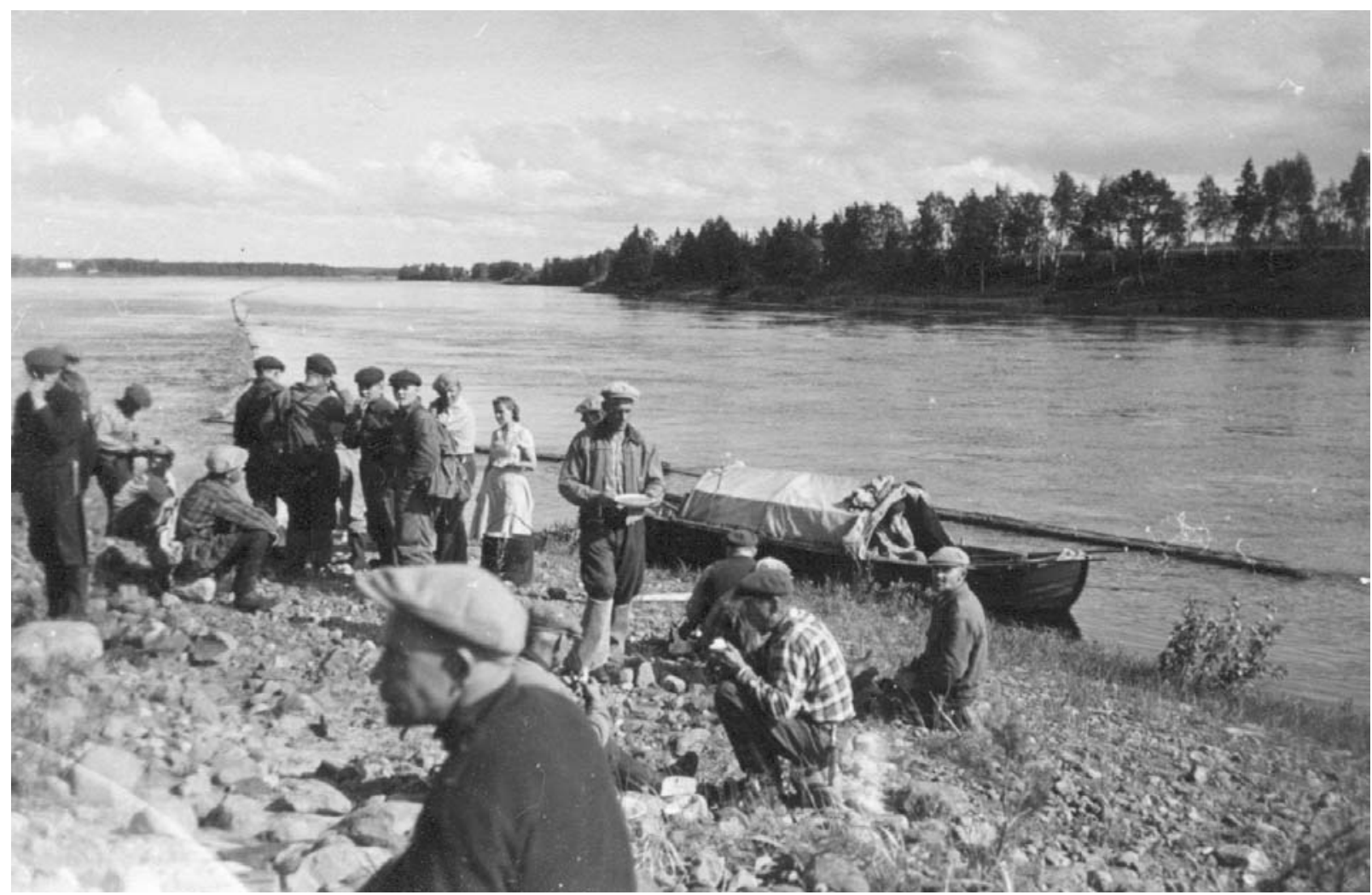


topics, and to give small awards to the best informants. Today the Finnish Literature Society Tradition Archive depends on two major activities research workers do field work and collect material by recording, and voluntary informants also write about their personal experiences on chosen topics. Collections have concentrated on folklore material.

Older collections at the Finnish Literature Society Tradition Archive deal mostly with rural culture, but during the last decades the gathering of narratives has expanded to urban culture. In 1965 the Finnish Literature Society collected information about incidents during the Civil War (1918). After that, the collection of material for the study of labor has been important.

One way to collect narratives is to organize competitions with prizes. The Finnish Literature Society has organized such competitions since 1969, when a competition about lumberjack traditions was initiated. Since then such competitions have been conducted almost yearly. A competition with prizes is aimed not only to involve the permanent network of informants but also to reach a greater audience. The idea behind such a competition is that a special topic is announced and people are asked to write about their own experiences. Restrictions about writing and stories to be told are not strict; usually participants are asked to write about the topic freely. The best ones are then given prizes. In general, competitions are planned in cooperation with an organization - a community, trade union, or company. Cooperating organizations help to reach more participants and to finance the competition, but they have no special interest of their own nor do they exert influence on the collection of material. That kind of activity, done for the public good, is quite common in Finland.

The 1969 competition entitled "Lumberjack Traditions" was launched in cooperation with a bank which sponsored the prizes and publication of an anthology after the competition. The bank's magazine was also used as a channel to inform people about the competition, and the event was announced nationwide in newspapers. Instructions for the competition urged people to reminisce about work at the lumbering and logging sites. The topic was loosely defined. The writers were invited, for example, to tell their life stories.

The competition was a success: 789 informants from different parts 
of the country participated -20 percent of them from Lapland - and the collection amounted to about 18,000 pages. This material is filed in the Finnish Literature Society's Tradition Archive in Helsinki and is available for researchers.

To supplement the reminiscences from Lapland, I interviewed old or retired floating workers in Lapland. The informants were born in the beginning of this century and had started floating work from the 1910s to the 1940s. Interviews in informants' homes lasted from approximately one to three hours. They were recorded on tape and transcribed. The material is filed in the Oulu Provincial Archives. The time range of the responses, both written lumberjack traditions and interviews, is from the end of the nineteenth century to the 1960s, which covers the whole period when floating and lumbering were important and required intensive labor.

In the following section I will illustrate the reality of lumberjack living in the early 1900s by examining the working year as it is explained in interviews and in the Finnish Literature Society's Lumberjack Traditions material. In the following text I refer to the Finnish Literature Society Tradition Archive material unless otherwise mentioned.

The working year for the lumberjack started in September in the logging site. The workers heard about lumbering sites where labor was needed from drifting workmen or read job announcements in newspapers. When there was a shortage of men in the forest, jobs were also announced in churches. The homeless men who had come to Lapland from other parts of the country as well as the locals who wanted some extra earnings came to the logging site in early autumn. The work in the forest first involved preparations for felling and transportation of timber. The lumberjacks had to clean the timber collecting depots and the roads. They also had to build housing for the workers. If the lumbering was to continue for several years on one site they were responsible for building a house for the store and the foremen. For building material they used mainly timber, rocks, clay, and birch bark. Axes and saws were used as tools. Shacks were temporary, often to be used for only one winter. ${ }^{8}$

During autumn work lumberjacks lived in temporary primitive shelters and huts because the sturdier log cabins were not ready yet. An open fire was the only form of heating, although this is not sufficient to stay warm 
outside, overnight, in Lapland. Often the men were penniless during the autumn season because they had been unemployed for most of the summer. Most of them were not given pay in advance and had to work in the logging site without money or food for some time. First to be purchased from the logging site store was often a pair of mittens and warm clothes. The lumberjacks prepared their own food, which was mostly lard, bread, and coffee.

After snowfall in November the felling of timber began being transported by horse to the timber collecting depots on river banks. A working team consisted of one beater, who also owned the horse, and two fellers. Usually the beater was a local farmer and the fellers were workers who didn't have enough money to buy a horse. ' There were dozens of working teams in one logging site. The working conditions were hard; during winter months in Lapland the temperature can fall to below $-40^{\circ} \mathrm{C}$. Snow drifts can be over a meter high and daylight occurs for only a few hours. Felling by ax and saw was also heavy manual labor.

The beaters and fellers lived in log cabins, built during the autumn, with earth floors. The single room was just high enough for a man to be able to stand up in the middle. The cabin was heated with a heating stove built of rocks, which also served for cooking. The bed was made of split planks; all men slept on this wide bed side by side. Sometimes there was no bed and the men slept on spruce branches on the ground. The stable, where the beaters' horses were kept, was often placed at one end of the cabin. If there was a female cook who was responsible for the cooking, a corner was set off for her with cardboard to establish privacy.

According to the narratives it was so cold at night in the flimsy cottages that at bedtime the men had to dress warmly: mittens, a hat, dry woolen trousers, a pullover, and a warm jacket. Lumberjacks rarely had a change of clothes with them on the lumbering site. To dry the clothes that had become wet in the forest they hung them on the roof beams before going to bed. No washing facilities existed in the cabins. Approximately once a month the men made a trip to the foremen's better equipped house several kilometers away where they had a bath in the sauna. They also made necessary purchases in the store. It is not surprising that because of poor hygiene, vermin were a permanent nuisance. Many lumberjacks changed their shirts only when they 
were worn threadbare.

The food on the lumbering sites was unbalanced, especially when it was prepared by the men themselves. After 1928, the employer was responsible for hiring a cook to prepare meals for the lumberjacks who returned from the forest in the evening. This meant a change in the monotonous diet: lard and bread were now accompanied by root crops and vegetables, which had never been seen before at lumbering sites. Before the company cooks, the men sometimes had hired cooks themselves, who often were lumberjacks' relatives.

Lumbering continued from November until March or April. Most of the lumberjacks stayed in the forest all winter. The lumbering sites were in unmarked wilderness, hundreds of kilometers away from civilization. Those who had a home often went there for Christmas, but many stayed on the lumbering sites or made a short visit to the neighboring village or to Rovaniemi. Men passed their time, when they were not working or sleeping, by playing cards. Cardsharpers often went from one logging site to another, cheating the lumberjacks out of their hard-earned money. Prostitutes and bootleggers were also regular visitors on the lumbering sites.

The turnover of the labor force on the lumbering sites was high. When the year was good the lumberjacks earned well, whereas during bad years all the money was spent on food in the company store. When there was depression in the lumbering market lumberjacks skied from one lumbering site to another, desperately looking for work. They were only saved from starving by the goodwill of the locals; it was the custom in Lapland to give a free night's lodging and food to anyone who was wandering in the wilderness. Many came to Rovaniemi, where they got free room and board in the settlement house. Even those who had work sometimes moved from one site to another in hopes of better pay. For those who belonged to the union it was sometimes difficult to find work if an employer had a blacklist.

During the thaw in March and April when it was no longer possible to use the frost-damaged roads, work on lumbering sites finished and the lumberjacks were unemployed. This is when luppo, the lumberjacks' leisure time started. Luppo is an essential part of the romanticized picture of how the lumberjacks lived. During luppo, the lumberjacks went to the more inhabited areas of Lapland. If they had been prudent they had saved their 
winter's earnings and for the first time in months had a chance to enjoy the fruits of civilization. Many went to the Rovaniemi Fair.

Rovaniemi Fair was first held in 1881 and has a legendary reputation; it is often called the Northern Klondyke because of the thousands of vagrants who sought work at logging companies after the rise of the timber industry in the 1870s. There are numerous stories about rowdy behavior at this fair, and tales of girls waiting for the lumberjacks in Rovaniemi. The stories have some factual background. Very early complaints were made to the governor about the disturbance caused by lumberjacks. Rovaniemi Fair was held four times yearly - in February, around Easter, Midsummer, and Michaelmas. It is probable that one reason for the offense given by lumberjacks was the fact that the fair was held (the winter market being an exception) at a time of church holidays. Naturally lumberjacks who were enjoying their free time attracted the churchgoers' disdain. ${ }^{10}$

Lumberjacks were seen at all fairs, since the times coincided with the lumberjacks' holidays and periods of unemployment. But it was not only at market times that lumberjacks populated the village of Rovaniemi: they wandered through Rovaniemi a couple of times during the year on their way to logging or floating sites. ${ }^{11}$

In their own narratives lumberjacks have pointed out that the luppo was not a welcomed holiday but illustrative of poor conditions. Every year all lumberjacks were unemployed at the same time for a few months. The Finnish Literature Society material shows that lumberjacks during this period of unemployment had the opportunity to do the following:

1) The locals took their wages and went home to work on their farms.

2) The homeless usually went to Rovaniemi Fair to meet friends and to make some purchases (e.g., new clothes) and to amuse themselves.

3) Those who had come from southern Finland often decided to return home during luppo. Many of them never got further than Rovaniemi, the site of the northernmost railway station. 
4) Those who had no money were not able to go to Rovaniemi, but had to try to find work. Usually some of them got work on local farms. If they got no work at least they usually got a free meal where they went asking for work.

5) Some got work in the timber collecting depots debarking lumber or preparing tools for floating. During luppo some lumberjacks skied hundreds of kilometers trying to find work.

6) Some stayed on the lumbering sites waiting for the floating season to begin.

Luppo could last from March until May, which meant a two-month period of unemployment for the lumberjacks. Even if they had been able to save some money during the winter it was all gone by May. The next phase in lumbering that needed many laborers, floating, depended on water levels and usually started in May after the ice broke up in the rivers and streams. The men gathered along the floating channels in good time to wait for the work to begin. In the narratives there are numerous descriptions of bitter and hungry men living in local houses, called hunger houses, impatiently waiting.

Floating consisted of different types of work-stream floating, river floating, and lake floating. It also entailed the separation of timber according to the owner. Floating work was much easier than lumbering, although the Finnish summer in Lapland is not always warm. Floating was also less monotonous than felling. The lumberjacks followed the lumber from headwaters to the reaches, where the separation of lumber took place. At times the work was heavy-breaking log jams - and at times light, involving only observation. After the floating was finished in one part of the water system the men were paid and were able to look for work on another floating site. Local farmers usually only worked up to 20 kilometers away from their homes, but the labor force that had come from farther away traveled hundreds of kilometers.

During the floating season men slept either in the open air by a fire, or in temporary huts or log cabins that were similar to the lumbering site cabins in the forests. When floating workers were near a village they slept in the local houses. Food and free time activities also followed the same line as on 
the lumbering sites. However, the floating channels went through inhabited areas. Therefore, $\log$ floaters were a more visible site than fellers. In the villages the log floaters organized dances which enlivened the small villages in the backwoods. Marriages between lumberjacks and locals were not uncommon. ${ }^{12}$

After the floating was finished another luppo, a period of unemployment, started. The luckiest got work in the separation of timber, which was best paid. Others usually sought work in the nearby farms: making hay, harvesting, chopping wood, or in construction work. The farmers were able to employ themselves. In the 1920s it became common to fell lumber even in the summer, to the great relief of the lumberjacks who welcomed the summer employment. The summer luppo was finished when autumn work started. In this way the full working year passed.

Lumberjacks' narratives emphasize the hard life and poor conditions on the lumbering site. Attention is also given to the feeling of homelessness; most of the informants were not from Lapland but had come there only to work. They had been forced to leave their homes while still very young and had had no homes for years after that. The lumberjack's home was his rucksack; when he lay down to sleep and rested his head on it, he was home.

The luppo is described as a miserable time that often overwhelmed the weaker ones. Fights were often the outcome of heavy drinking and some died from violence. Instead of a feeling of freedom, the narratives reflect bitterness and worry about making a livelihood during the long periods of unemployment.

\section{The Romanticized Portrayal of Lumberjacks}

According to Matti Peltonen, an economic historian who has studied the history of floating, the romanticization of the life of lumberjacks started in fiction at the turn of the century. In the works of Pakkala (1899), Linnankoski (1905), and Kataja (1914) we can find the most important mythical elements of this romanticization. ${ }^{13}$ It is characteristic of all these works that in their descriptions of floating the writers pay attention to things like singing, shooting of the rapids, or adventures with women. All these elements do 
have a basis in the floating work, but in reality they were trivial compared to the actual heavy labor that floating involved. The lumberjacks' freedom has also been emphasized in fiction, often in descriptions where the free and easy life of a lumberjack is contrasted to that of a farmer who is tied to the land.

Peltonen argues there are basically two reasons for the romanticization of lumberjacks in the fiction of the early twentieth century. Floating had become the most important form of transporting timber at the end of the nineteenth century and was by then so common and familiar that it had to appear even in fiction. Second, conflicts between farm owners and the landless population were enormous. Floating as a trade, often treated romantically, could easily come into works dealing with this conflict between different layers of the population. Lumberjacks were clearly representatives of the landless population. ${ }^{14}$

The foundation of romanticization was thus laid as early as the turn of the century, and between 1930 and 1960 the myth was spread by film and the popular music industry. Radio and television brought the lumberjacks to an even greater audience. ${ }^{15}$ The romanticized version of the lumberjacks' freedom and luppo is often connected with Lapland due to a film made in the 1950s, "Rovaniemi Fair," which gives the filmmaker's view of logging life rather than the reality. ${ }^{16}$

The lumberjack myth has a lot in common with the frontier myth in the United States. ${ }^{17}$ In both the initiating force was fiction and both were glamorized by the film industry. It is typical of both western and lumberjack films that people joined together by the same work are described in a setting where work is of little importance. The moviegoer rarely finds a cowboy working cattle or a lumberjack cutting forest. ${ }^{18}$ The romanticization of lumberjacks in films deviates especially from reality because their lives are only seen during the summer when work was easier. ${ }^{19}$ Equally, the forced unemployment is presented as voluntary.

\section{Conclusion}

In Finland the romanticized picture of the Lapland lumberjacks is a prevail- 


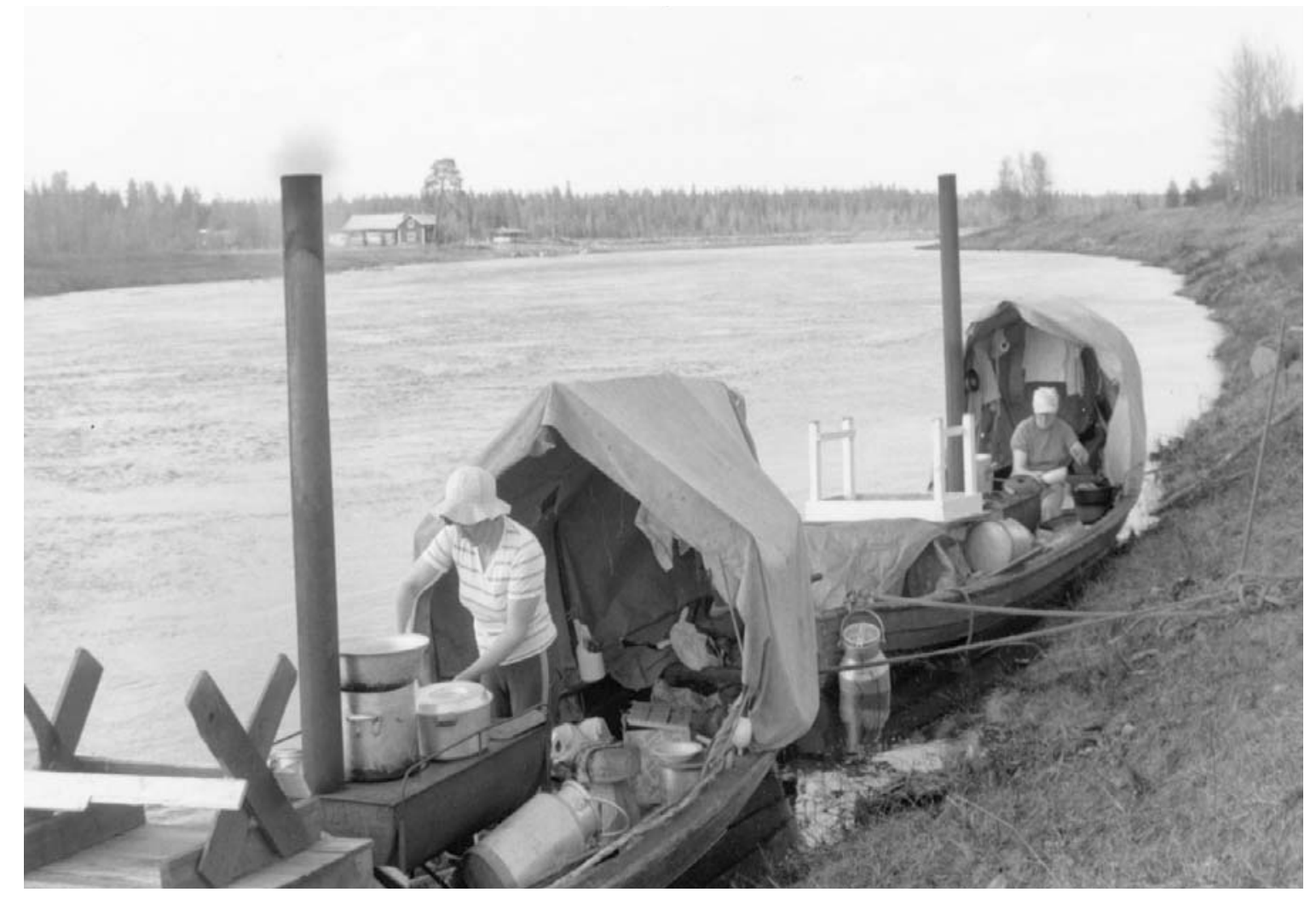


ing stereotype. When any ordinary Finn is asked to describe the image he has of lumberjacks in Lapland some 100 years ago he will most likely describe a mythic figure free to roam, depending on manly strength for survival, drinking heartily, surrounded by comely women, and often being boisterous at the Rovaniemi Fair. There are numerous stories of lumberjacks spending money carelessly and even giving champagne to their horses to drink. Curiously, lumberjacks may have stimulated this mythic view by disguising necessity to look like freedom of choice, and suggesting work was a task to be done at any time of day when actually they had to work long hours in order to survive. Their itinerant lifestyles contained more hard reality than romance. Memories of their own lives, recalled in their own words, contribute to a better portrayal of life in the Lapland forests.

This article was published earlier in International Journal of Oral History. Vol. 10 No. 2, June 1989: Meckler Corporation. 


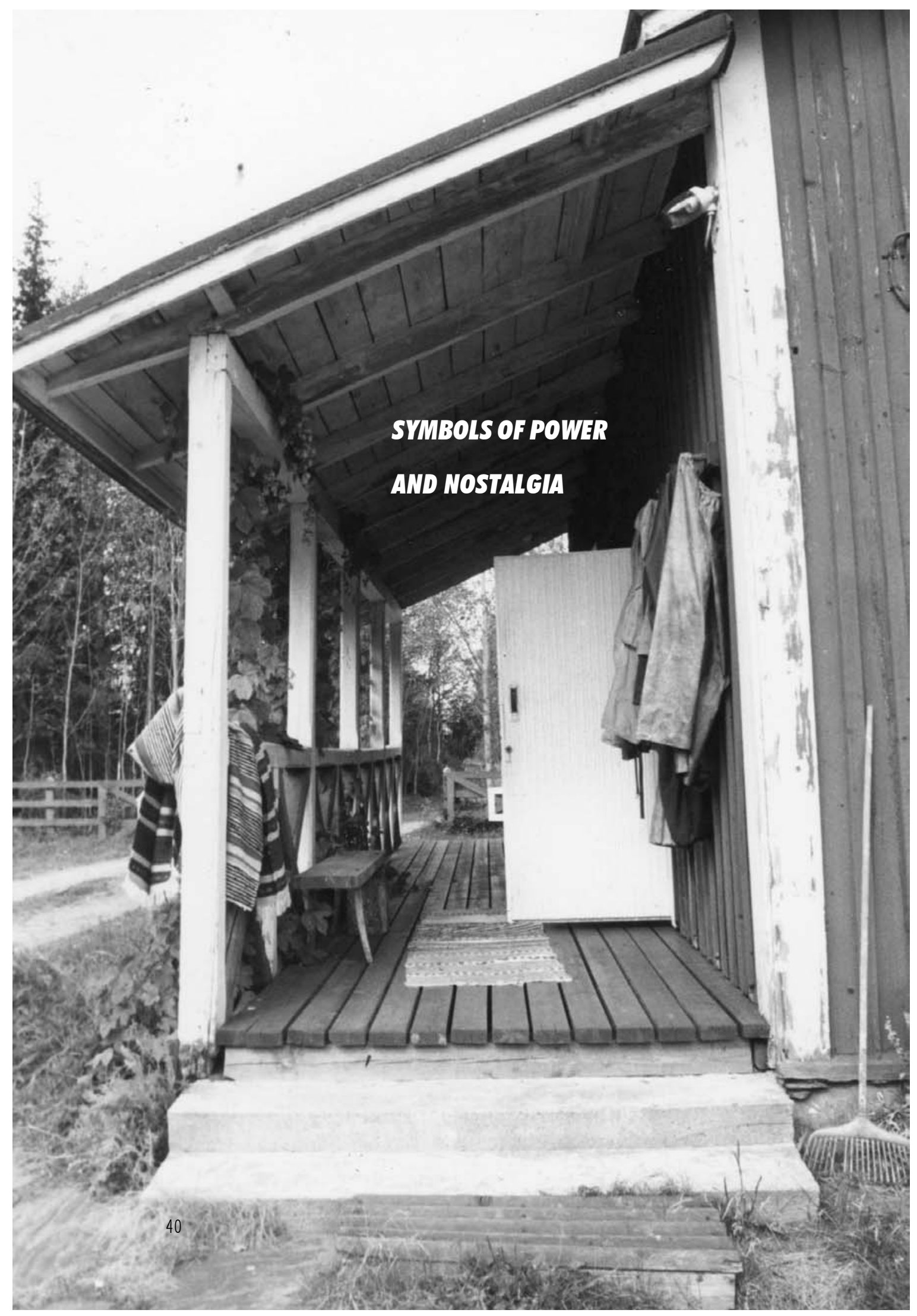


As early as the 1950s Finnish scholars called attention to the importance of conducting an ethnological study on lumberjacks. ${ }^{1}$ For a long time the theme was only treated in articles dealing with a very limited area. ${ }^{2}$ Lumberjacks' narratives were, however, frequently collected. ${ }^{3}$

This article will similarly treat only one narrow aspect of floating, namely the floating camps built along the most important passage for floating logs in Lapland, the Kemi River waterway. I will discuss the motives which led to building operations in the Kemi River area, and describe how these motives have been reflected in the architecture of the dwelling houses. I will not discuss the buildings merely as artifacts, but will try to find factors in their architecture which connect them with a certain era, area and society. ${ }^{4}$ Buildings should be considered as mirrors of the society which created them.

What makes the River Kemi region especially interesting from the research point of view is the fact that Lapland was the first area in Finland to systematically build dwellings for floating workers. In 1905 there were on the River Kemi at least nine such dwelling houses equipped with a telephone. ${ }^{5}$ Investigations have established that the first dwellings were built between 1900 and 1904, when the first channels on the River Kemi were made suitable 
for floating according to Sweden's example. ${ }^{6}$ The precise date when the first dwellings were built is uncertain in the absence of source material. It is, however, known that the wide-scale building of dwellings for floating workers did not begin elsewhere in Finland until the 1920s. ${ }^{7}$

In what follows I will use the term camp for the floating workers' dwelling houses although in the floating camps of the Kemi River area there are other buildings - saunas, store houses, boat houses, cellars, outhouses and smithies - as well. ${ }^{8}$

As research material I am using archive documents and the results of my field work in the floating camps. The Kemi River Floating Company (fi. Kemijoen Uittoyhdistys), which was responsible for floating in the area, has kept files on the floating camps it owns since the end of the 1940s, yielding important information about the building materials, the year of construction, as well as ground plans.

In 1912 there were 23 floating camps ${ }^{9}$ and 53 in $1969^{10}$ in the Kemi River area. In 1989 there were 41 floating camps which had been or were still owned by the Kemi River Floating Company. ${ }^{11}$ Of these remaining floating camps, I visited 20 during my field work in 1986-1989. The Kemi River floating passage was at its longest in the 1950s and 1960s, 4,000 kilometers. $^{12}$ 
The Taivalkoski floating camp by the Kemijoki River in Tervola was still in use at the end of the 1980s.

The photos of this article were taken by Hanna Snellman.

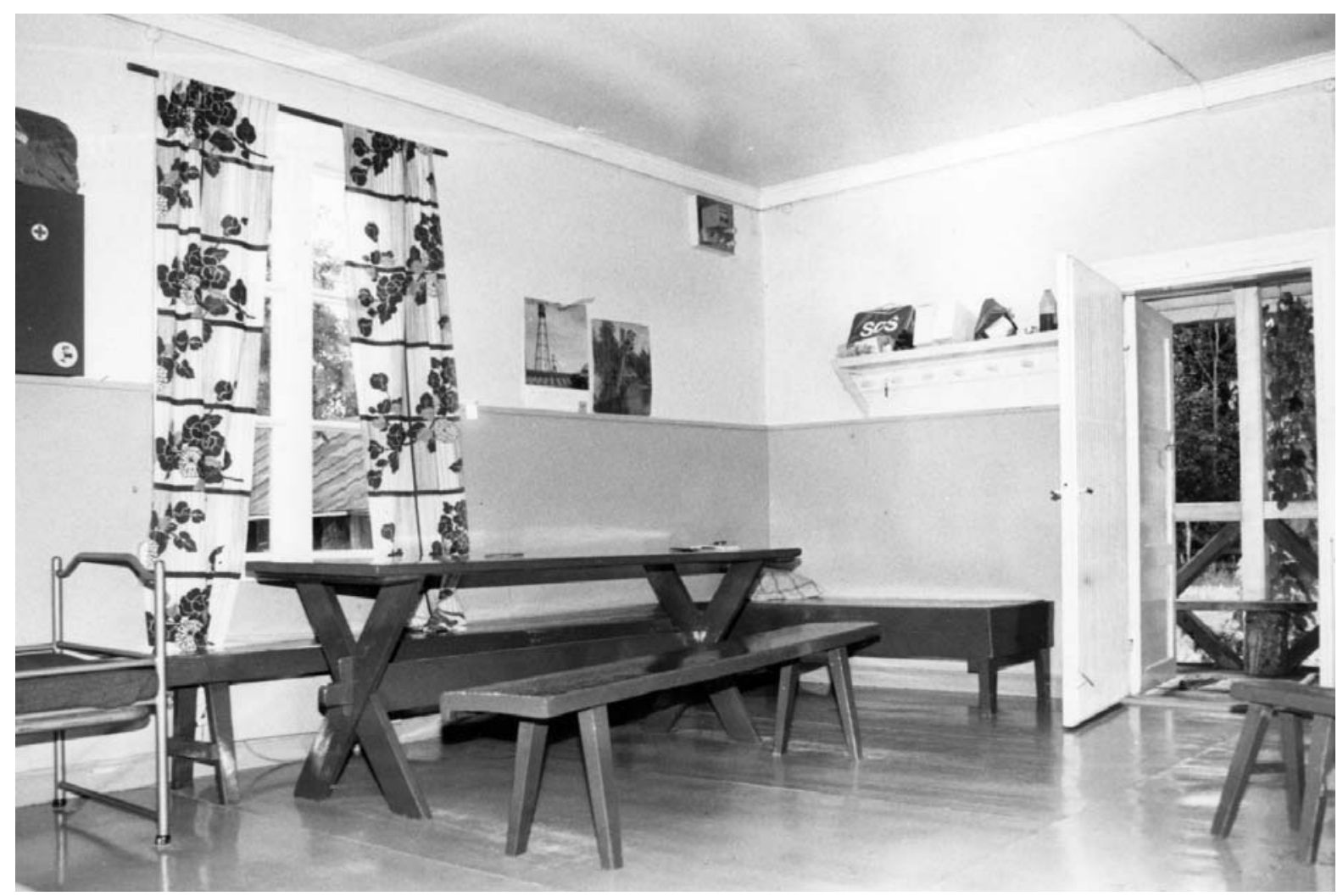




\section{Lumbering in Finnish Lapland}

Until the end of the 1800s the inhabitants of Finnish Lapland lived in an almost totally natural economy. ${ }^{13}$ Water driven sawmills, all located in Southern Lapland, were the sole industry. The acquisition of raw materials extended merely to the immediate surroundings of the sawmills, and local farmers performed the modest lumbering and floating tasks.

In the 1870s Norwegian industrialists became interested in the vast untouched forest areas of Lapland and the opportunities they offered for a steam-driven sawmill industry on the coast of the Gulf of Bothnia, becoming the first to start extensive lumbering in Finnish Lapland. Gradually lumbering expanded farther north. It soon became obvious that Lapland lacked enough skilled labor; at first labor was recruited from neighboring communities, but soon men had to be brought in from southern and eastern Finland. Originally the workers came to Lapland only for short periods to work at lumbering sites, but gradually much of the mobile labor settled down permanently in Lapland. Although labor was recruited from other parts of the country, the core of the working team consisted of local farmers working near their homes for additional income, and local workers. ${ }^{14}$

Two different life styles met when the forest industry entered a new era in Lapland. In addition to the fact that at micro level people from different social and economic backgrounds met at the logging and floating sites, the same happened at macro level when the natural economy clashed with industrialism.

\section{Typical Features of Floating Camps}

The floating camps in the Kemi River area built between 1900 and 1960 differ considerably depending on the time of construction. The camps constructed between 1900 and 1920 resembled the local architecture both in shape and building materials. They were usually one or one-and-a-half story buildings built of logs with saddle roofs originally covered with shingles. ${ }^{15}$

Yet the color, the porch and the ground plan often varied. The first camps in the Kemi River valley were originally painted white, while the local 
rural buildings were painted red. The camps were usually row houses and had a side corridor veranda as long as the building, a type of structure unknown in the local rural architecture. Usually the houses had one big room for the floating workers and smaller rooms for the female cook and for the foremen. Usually there were no doorways between the rooms, each room having its own entrance. ${ }^{16}$ The men slept in a communal bunk for up to 40 men, which was situated near the ceiling. The fireplace used for cooking and heating was open.

From the end of the 1920s onwards the side corridor veranda ceased to be the only type of porch built in camps, porches with a saddle roof being built as well. That as well as changing the color from white to red made the camps look more like rural dwellings. Yet there were still some differences: between the kitchen and the room where the men lived there was usually a small opening in the wall, through which the cook handed out the food. Open fireplaces were still bricked, but gradually portable stoves and cast iron stoves came into use. The communal bunks were built at sitting height.

The side corridor verandas, row houses and communal beds were no longer built after the Second World War. Even though some camps were still built of logs at the end of the 1950s, boards and prefabricated building materials were already more common immediately following the Second World War.

In conclusion let me return to the typical features of the Kemi River area camps constructed at different times with the aim of finding factors which associate their architecture with the motives for building. As Konrad Bedal has stated, every building indicates the economic, social and cultural circumstances of its construction time: "Jeder Bau ist ein Indikator Wirtschaftlicher Verhaltnisse, Sozialen Beziehungen und kultureller Leistungen einer Zeit, einer Gegend und einer sozialen Schicht". ${ }^{17}$ These socio-economic factors have not only affected the way the camps were built but also the actual activity of building.

Until $1933^{18}$ building floating camps was purely a matter for the forest companies. The reason for having camps built was their functions, which were both use-related and symbolic. Even though housing workers seems to have been both the most important use of the camps and the major 
motive for building them, in reality the effective organization of work in the pathless wilderness was more important than housing. As the amount of timber to be floated increased, organizing the work became more difficult. It was no longer sufficient to have young boys running important messages "start floating!" or "stop floating!" to the working bases. Messages from headquarters had to come fast and telephones were needed for foremen working along the rivers. ${ }^{19}$ Floating camps were built at strategic locations where work demanded constant surveillance or a large number of workers: on the streams floating camps were built close to dams, along the rivers at deltas, rapids and by $\log$ booms, and on the lakes at locations important for warping. However, as hitherto, most of the workers rested in temporary primitive shelters. ${ }^{20}$

But why were the camps called "workers' dwellings" even though they were merely office buildings? The term must be seen in the light of public opinion at the time. From the 1850s to the 1930s workers' housing was one of the main issues of social policy in Finland. ${ }^{21}$ The subject was discussed both in the press and in research, especially at the turn of the century. ${ }^{22}$ According to the beliefs of the early labor movement, building decent dwellings more than high wages was supposed to guarantee satisfied employees.

Simultaneously the forest companies had problems with labor, ${ }^{23}$ so that the office buildings were called as they were, because at least some workers had a warm place to live in and everyone had an opportunity to go to the sauna. This more or less symbolic gesture was meant to diminish subversive activities and create a good public image for the floating company.

\section{Social Differentiation}

The camps had to satisfy the needs of three different groups of workers, namely male floating workers, male foremen and female cooks, factors which influenced the typical camp ground plans. In row houses different groups were easily separated from each other; the men lived in the living room (fi. pirtti), the cook in the kitchen (fi. keittiö), and the foremen in the office (fi. konttori). Each room had only one door, which led to the side 
corridor veranda. The men communicated with the cook mostly through the serving hatch (fi. elämänluukku) in the wall.

It was not always easy to provide the cook with separate accommodation, because not all the dwellings had a separate kitchen and the cooking was done in the living room. Nor was the cook's room known by an established name, unlike the other rooms. For example, in the oneroomed dwelling at Tohmonsaari (built in 1915) a small area (fi. karsina) was divided off - probably by a flimsy partition - in the corner of the living room for the cook. ${ }^{24}$ At the Javarusvastuu camp consisting of a living room with an entrance hall (built in 1900) the cook had a little room (fi. nukkumahuone) leading off the hall ${ }^{25}$. The Luuksinsalmi camp had a separate kitchen, but the cook did not sleep there and had a bed of her own in the office. The bed was, as it were, almost a room in itself, since it was surrounded by thick curtains. ${ }^{26}$

Even though the group of male floating workers was by no means homogeneous, being from different social backgrounds and from different parts of Finland, ${ }^{27}$ as far as life in the camp was concerned they were equal. Old floating workers emphasize that delicate matters which could have created conflicts were avoided in order to maintain the spirit of comradeship necessary in the harsh circumstances of the wilderness. The atmosphere was especially tense after the Civil War. ${ }^{28}$

\section{Symbols of Power}

It is far more difficult to indicate the symbolic functions of the camps. The side corridor veranda and row house ground plan were typical exterior features of the first camps in the Kemi River valley. They had no connection with the rural architecture of Lapland, but they took tenement houses, i.e. the gallery access houses of factories and sawmills with a side corridor along the building as a pattern. ${ }^{29}$ Painting the camps white made them public buildings, distinguishing them from the rural dwellings.

But why was it important to emphasize the industrial character of the buildings in sparsely inhabited Lapland? The answer lies again in the socioeconomic circumstances at the time; the camps manifested the significance 
of floating at a time when the floating companies were fighting for a foothold in northern Finland.

Until the 1870s salmon fishing was an important source of income for peasants in the Kemi River valley. When extensive lumbering started in the 1870s, floating impeded that old source of livelihood. For decades the floating companies and local peasants struggled for their rights. Gradually the peasants lost their immemorial rights to fish with weirs in the Kemi River. But it was not until 1920 that the state considered floating to be so important for the economy of Finland that it was allowed with no restrictions. ${ }^{30}$

From 1900 to 1904, simultaneous with the construction of the first floating camps ${ }^{31}$, the fight was at its fiercest, because the floating companies assumed the occupancy of the salmon weirs on the Kemi River. ${ }^{32}$ The first floating camps were built on the very same rapids as the salmon weirs. ${ }^{33}$ Stately buildings functioned as symbols of power ${ }^{34}$ and they were supposed to show the peasants that their struggle against the forest companies was futile.

The need of the first Kemi River camps to impress is particularly noticeable on comparison with the log camps (fi. ruukinpirtti) built by the same company for timber harvesting and driving. They usually consisted of not only a dwelling but also a shop, a stable, a sauna, a cellar, a privy and storage sheds. There were mostly foremen and cooks living there, because the loggers had their own camps. As in the dwellings for floating workers, there was a social differentiation in the log camps; the women's domain, the kitchen, was connected to the rooms inhabited by the men only by a serving hatch. ${ }^{35}$

The log camps in Lapland in many respects set the pattern for the floating workers' camps. The biggest difference was, however, that the architecture of the log camps did not, it seems, need to be so impressive as that of the riverside floating camps. The contention over the status of the forest industry culminated specifically in floating, so the buildings needed for harvesting and driving timber had only a practical function.

\section{Centrally Directed Building of Camps}

The year 1928 marked the beginning of a new era of centrally-directed camp building, since the activity was prescribed by law. ${ }^{36}$ Analogous laws, 
with similar content had already been enacted in Norway in $1915^{37}$ and Sweden in $1919^{38}$. In 1947 and 1967 the Finnish law was reenacted, again on Scandinavian models.

Floating camps ceased to have the same symbolic function, since the forest industry was already firmly entrenched in the Finnish economy. Mere usage function was reflected in the simple architecture, cheaper building materials and standardized plans. The changes in the architecture of the camps after 1928 can be traced to the ordinances: according to the law the camps were supposed to have a porch, so the side corridor verandas were no longer built. It was obligatory to employ a cook in the camps, so that dwellings were provided with portable stoves or cast iron stoves, which were better for cooking than open fireplaces. Communal bunks were no longer built, because according to the law of 1928 the bed had to be at sitting height and by 1947 everyone was supposed to have a bed of his own.

\section{Floating Camps Today}

Finally the regulations became so strict that utilization of the camps diminished; since 1967 the law required the employer to pay extra compensation for expecting the employee to stay in the camp. As a result employers usually organized daily transportation from camps to home when possible, and the camps were only used as lunch rooms and store houses. Only a few camps retained their original use.

The new functions of the old floating camps again reflect their time; old camps have been purchased by private persons and associations to serve as summer cottages and holiday camps. It would be interesting to analyze the restoration and interiors of these holiday camps. It is possible that the new owners emphasize the symbolic values ${ }^{39}$ connected with the general romanticization of lumberjacks of the buildings. Many times the restored camps are more real - that is traditional - than they ever were originally.

This article was earlier published in Ethnologia Fennica. vol. 19.1991: Ethnos - Association of Finnish Ethnologists:

Ethnos ry. 
Strikebreakers from Western Finland working on the River Kitinen at the beginning of the 1950s.

The photo was taken by Erkei Snellman.

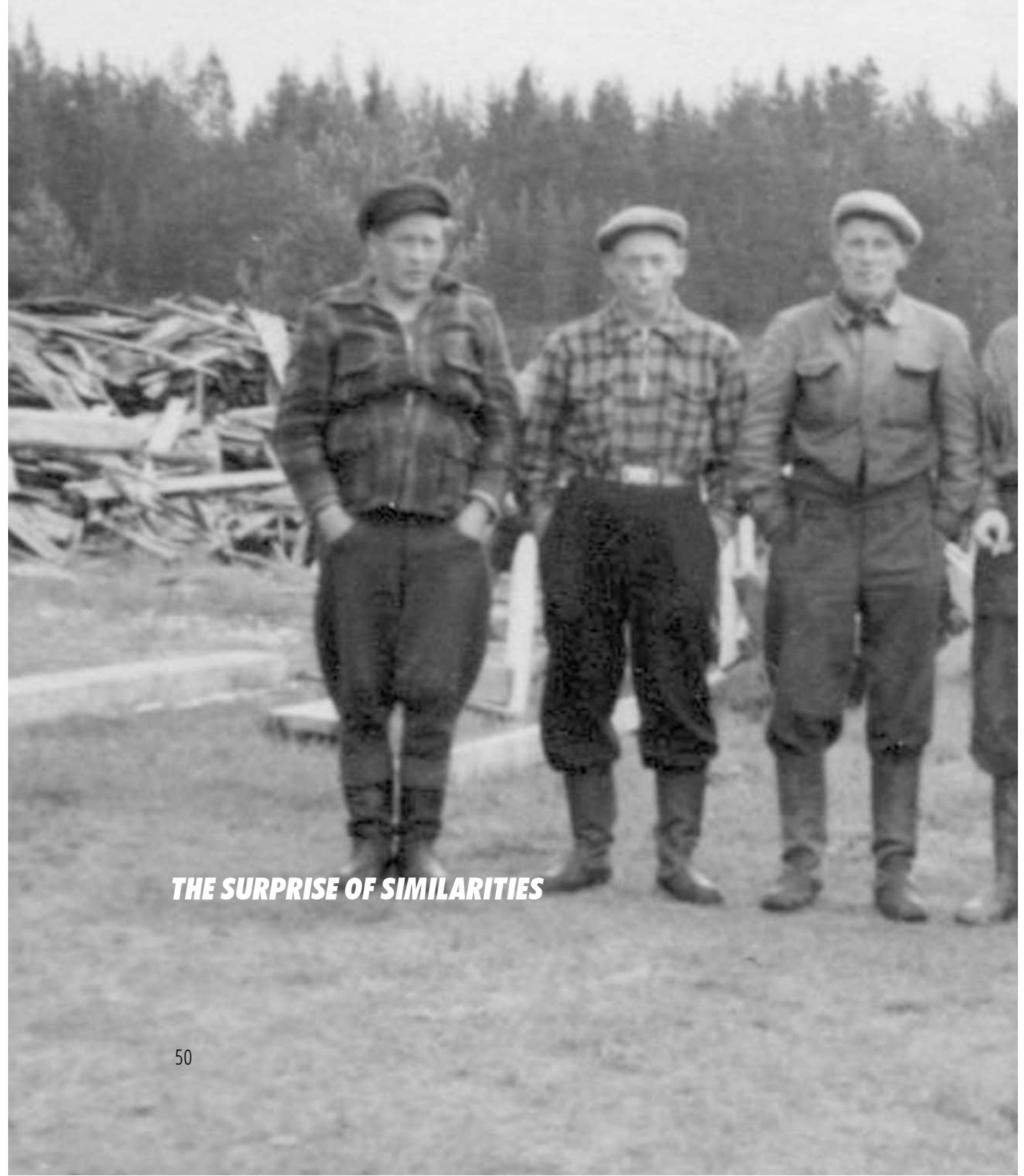




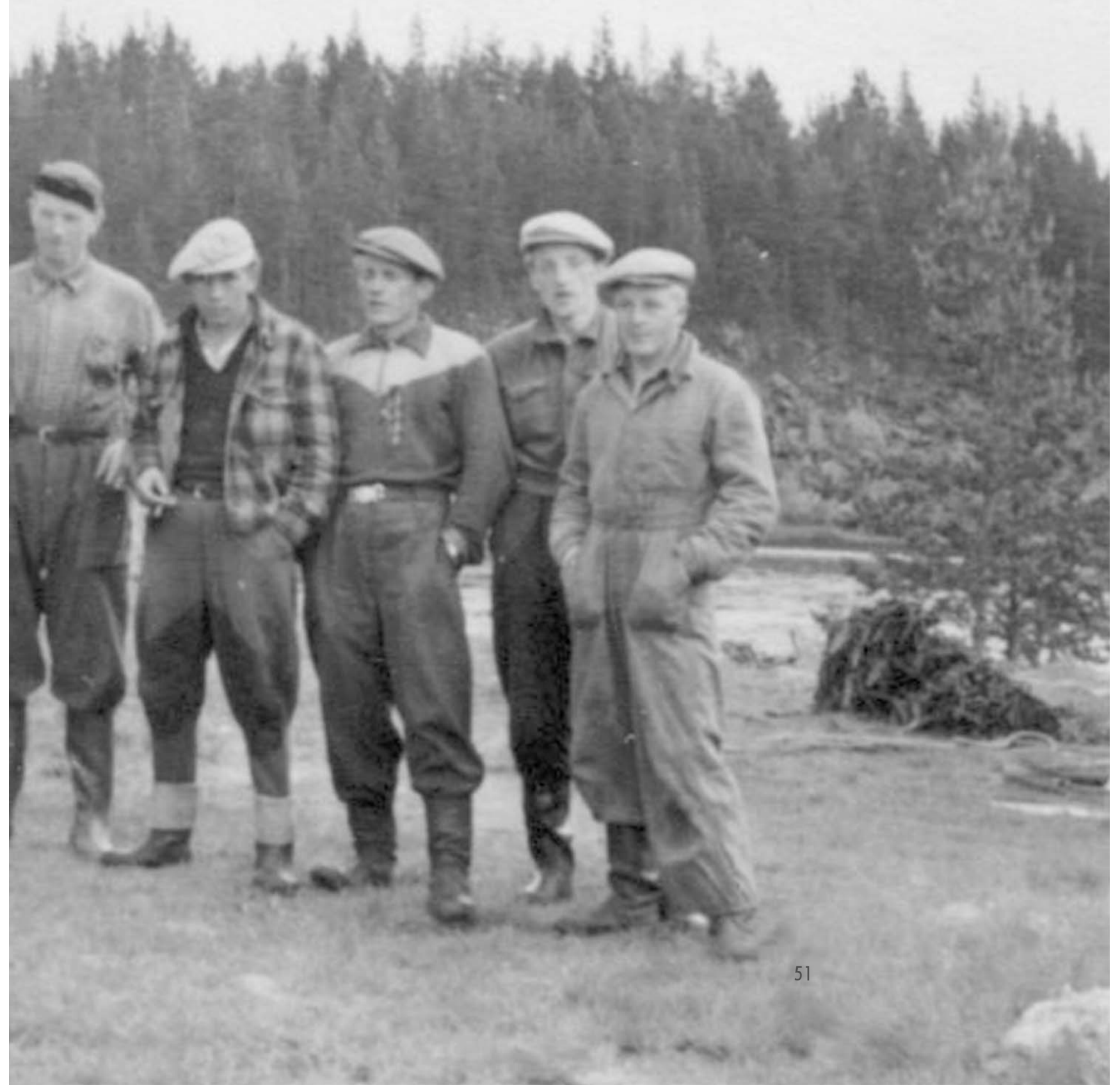


While writing my licentiate thesis on floating camps in Finnish Lapland, I was amazed to discover that the first floating workers' dwellings built in Lapland bore very little resemblance to the local rural buildings. Knowing that forestry had been - especially in its early days when virgin resource areas had to be found - an international industry, I started looking for parallels in the camp architecture of other areas.

Study of migrants' culture has, in addition to that of cultural contacts, ${ }^{1}$ come to be regarded as the specific field of ethnological migrant research, examining what migrants brought with them from their original areas and what features of their original culture they preserved in their new living environment. ${ }^{2}$ In an article published in the 1950s Sigurd Erixon debated the question of whether the notched corner technique was taken to the United States by Swedish emigrants. ${ }^{3}$ American research into buildings has subsequently touched on the same theme: Signe Betsinger has studied the influence of Denmark ${ }^{4}$, Claire Selkurt of Norway ${ }^{5}$ and Matti Kaups and Terry G. Jordan of Finland ${ }^{6}$ on the folk architecture of America. In their studies these writers have singled out individual migrants as spreaders of innovations, but in the modern industrial society described in this article the spread of innovations tended more to be centralized. 


\section{Cut Out and Get Out}

Ecologically the conditions for the forest industry are the same throughout the northern coniferous zone. With time the regional biases in forestry have, however, changed as the forest sector has expanded, since it was for a very long time possible to move on to new, virgin resource areas. If necessary the timber companies moved beyond the borders of their own country. The native population of the new areas was not as a rule sufficiently large, or capable of doing the work required of it, so the know-how passed to the new areas by means of migrants.

In the Nordic countries and Russia the wood-processing industry only acquired its subsequent vast proportions with the establishment of steam sawmills. The forest industries of Sweden, Finland and Russia can all thank the Norwegian timber companies for starting up a steam sawmill industry. The Norwegians operated at all levels of the forest industry, from woodcutters to big investors, and to such an extent that some claim that the development of the forest industry in these countries (Sweden in the 1850s, Finland in the 1870s and Russia in the 1910s) was to begin with dependent on migrants. ${ }^{7}$ 
Finnish Lapland is a good example of the Norwegian influence in the early days of the forest industry. During the water mill era cutting was confined to the areas around the sawmills and the necessary logging and floating was done by the villagers themselves. As the international demand increased and the establishment of steam sawmills became possible, the value of the vast, untouched forests of northern Lapland began to be appreciated. The first major steam mill in the area was that found by the Norwegian company of Hoist \& Fleicher in 1873-1874, which was the first to extend its cutting and floating north of the Arctic Circle.

Since the local laborers were not sufficiently skilled, and there were not enough of them, the company recruited workers from other parts of Finland and Norway. To some extent this was, of course, on account of the language problem existing between the company and the local population; the work went more smoothly if the workers were Norwegian too. ${ }^{8}$ The company accounts for 1872 show the traveling expenses for 31 persons from Stockholm to Haaparanta, their board and lodging there and further transport to Kemi. In 1873 the Senate again granted forty Norwegian sawmill workers permission to bring personal property to Kemi without paying customs duties. ${ }^{?}$

Over in Kemi the newcomers got a mixed reception, as is evident from the following contemporary report: “... There were a tremendous number of Norwegians in Kemi. Some ordinary workers, some foremen, others neither. Life in Kemi at that time was wild. In the evenings they all got drunk; brawled and fought in the streets so that the ordinary people hardly dared to step outside. Every single night there was a grand set-to outside a tavern; there would be dozens of men fighting one another and then vanishing into their dens to heal their wounds. Believe me, there's never been anything like it in Kemi since, and never will be." ${ }^{\prime 10}$

The Norwegian companies were clearly unfamiliar with conditions in Finland, for they paid wages way and above those paid by Finnish companies. The logging companies also provided their workers with food, which was unheard of in Finland. The Norwegian workers probably also had companybuilt accommodation. ${ }^{11}$ In 1890 the sawmill passed into Finnish hands, but because some of the Norwegian workers remained in the service of the new employer, the Norwegian influence continued to be felt. Similar 
examples of Norwegian activity are to be found elsewhere in Finland, too, and in Sweden and Siberia. ${ }^{12}$ The companies of northern Sweden also got some of their timber from Finnish Lapland. ${ }^{13}$

In North America workers traveled about the country to wherever there was work to be had. In the early 19th century the US forest industry centered on the northeastern states, especially Maine and New York. The loggers were mostly French Canadians with experience of logging in Canada. In the 1880s the center of the forest industry - along with the companies and many of the workers ${ }^{14}$ - shifted westwards and to the Mississippi valley. The men seeking work as loggers around the Great Lakes were emigrants from the Nordic countries who had experience of logging in their own country. In the south the loggers were usually the descendants of slaves and Mexicans. ${ }^{15}$ In the eastern parts of Canada they came from the permanent French speaking population, but in British Columbia they were migrants, and very often of Nordic origin. ${ }^{16}$

On settling in their new homeland the Finnish emigrants often sought jobs as loggers. The majority of the Finns migrating to Sweden in the 1880s made for Norrland, Sundsvall and Härnösand, which had developed a thriving sawmill industry. ${ }^{17}$ For the migrants heading for America the chance of finding work in a field already familiar to them sometimes acted as an incentive to emigrate. ${ }^{18}$ Even in their new homeland the logger migrants usually continued to move on to new areas as the timber supply areas changed. ${ }^{19}$

\section{Ideas from Abroad}

The foreign foremen and workers took with them innovations to areas where the logging and floating techniques were still only primitive. For the same reason, men who had worked abroad, such as former American migrants, were undoubtedly in great demand. The time spent working abroad was for loggers and floaters something of an apprenticeship that was useful to employers. The foreign influence is reflected in, among other things, the Finnish floating terminology, which is based almost entirely on Swedish, English and Russian models. ${ }^{20}$

Forest workers were also sent abroad to learn more about logging and 
floating techniques. Companies wishing to improve their felling and transport methods would usually send their skilled workers to North America, where these were most highly mechanized. When, for example, an experiment was made with steam engines in hauling, the company's engineer was sent to the United States to see how mechanical hauling was done there. Over in America the trainees were instructed by Finnish emigrants. According to a letter sent by the engineer, the Americans were technically ahead of the Finns in winter logging but behind in floating. ${ }^{21}$ When, in the early 20th century, work began on improving the most important floating channel in northern Finland, that of the River Kemi, the chief forester of the biggest company went on a study trip to Sweden, after which the floating channels were improved to a great extent according to Swedish models. ${ }^{22}$

Trends in logging and floating were also followed closely from international publications. International trends were one of the subjects in the training of the top company foresters - or so it seems from the extensive literature on forestry dating from the turn of the century in the forestry library at the University of Helsinki. International influences, in the form of study trips, publications, exhibitions and conferences, had been important in industry since the late 19th century, and instead of local culture it would be more apt to speak of the cultural uniformity of some particular branch of industry.

\section{Internal Migration}

It has already been pointed out that the lumber industry, itself a migrant, turned many of its workers into migratory laborers. I have already mentioned that workers in the American forest industry followed the company when it moved on to new areas. The same applied elsewhere: between 1801 and 1914 six million Russians moved to Siberia ${ }^{23}$, while in Sweden some loggers from Värmland and Småland chose the big logging camps of Norrland instead of North America. The migrant Värmland loggers seasonally employed in Norway are even regarded as having been teachers of logging and floating technology in Sweden. ${ }^{24}$ In Finland, too, logging and floating were a welcome source of employment for the surplus population of eastern 
Finland in particular from the end of the 19th century onwards. ${ }^{25}$

The following account of the everyday life of an American logger could just as well apply to that of his Nordic counterpart: "At the end of the 19th century loggers were largely transient workers, spending the winters in snowbound camps remotely located deep in the forests, and leaving in the spring, when logging and river driving ceased, for summer idleness or odd jobs. They frequently changed jobs even during the winter, walking from one camp to another and working at their trades." ${ }^{36}$

Over the years many of the loggers in seasonal employment settled permanently near the camps. Of the marriages contracted in the municipality of Sodankylä between 1881 and 1915, a considerable proportion was between loggers from elsewhere and local girls. ${ }^{27}$

\section{Migrating Innovations}

Having taken a look at the expansive stage of the forest industry in the northern coniferous zone and its effects on population mobility, I now wish to venture into a far more hypothetical area, the mobility of cultural features. $\mathrm{I}$ in fact intend only to give some examples of how the international nature of logging and floating was reflected in the everyday lives of the workers at the turn of the century.

Although the migration of forest workers has received some coverage in the literature, only in a few cases has any attention been paid to the influences transmitted by migratory workers. ${ }^{28}$ The significance of international contacts and mobility in spreading innovations has, however, been dealt with in other contexts. $^{29}$

The aim wherever timber harvesting and transporting were carried out was to develop methods yielding the best possible result. One problem facing the remote camps in the wilds was looking after the workers. Often the workers themselves were left to find their own food and lodging, but some employers began to provide this even before they were obliged to do so by law, in order to achieve effective results.

The loggers' dwellings built in Sweden and Norway for a number of years' use were modeled on the buildings eldpallskoja and spiskoja type. The 
eldpallskoja had a living room with an open fireplace in the center and the spiskoja a bricked stove in the corner of the room. There was a stable either adjoining the dwelling or separate, and sometimes the horses lived in the same room as the people. ${ }^{30}$ As logging and floating companies grew up in Sweden itself, many of the seasonal workers from Värmland and Småland who had previously worked in Norway headed for the camps of Northern Sweden. It is therefore claimed that they took with them the eldpallskoja camp from Norway to the Swedish logging sites. ${ }^{31}$

The innovations may have spread to a restricted area only, as at Namdalen in Norway, where the timber company had a German manager in the 1860s. He introduced the logging camp of German influence and the same type of building was used in the area until the First World War. The ground floor of the two-storied round timber building with a saddle roof was used as a stable and the upper floor as living quarters for the loggers and cook. ${ }^{32}$ This type of building was not known anywhere else in the Nordic countries.

In western Canada, British Columbia and parts of the United States accommodation was usually provided for the loggers by building dwellings - and other facilities - on rafts. The advantage of the floating camp was that the buildings could be transported by water to the next camp when work came to an end. The floating camp consisted of several rows of buildings, one housing a cookhouse, accommodation for the kitchen staff and a storehouse, another the foreman's dwelling and office, and a third the loggers' sleeping quarters. ${ }^{33}$

In the northeastern parts of the United States and the Midwest, the floating camps had log rafts on which was a rough hut of fabric or planks, steered by two big oars. As a rule the floating camp had only one raft per working team and it was therefore used for meals and storing goods, while the men slept in tents on the shore. The raft traveled down the river with the men as work progressed. ${ }^{34}$

Similar solutions to the problem of providing board and lodging for floaters were also to be found in Finland. Until the Second World War some of the floaters spent the night near the sorting base on mobile rafts. ${ }^{35}$ This raft was called a soho, and is the name also used for the cooking rafts and boats along the river. The name generally used for the cooking raft in North Karelia and northern Finland probably comes from Russian; the word 
hartsusoho (hartsonja) has become abbreviated to soho. ${ }^{36}$

At the end of the 19th century typical logging camps in the northeastern parts of the U.S. and the Midwest were log camps. These generally comprised the following buildings, all made of logs notched at the corners: an office and store, which were the headquarters and the sleeping place of the foreman, camp clerk and log sealer, a cook shanty, which housed the kitchen and dining compartment, and a bunk house which provided lounging and sleeping quarters for the men. The cook shanties and bunk houses were generally separate buildings, though in the Northeast they were often apart and the gap was covered with a roof, boarded up in the rear and used as a storage place. ${ }^{37}$

What makes the log camps interesting from the migration point of view is the argument that they were first built by Canadian immigrants working in the U.S. ${ }^{38}$ Furthermore, the companies operating the large logging sites in northern Finland began building very similar camps (known in Finnish as ruukinpirtti). ${ }^{39}$ The model for these was probably imported from North America by men who had gone over to study logging there, or returning emigrants. Another indication of the American influence on Finnish log camp culture is the spreading south of the Finnish word kämppä (from English camp) from northern Finland at the beginning of the $20^{\text {th }}$ century. ${ }^{40}$

At the beginning of this paper I mentioned that floating workers' dwellings in Lapland did not consistently observe the vernacular architecture of Lapland. This being the case, the log camps of Lapland - and North America - in many respects set the pattern for the floating workers' camps. However, the architecture of the floating workers' dwellings was more refined, the side corridor veranda and row house ground plan being the most typical exterior features of the first camps. ${ }^{41}$

\section{Migrating Ideas and Images}

As a result of migratory labor and the international nature of the workers' movement, the demands concerning the working conditions of logging and floating workers were surprisingly similar the world over. In 1911 the 
members of the American "Brotherhood of Timber Workers" laid down a series of demands, which included a minimum wage of two dollars for a ten-hour day, bi-monthly payment, freedom to trade in independent stores, reasonable rents, the revision of doctors' and hospital fees, improvements in camps and towns, the disarming and discharge of company guards and the rights of free speech and assemblage. ${ }^{42}$ In 1906 the forest workers of Finnish Lapland had made precisely the same demands. ${ }^{43}$

The labor protection legislation was likewise international in nature. For example, a law on the obligation of the employer to build dwellings for logging and floating workers was first passed in Norway (in 1915) took a very similar form in Sweden (in 1919) (5 $^{45}$ and Finland (in 1928) ${ }^{46}$. In North America similar state legislation was passed in the 1910s. ${ }^{47}$

Not only ideas migrated, but images too. It is in itself interesting to note that the descriptions of the lives of forest workers and the resulting stereotypes are virtually the same in North America and the Nordic countries. Loggers everywhere called forth a respect tinged with fear comparable to the romantic aura surrounding cowboy culture. Both rough neck occupations have also been an endless source of entertainment. ${ }^{48}$ 
This article was earlier published in Interacting Communities. Studies on Some Aspects of Migration and Urban Ethnology. The Fourth Finnish-Hungarian Symposium on Ethnology. Budapest 1993:

Hungarian Ethnographic Society. 


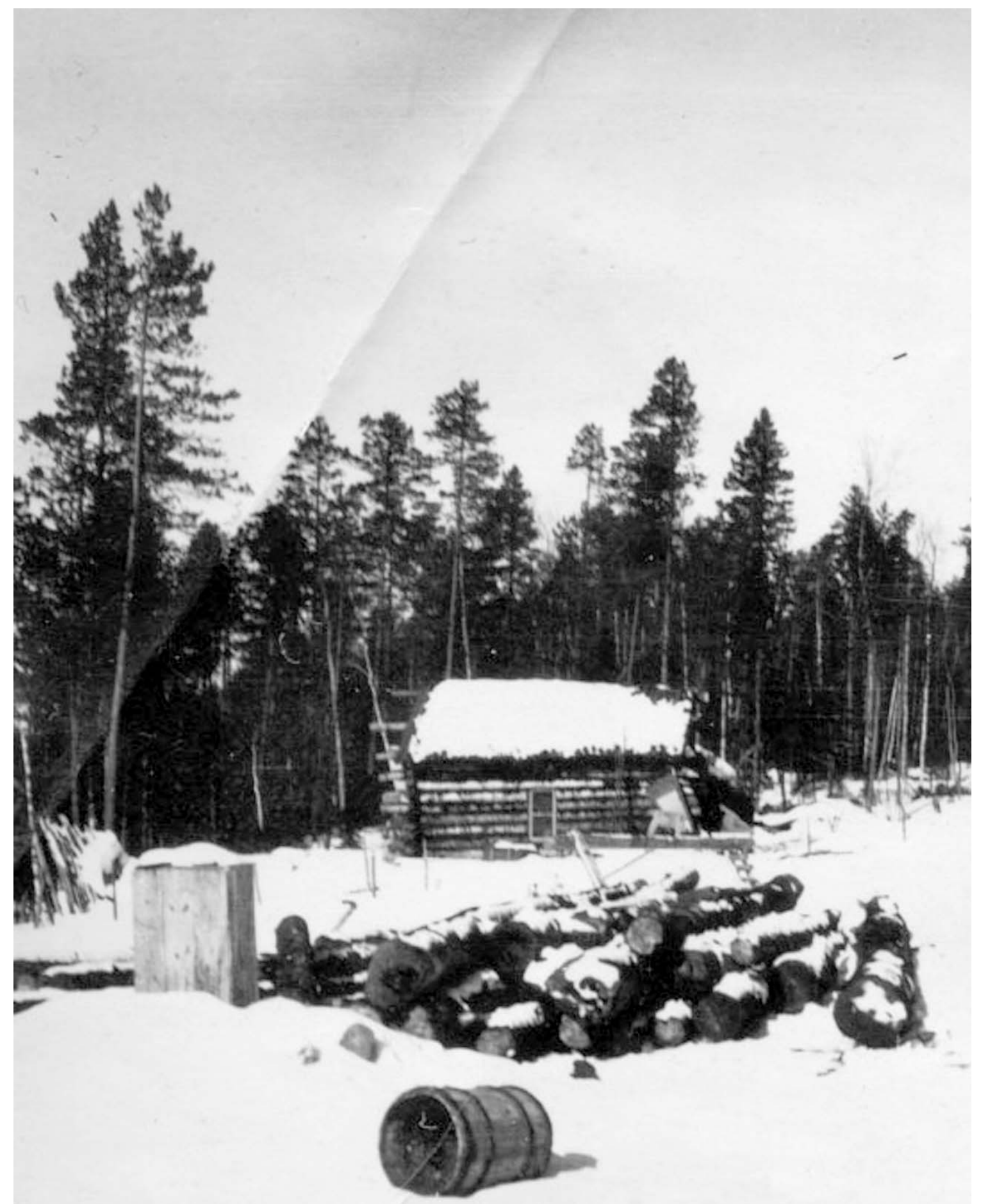




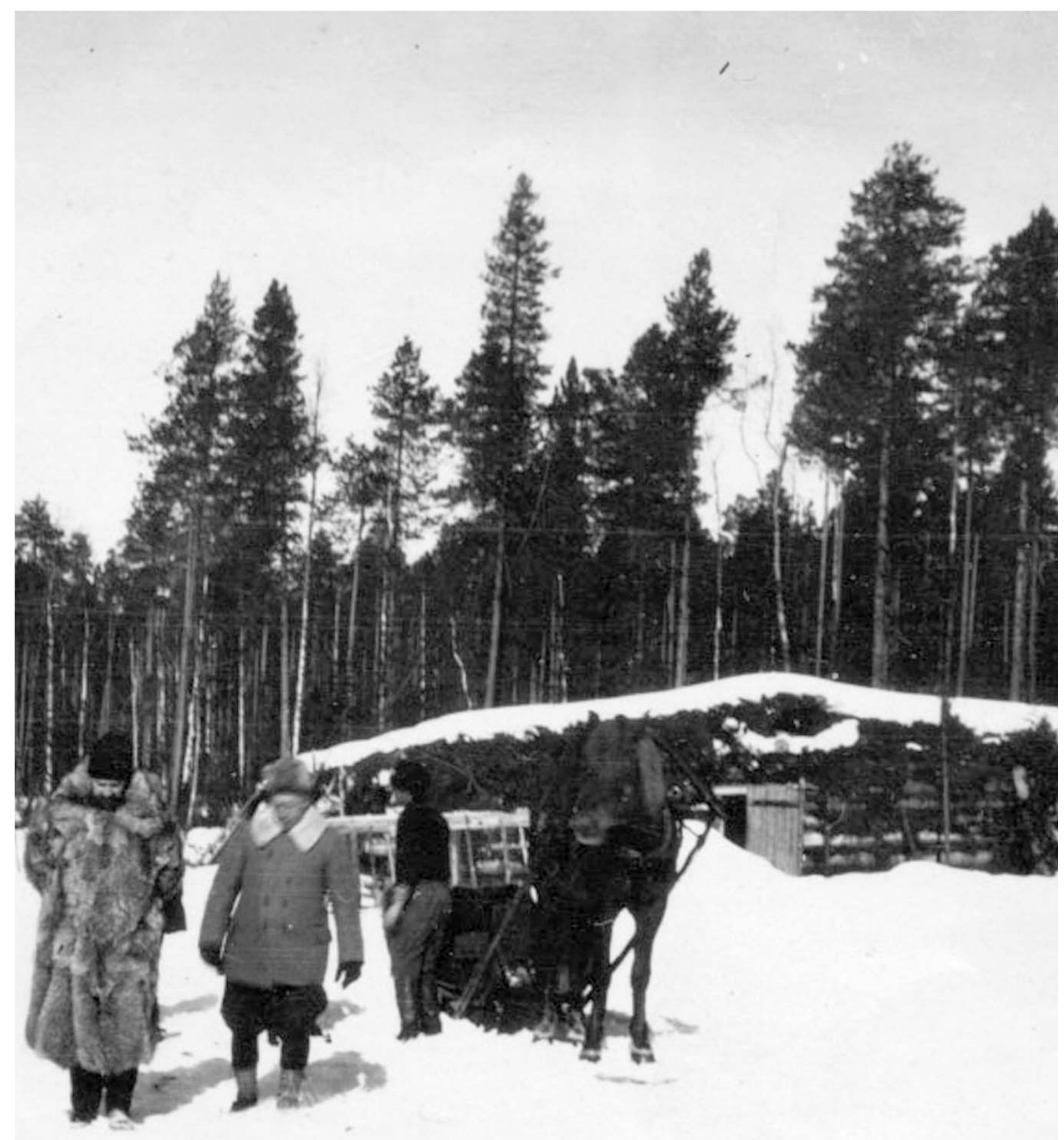

THE CHALLENGE OF DIFFERENCES

e. 
Two chief foresters in their fur coats visiting a logging camp in Lapland in the 1920s. A coat made of wolf's fur was typical for the heads of forest companies. Typical buildings of a remote logging camp can be seen in the photo: the sauna and the camp house, which had a dwelling and a stable under the same roof. In the summertime, work continued in the streams, rivers, and lakes of Lapland.

Housing was even more primitive in the summertime. The photos were taken by Hildur Larsson.

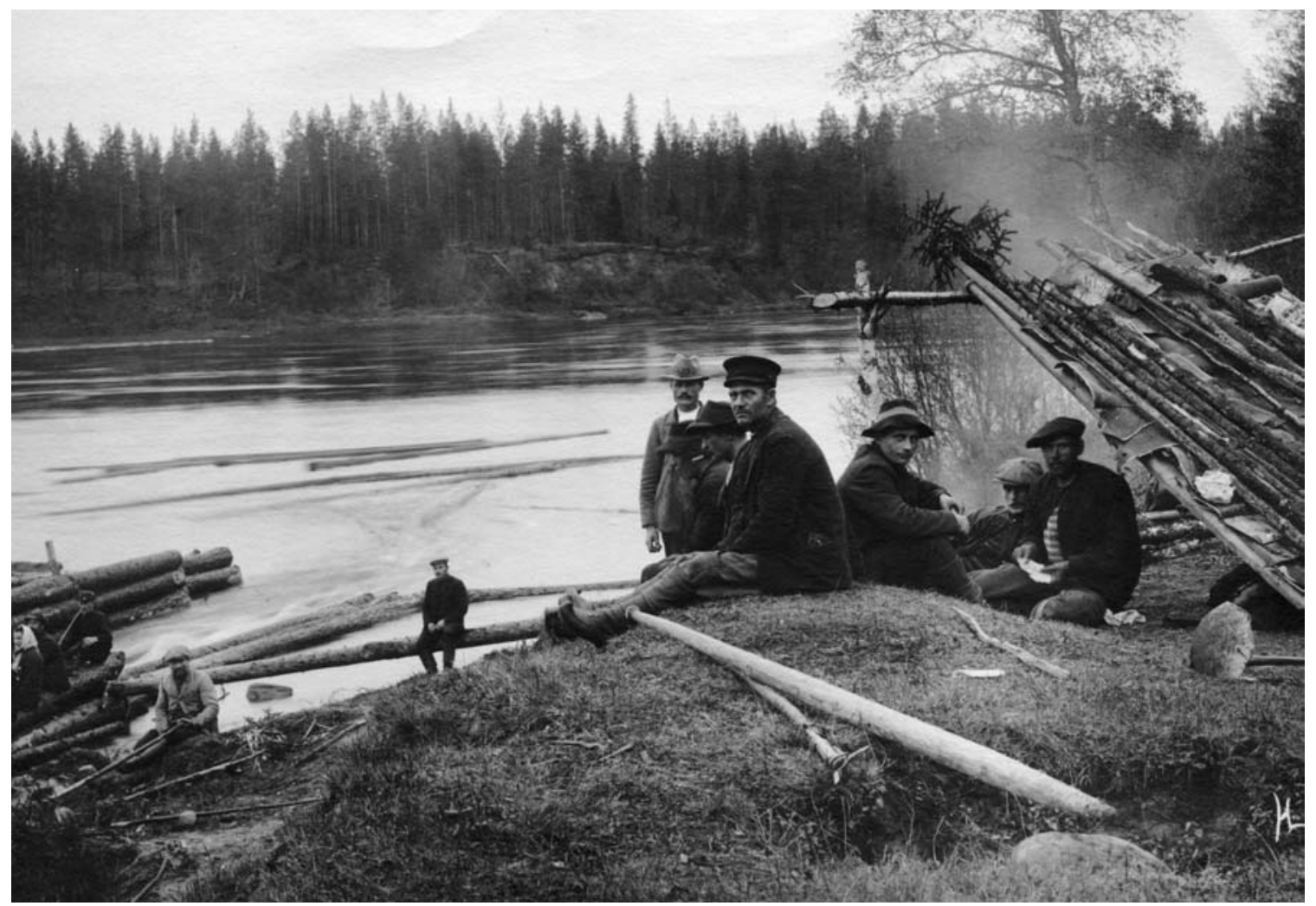


All communities have regulations on the use of space. In becoming socialized as a member of the family at home, the child automatically absorbs values and attitudes, often gender-specific, in dealings with other people which he or she then renews in adulthood. On moving to a new area or starting in a new job, adults likewise undergo what might be called a cultural apprenticeship so that they can learn how to act in the new environment. The way they act reflects the social relations of the community. The space they occupy is never neutral; it is always a cultural jigsaw puzzle in which the pieces are walls and objects just as much as the people involved. ${ }^{1}$

A long time has passed since ethnological research first demonstrated the potential of clothing for enhancing group identity. A woman would, for example, cover her head as a sign that she was married. Research into workers' culture has, among other things, examined the clothing typical of a given occupational group, i.e. the way clothes are chosen to suit the job. ${ }^{2}$ This research has not been confined to description only, since it has also debated the significance of the way a worker dresses in making the working group distinct from representatives of other occupations and in socializing novices to become members of the working community. Printers, for example, could be recognized from other industrial workers by their white cuffs, making them look like white-collar workers and thus emphasizing their status as members of a working elite. ${ }^{3}$

The Finnish lumberjacks engaged in the felling and floating of timber also had ways of indicating their status in the community, their dress, kit and nicknames provided a clue to their skills and social status, and the work site observed an invisible social "town plan". ${ }^{4}$ The way people spoke and their use of time and space on the logging and floating work sites of Lapland were governed by many unwritten laws to which the new worker gradually became socialized. Here I wish to concentrate on one aspect of the manifestation of social identity, namely what members of the community could deduce from a person's outward appearance. What did a hat, scarf, trousers or kit bag say about their bearer? 
The group chosen for examination consists of loggers and floaters working in Finnish Lapland in the early 20th century. As my source material I have used interviews, oral history recorded in archives, works of literature and photographs. None of the sources give a clear indication of outward appearance; instead the information is hidden in references and clues that are difficult to find, as the social history written into subordinate clauses. My aim is thus to try to put together some overall picture from the details available.

\section{Headgear}

Virtually no ethnological research has yet been done in Finland into men's headgear, so it is impossible here to address the problems surrounding various types of headgear very closely. ${ }^{5}$ w would, however, venture to make a few observations. According to Ilmar Talve, the peaked cap came into widespread everyday use in around the mid-19th century, while Juhani U. E. Lehtonen reports that the hat with a brim might grace the head of gentleman and logger alike. ${ }^{6}$ The lumberjacks at the logging camps and on the rivers in spring mostly wore a fur hat, usually of sheepskin with flaps to cover the ears, but the foreman or wealthy farmer might sport a fur hat made of otter. With the coming of summer, some would discard their fur hat in favor of a felt hat with a brim, others a peaked cap.

We can see from photographs that the peaked caps were of two types. In one the peak is made of stiffened cardboard, and in the other the peak is covered with cloth. The former was known, at least among industrial workers, as a vega cap, the latter as a lätsä. The vega cap and brimmed felt hat were abandoned by industrial workers in the 1930s with the spread of lätsä caps. ${ }^{7}$

The broad brim of the felt hat protected the wearer from the rain and sun. For this reason, many floaters adamantly refused to wear a peaked cap instead. Oral history reports that the young men wore peaked caps while the old hands preferred their hats with brims. This is not, however, entirely true, because judging from the photographs, children and young men might wear a brimmed hat and old men a peaked one.

One thing we notice on examining the photographs is that not one of the skilled floaters or men high up in the working community hierarchy is 
wearing a cap of the lätsä type. Another thing we observe is that the young men recruited from other parts of Finland to work on the River Kemi in 1946 are wearing peaked caps while the local men of the same age are wearing brimmed hats. It is possible that brimmed hats were worn mainly by the old, skilled floaters and persons wishing to identify with them. It was thus possible to at least try to deduce a man's background and skill from the type of hat he was wearing.

\section{Trousers}

Outward appearance might also be a means of communicating the wearer's wealth and even his political leanings to other members of the community. According to one informant, foremen in the 1920s wore breeches, whereas workers looked upon breeches as being exclusive to their superiors, "the nobs". On the other hand, another informant reports that lumberjacks wore baggy frieze trousers. References to the feelings of enmity aroused by breeches are also to be found in fiction, ${ }^{8}$ while interviews indicate that in the 1920 s breeches were in some places a sign that the wearer was a supporter of the [right-wing] Civil Guards, and that the Communists only ever wore straight trousers.

Jukka Eenilä reports that the new footwear and trouser fashions were first adopted by the foremen. The workers were against wearing breeches because they were regarded as a statement on the events of 1918 [the year of the Finnish Civil War]. What is more, a man in breeches had to wear straight boots, which were felt to be less practical in the forest than the laced

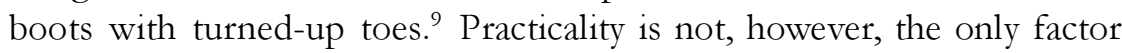
explaining this, because ordinary boots were worn in the summer. The men's unwillingness to wear breeches is no doubt explained by the Civil War. When the war broke out in 1918, the Civil Guards set off in their civilian clothing and wearing a white armband. The Civil Guards uniform later introduced was virtually a copy of the temporary military uniform worn during the war of 1918. Breeches were not compulsory with the Civil Guards uniform, but they were commonly worn. ${ }^{10}$ 


\section{Scarves}

With their smocks the young floaters of southern Finland wore a colored square scarf called a hurjan silkki (dashing silk). ${ }^{11}$ Pentti Haanpää the writer wore a red scarf round his neck when he wanted to appear as a lumberjack. ${ }^{12}$ The interviewees could not recall scarves being worn in the River Kemi region, and nor are there any mentions of them in the other oral history. But in a novel set in the 1910s Jussi Hagberg, a member of a timber-floating community, mentions the colorful scarves swathed round floaters' necks and bought from the market on pay day. ${ }^{13}$ The photographs also show scarves in use: in one photo taken on the River Kemi in the 1910s the floater is wearing a rectangular scarf.

Just what these silk scarves were meant to communicate is not sure. At least they kept their wearers warm while working on the freezing-cold streams. They also provided protection against the sun and the mosquitoes. The fact that the scarf was known as a "dashing silk" suggests that it was also worn as a flamboyant gesture. Maybe the custom was borrowed from seamen ${ }^{14}$; many of the floaters were general laborers who had also been to sea at some time during their lives. The color red might also indicate the wearer's political sympathies. A humorous magazine appearing in 1909 states that no political emblems were allowed at the logging and floating camps of Lapland. "Any sign of red will get you the sack", was how the atmosphere in the camp was described. ${ }^{15}$

\section{Kit bags}

Workers also fell into distinct groups according to what they used to carry their belongings in, but this time the division was not, according to the interviewees, one of political opinions or occupational identity but of wealth. The most affluent men would carry a leather bag on their backs with a broad strap passed over the head and attached round the chest to narrow straps from the bottom of the bag so that it snugly fit the body. ${ }^{16}$ Instead of a leather bag, men from southern and eastern Finland might carry a satchel made of birch bark. Some even carried a suitcase. Meanwhile the 
poorest would carry on their backs a lammas (sheep) or pussi (bag) made from a fifty-kilo hemp sack with rope straps made from string and possibly a little bell sewn onto the bottom. ${ }^{17}$

Similar kit bags were also reported in other parts of Finland. Life at the Voikkaa paper mill was said to have changed with the coming of the "sack backs" from Mäntyharju. ${ }^{18}$ Meanwhile there are reports from the Ikaalinen region that floaters in the 1890s began to use bags called pässit (rams) made from cloth or old sacks in which to carry their belongings. ${ }^{19}$ The lumberjack migrating from one work site to another in eastern Finland could be recognized by his kit bag; if there was a nail for his kit bag that was the man's home..$^{20}$ Bells are not actually mentioned in the material.

Just why the lumberjacks of the River Kemi region sewed a little bell onto their kit bags is still a matter of conjecture. It may have been the sign of a migrant worker, the Finnish name kulkunen meaning both a traveling man and a jingle bell. But assuming that it was a sign of social identity demanded by the community, many reasons can be put forward for its use. ${ }^{21}$ The traveling man with a sack on his back might be looked upon as a threat, but if his jingle bell announced his coming, people knew he was on honest business. The horseman could be heard from afar from the tinkling of the sleigh bell. And a sleigh bell was obligatory so that anyone traveling the roads, especially in the dark, would know when a heavily-laden sleigh was approaching. The jingling bell might also keep the tired traveler awake as he tramped long distances in the dark. Another explanation might be that during the famine years at least many church congregations issued the needy otherwise unable to find sufficient assistance with signs to be worn round the neck, for example, granting the right to beg. This was done in order to prevent illicit begging. ${ }^{22}$ A sack was also a common sign of a beggar, so the little bell may well have something to do with begging. ${ }^{23}$

There is another interesting point about the custom of sewing a little bell onto the lumberjack's kit bag. A traveler without a bell on his sack would be jeered at by making the sound of a sheep. The traveler did not necessarily sew the bell on his kit bag himself; it might be done by his companions. Again, the reason for this custom has not been explained, but oral reports of it prove that a bell such as this certainly had its uses. ${ }^{24}$ 


\section{Conclusion}

In her study of the printing profession, Susanne Lundin deals with the significance of cultural capital in occupational culture. By symbolic capital she means the capital affording a boy the easiest entry into a profession because his father or some other close relative is already engaged in this profession and learning the job is easy because the family backing has been socializing him to the profession ever since childhood. Lundin divides symbolic capital into family capital and professional capital. ${ }^{25}$

When a boy from the River Kemi region set off in search of work at the nearby floating site, he had the advantage of both family and professional capital. He was often accompanied by his father, grandfather, a brother or neighbor, and he already knew something about the job either from watching from the river bank at home or even from joining in, partly as a game. Many had already accompanied a relative on his travels before actually seeking work themselves. A boy might already know the foreman from whom he was seeking his first job. The foreman might be from the same village, a relative, or someone who stayed at the boy's home while traveling in the wilds. Many a boy had gained experience of the logging camps and floating streams while trading wares or taking coffee out to the floaters. In the process he got to know the foremen and workers, and this later proved useful in seeking work.

The local people usually worked near their home villages, and they had a mental picture, a sort of cognitive map, of the local terrain and conditions. ${ }^{26}$ This local knowledge was useful to them in, for example, positioning the guide booms, which were named according to their location. The local people had also been handling boats and balancing on longs ever since they were children. The northern Finns' pride at being allowed to take part in the demanding floating jobs when they were still only very young is in fact marked in the oral history material and in this respect they considered themselves superior to their southern counterparts.

Floaters other than second-generation ones may also be examined from the perspective of symbolic capital or its absence. Symbolic capital classified the members of a working community according to their origins and skills. Family capital could only be acquired by being born into a certain family, 
extended family or village, but professional capital could be amassed by others and could be added to over the years. Thus workers from outside the River Kemi region tried to demonstrate their professional skills and thus to safeguard their place in the working community. And in a community where written testimonials were unknown, dress and other accessories provided some kind of indication of a newcomer. The foreman could judge an applicant's background and skill from the way he looked.

Dress was also a means of enhancing group identity: it could be a sign of political sympathies. One indication of this is the fact that the lumberjack with left-wing tendencies did not wear breeches in the Finland torn by the Civil War of 1918, but that he might, even under threat of losing his job, tie a red scarf round his neck to show where his sympathies lay. Dress was a silent statement, even a protest.

This article was earlier published in Ethnic Communities Ethnic Studies - Ethnic Costumes Today. Ed. János Kodolányi jr. Budapest 1999: Hungarian Ethnographical Society. 


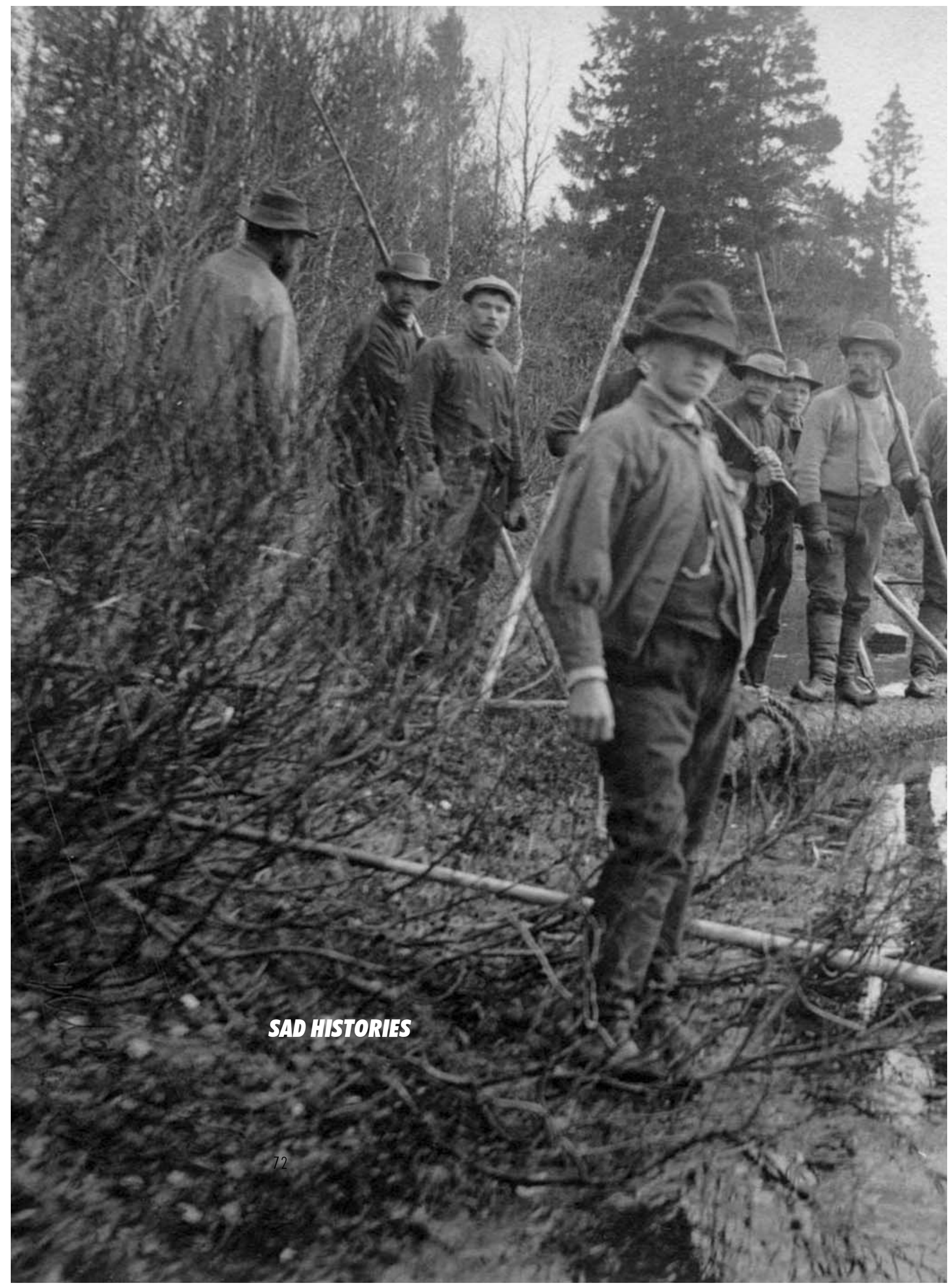




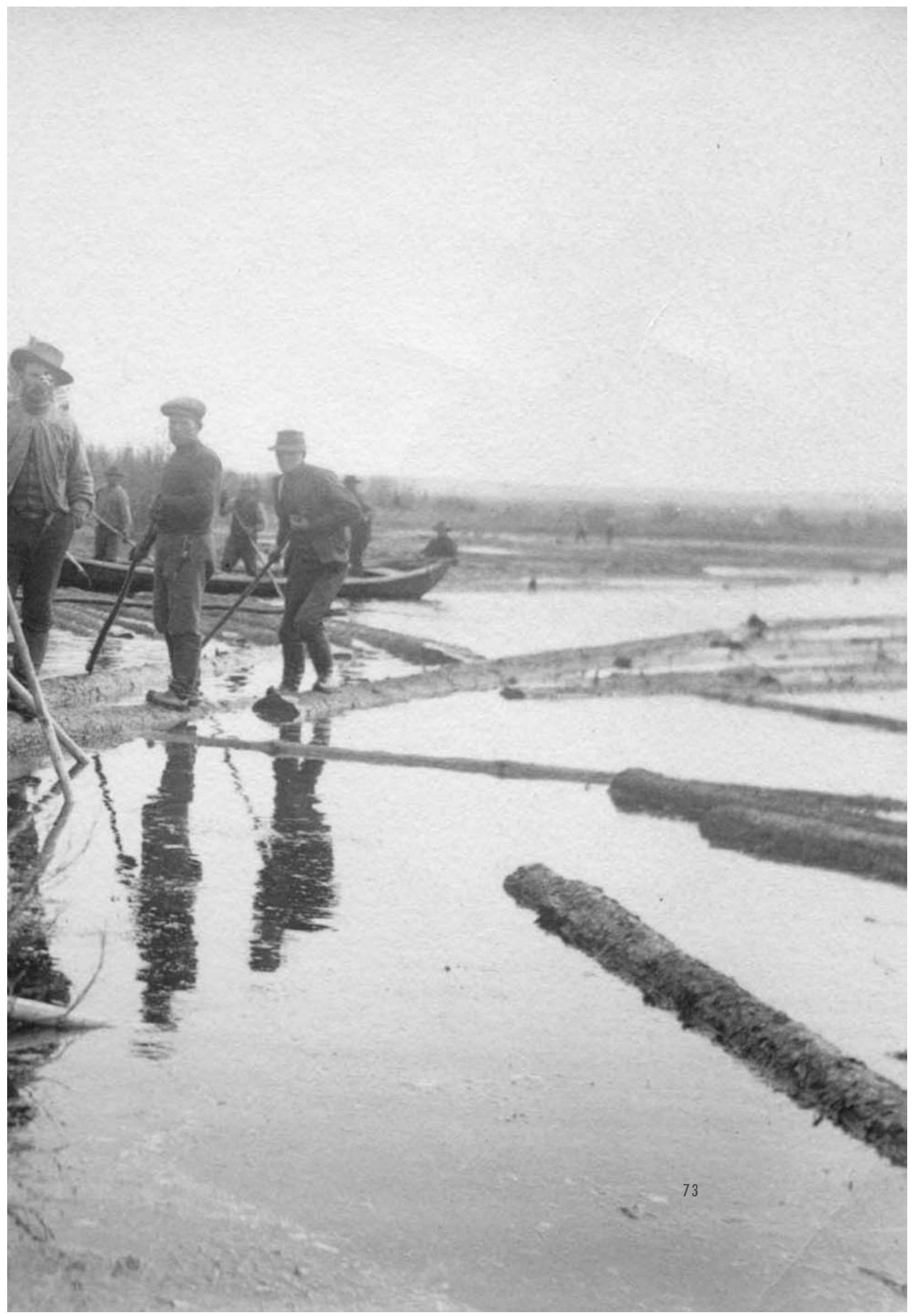


European ethnologists have been accused of making the world a much nicer, happier and safer place than it is. In the 1970s the German scholars Utz Jeggle and Hermann Bausinger pointed out that idealizing the past has been the besetting sin of former generations of ethnologists ${ }^{1}$. In Finland the ethnological overviews of Finnish popular culture emphasize the united front of the rural community; poverty and destitution are not mentioned, as Satu Apo has pointed out. ${ }^{2}$ Therefore, it is not surprising that prostitution has seldom been treated in Finnish ethnological research before the 1990s; it actually did not exist in the texts of ethnologists. The situation - embroidering the truth and creating nostalgia - has been about the same in Sweden ${ }^{3}$, with the exception of Jonas Frykman's book ${ }^{4}$ about women with bad reputations. However, all this can be accounted for by the history of ethnology, its roots being in national romanticism. 
The aim of this article ${ }^{5}$ is to try to find information on the everyday lives of women accused of prostitution in sparsely inhabited Finnish Lapland. This theme is a part of my research project "Women working their way through logging camps" which examines women in logging communities. ${ }^{6}$ Everyday lives of women are examined from three angles: First, their work in isolated homesteads taking care of children and cattle while husbands were away working in the woods for long periods of time; second, as cooks in the isolated camps among men; and third, as women on the loose, selling liquor and their company to lumberjacks. In this article the focus is on the third theme, prostitution.

The oral history material ${ }^{7}$ - if accepted as such - used in this case study about prostitution on the periphery, far from cities, consists of documents produced by policemen when they were questioning women accused of prostitution. These interrogations of suspects were done in the years 19141916, 1918-1920 and 1923-1932 in Rovaniemi, a sort of a capital of this sparsely populated area. The main question in this article is whether this material, examination notes made by policemen, gives any information about the informal economy and everyday lives of the women accused of prostitution. As an ethnologist, I am not interested in whether the women were actually criminals or not, nor am I interested in the way society treated these women. What I will focus on is their life as women without permanent work in an area where men outnumbered women.

\section{Lumberjacks of Lapland}

Ecologically the conditions for the forest industry are the same throughout the northern coniferous zone. Through time, however, the regional biases in forestry have changed as the forest sector has expanded, since it was for a very long time possible to move on to new, virgin resource areas. That was exactly what happened in Finnish Lapland at the end of the nineteenth century: In the 1870s industrialists became interested in the vast untouched forest areas in Finnish Lapland and the opportunities they offered for a steamdriven sawmill industry on the coast of the Gulf of Bothnia. A professional group of lumberjacks who specialized in the felling and transport of timber 
was formed in the area. Many of them were like nomads, working in forests during the winter and autumn months, and by rivers during the spring and summer months. Some combined logging with farming or reindeer herding, others with periods of unemployment or construction work. ${ }^{8}$

The logging camps of Finnish Lapland were meeting places for a heterogeneous group of men, many of whom were born beyond the boundaries of Lapland, a territory itself large in area. Men with different social and cultural backgrounds spent months in isolated logging camps built in the wilderness. River driving brought them closer to settlement but still they were mostly living away from society, where communication with people other than fellow male workers would have been possible. Due to long distances, for many it was only a few times a year that communication with women was possible: mostly in the spring and in the autumn. ${ }^{9}$

The lumberjacks were mostly men who had migrated to Lapland. Though not officially recognized, due to the fact that many of them were seasonal workers from eastern and southern Finland and they were registered there, but at least in practice, men outnumbered women in Lapland for some time. For the topic under consideration, prostitution, this outnumbering is essential: Work as a lumberjack was physically demanding, so one can assume that the first tides of immigration were composed overwhelmingly of unattached young men in the prime of life, with the physical strength needed in the work. It must be stressed here that this is only an assumption: even though Finland is famous for its detailed demographic statistics, the seasonal workers are a problem in that sense. Seasonal workers could live permanently hundreds of kilometers from the communities where they were officially registered.

As the forest industry was established in Lapland at the turn of the century, the population of, for example, Rovaniemi, tripled. In 1870 the population of Rovaniemi was around 4,000 and in 1910 around 11,000. ${ }^{10}$ However, the statistics do not tell the whole truth. At the same time there were thousands of seasonal workers, all men, who worked in Lapland without being officially registered. So far no one has been able to give the exact number of them. ${ }^{11}$ It has been estimated that each year more than 10,000 men drifted to Lapland to work, and most of them either started looking for work from Rovaniemi (because of the railway and the fact that 
the timber companies had their offices there), or returned to their home communities via Rovaniemi. Rovaniemi was also famous for its fairs which attracted lumberjacks during times of unemployment. ${ }^{12}$

Most likely 10,000 men wandering to the forests of Lapland through Rovaniemi every winter is an exaggeration, but even if the number was much smaller, the ratio between the male and female population stays the same. From oral history material collected among lumberjacks one can read that those who came to Lapland to work at the logging camps were either bachelors or husbands who had left their wives and families at home. Even though bachelors did marry local girls, there certainly was such a shortage of marriageable women that the unwed seasonal workers were condemned to single blessedness by simple arithmetic.

Mass migration had knocked normal male-female ratios completely out of balance. Nonetheless, again it is impossible to deduce this from the statistics. The demographic statistics of Rovaniemi indicate that the male population outnumbered the female by only 4,198 to 4,123 in $1900 .{ }^{13}$ In the narratives of lumberjacks, however, one can learn that a man usually officially left his seasonal worker's status only for two reasons: if he was married or if he gained possession of a farmstead. According to same oral history material it was easier to get a homestead from the state if one was married. ${ }^{14}$ All in all, again it is shown that oral history material can fill the gaps in the archive material.

Gradually, a part of the workforce settled permanently in Lapland and lumberjacks became official residents of the area where they worked. In 1950 more than half of Lapland's rural male workforce was seasonally occupied as lumberjacks. ${ }^{15}$ From the Second World War onwards forest work was gradually mechanized and professionalized, and therefore the profession of the old-time lumberjack became history.

Since there was an overwhelming surplus of males in Lapland for some time, the situation had its consequences. The existence of this large itinerant single male population created an environment, known as the "rest and recreation culture", in which prostitution could flourish, and flourish it did everywhere where there were lumberjacks: in population centers such as Rovaniemi, but also in small villages and logging camps built in the middle of the wilderness. 
Hard work in a male environment was a typical feature of the lumberjacks' occupational culture.

The photos in this article were taken by

Hildur Larsson in the 1910s.

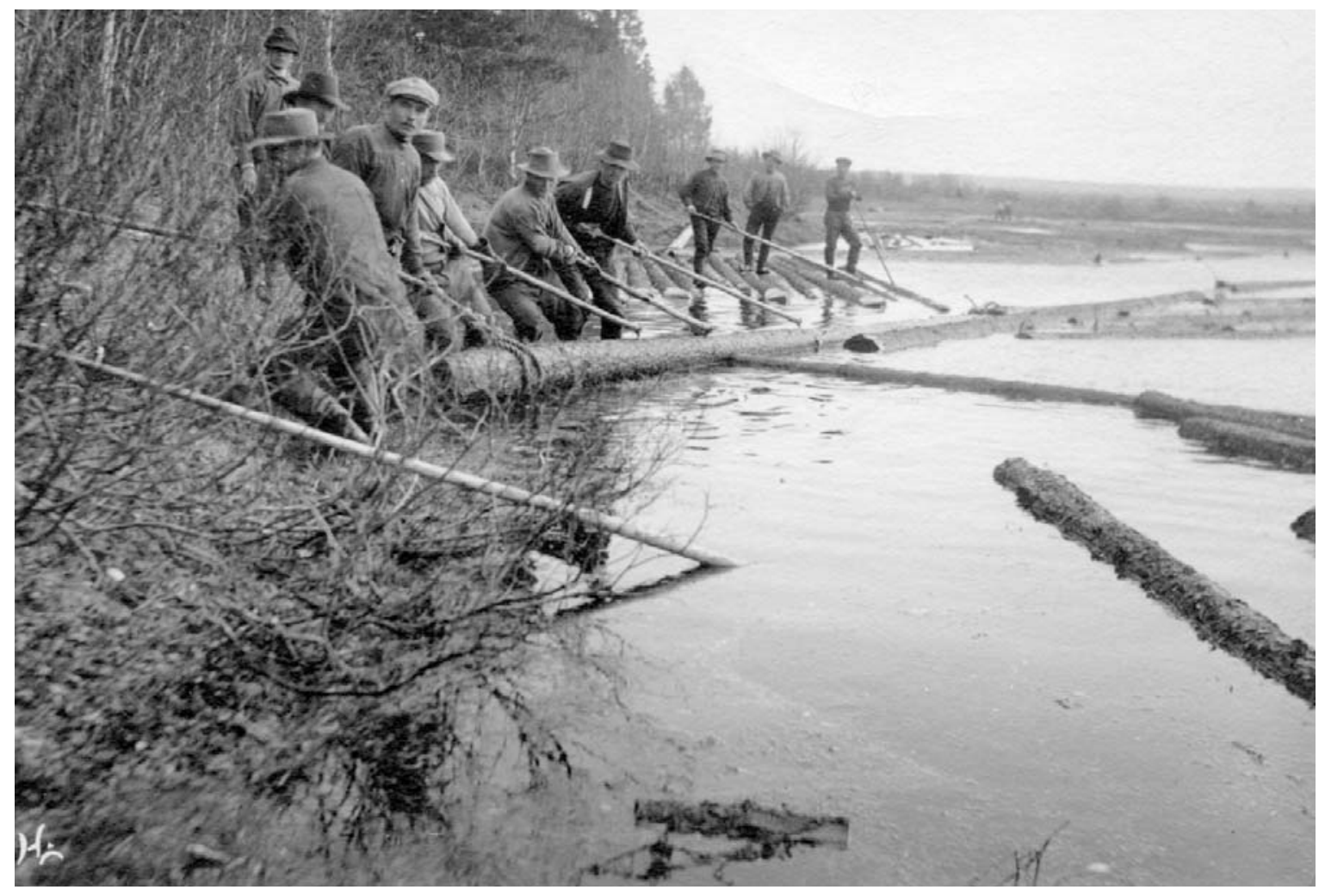


According to a Finnish social historian, Antti Häkkinen, prostitution was not common - at least in the sense we understand it today - in the Finnish countryside before the 1890s. The situation changed radically between the World Wars: the expanding amount of so called roughneck occupations, i.e. lumberjacks, railroad and construction workers, kept the courts busy with charges against women accused of a disreputable way of life. Not only was prostitution criminalized, but also vagrancy, idleness and alcoholism. ${ }^{16}$

Those women accused of indecent behavior were questioned by the police in order to find out whether they should be punished by society or not. Usually women were asked to tell their life stories in order to find out how long they had led the life they were accused of. They were also questioned about their lifestyle for the same purpose. In addition to that, the police described the circumstances of the arrest. Therefore, the notes include information about the small routines of people living on the margin, and about lives of individuals. Yet one must remember that the information is construed by the examiner, not the interviewee.

The life story of 33-year-old Saima was written down by the police in 1928. In a few lines one can read not only the sad history of an individual but also about war orphans of the Civil War $^{17}$ and the questionable system of taking care of the ill-fated:

... was an illegitimate child, no sisters or brothers, father not known, mother 
dead. Has been married, but the husband was killed in the Civil War and the four children of the couple were taken away from the mother and their maintenance was entrusted to the lowest bidder. Was a parish pauper herself until the age of 15, since when has earned her living by being a maid in different farms in Lapland. Two years ago moved to Rovaniemi. Summer 1927 she was in Kemi. The winter of 1927-1928 has been living in the cottage of Sierilä without work, earning her living by selling home-brewed beer, lemonade and tobacco. Admits that she has taken a drink when men visiting Sierilä have offered her one, but has not known the men because they have been vagabonds. ${ }^{18}$

\section{Needlework and Boołlegging}

Women without permanent work lived on the margin in many ways: their homes were on the outskirts of communities and their lifestyle was despised by "decent" people. Even lumberjacks who visited their flimsy shacks whenever possible often describe them in a negative way. Affection is not necessarily mentioned in their narratives, but the women's ugliness - with some exceptions - and alcoholism are. A very typical recollection includes heavy drinking, a hasty coupling, passing out and a hangover the next morning. The company of men was as important as the company of women. Therefore - and to reduce the price - a man had the woman not only for himself, but a group of men were waiting in line for the same woman. The location could be anywhere, for example, inside a cottage or a shed or outside in the bushes. Lack of affection and plenty of alcohol for both the men and women is striking. ${ }^{19}$

This is what we usually hear about prostitutes, and that is also the sort of information that is emphasized in the material - not that it is a surprise as after all the interviewers, the police, were interested in possible crime. They were not anthropologists. Yet some information about life beyond the life of a social outcast can be found in the documents. In the following, the information given in the documents which includes information about sources of income other than prostitution is summarized.

Hilda (18 years old) was arrested on 10 June 1916 at 7 p.m. She told the 
police that the previous September she had left the home of her parents in Kemi, the neighboring town. The reason can be read between the lines: in July she had given birth to a baby, now in the care of the girl's parents. The past nine months she had been living in three different towns without permanent work. In February she had moved to Rovaniemi, but soon her male companion had been sent to prison after being charged with the procreation of women. Simultaneously Hilda was sent to the nearest hospital because she had venereal disease. She told the policemen that in addition to prostitution her income consisted of washing and repairing clothes, washing dishes and selling home-brewed beer. She had visited her hometown every now and then, which could mean that she was seeing her baby. ${ }^{20}$ Hilda disappears from the documents after this one arrest. Being charged with prostitution did not mean that the person would be a prostitute all her life. ${ }^{21}$ Drinking is not mentioned in the report, which is quite exceptional.

On 6 March 1919 two women, Lyyli and Maria, were arrested at five in the afternoon in a cottage on the outskirts of town. Eighteen-year-old Maria, daughter of a crofter, had already been in prison for prostitution. After prison she had first lived with her parents for four months and later with a man in the centre of Rovaniemi. She had earned her living partly from needlework. At some time she had been in the hospital for four weeks because of venereal disease. On July $7^{\text {th }} 1920$ she was arrested again at 3 p.m. at the same cottage - known to the police "as a place where prostitutes and thieves live". The records state that Maria had been dating mostly soldiers lately.22

Maria's life continued along the lines typical for a prostitute. At the age of 25 Maria is an alcoholic and also physically abused; she had scars on her face and head. ${ }^{23}$ According to contemporary accounts, the erratic lifestyle of prostitutes was soon visible in their physical appearance. ${ }^{24}$ Maria had already been imprisoned for four times, in 1919 for 4 months, in 1921 for 6 months, in 1922 for 12 months and 1924 for 15 months. Now she was sent to prison for 12 months. At times she had been working as a maid or in hay-making. ${ }^{25}$

Lyyli's life story is similar, her life circulating around home, prison and hospital. She had left her parents' home at the age of 19 and had been working on farms and at an inn. At the age of 21 she was sent to penal 
servitude for four months, charged with prostitution. After returning to Rovaniemi she started working in a delivery room of the hospital but because of a venereal disease she had to give this up and become a patient in the hospital herself. The next years of her life she was either living with her parents or in the hospital receiving treatment for her venereal disease. At times she was working as a sales girl in a shop or doing needlework for a living, but from the dates of the arrests one can read that she was the companion of lumberjacks: the arrests took place at times and places where there were a lot of lumberjacks. She was also arrested in neighboring towns. ${ }^{26}$

Needlework was also a source of income for 17-year-old Impi, who was arrested on 4 November 1926. In the examination she told the police that she was going to work in a tailor's workshop. When she was examined again the next year she told the police that in addition to prostitution she had earned her living by needlework and crocheting lace for sale. Impi who, according to the notes, had started loose living when 15 years old, lived in the home of her parents, which is rather exceptional in the material. ${ }^{27}$ Yet there are other examples of that, too, e.g. 23-year-old Anna who was arrested 1 January 1928. According to the police, the wall-eyed girl had earned her living by selling coffee and home-brewed beer all over northern Finland. Apparently the market had been in the remote logging camps of Lapland and the mother had acted as a pander for the girl. ${ }^{28}$

Hilda (aged 54) was arrested on $20^{\text {th }}$ October 1931 because for a long time she had been unemployed, without a permanent residence, drinking and sleeping with vagabond lumberjacks for money or liquor. Her only other source of income was laundry. She had lived partly in sheds and partly in cottages where lumberjacks spent the periods of unemployment. The police interviewed Hilda about her life. She said that her father had migrated to the United States when she was 9 years old and died there soon after. Hilda moved to her uncle's home when she was 12 years old. At the age of 14 she started working as a babysitter and later as a maid in different places. She changed places frequently. At the age of 32 she left her home village and moved southwards to work first as a maid and later in a sawmill. When she was about 40 years old she came back to Rovaniemi. In the cottage where she lived with other women not only was sex for sale, but also home-made beer, lemonade and tobacco. ${ }^{29}$ In the lumberjacks' narratives Hilda was one 
of the most remembered persons. ${ }^{30}$

Another person also found in the lumberjacks' narratives is Hilma. ${ }^{31}$ A crofter from the neighboring village was questioned by the police on 17 October 1931. Apparently a customer of Hilma, he told the police that he had come to Rovaniemi the previous Monday after which he had been drinking. The day before the questioning he went to Hilma's cottage where he had been drinking home-brewed beer with a number of people until he passed out. When he woke up in the morning his wallet was gone. The 39year-old Hilma had been questioned by the police many times. From the records we learn that she was a daughter of a farmer, and she had lived with her parents until she was 19 years old. She had also worked at agricultural tasks at home and on neighboring farms. At the age of 19 she married a tenant farmer and moved to another community. After nine years of marriage the husband died and Hilma was left with three small children. The maintenance of the two older ones was entrusted to a fanner in the village, ${ }^{32}$ and the baby who a little later died at the age of 6 months was left with the mother. At the age of 30 she moved to Rovaniemi where she apparently was a madam of a modest brothel. Hilma gave birth to another child who was taken away from her at the age of four. Earlier Hilma had also worked as a masseuse, but because of a bad drinking problem, she was no longer able to do massage. ${ }^{33}$

Aino (26) was arrested on $27^{\text {th }}$ July 1927. Two years before she had bought a cottage in the centre of Rovaniemi and started a business. She rented lodgings to men and women and sold home-brewed beer, coffee and tobacco to vagabond lumberjacks. The women were naturally prostitutes working for Aino. ${ }^{34}$

\section{Conclusion}

The Canadian writer James H. Gray summarized the social life of western Canada with a few words; "Getting drunk and getting laid". ${ }^{35}$ That characterizes the social life of itinerant lumberjacks and the sources of income for prostitutes as well. Selling alcohol, in this case strong home-made brew or moonshine, was illegal because of prohibition ${ }^{36}$ and therefore a successful 
business. Those who did not drink it too much themselves could make a nice - though illegal - living. ${ }^{37}$ However, the business had its dark side: undressing for men inevitably led the same women to put on the unpleasant dress of the prison or hospital, both far away from Rovaniemi.

The typical life story of a prostitute includes leaving home at an early age, work as maid on farms and starting a life of vice around the age of 20 : The impression one gets from the life stories of the women is that prostitution is connected with alcoholism - though which one came first is very difficult to determine. A professional prostitute in 1920s Helsinki spent half of her time in the prison for women or in hospital for venereal disease. ${ }^{38}$ There is no reason to believe the situation would have been different in Rovaniemi.

The aim of this study was to see whether the interviews with women accused of prostitution conducted by police have information about other sources of income these women had. The results are that the material concentrates - not surprisingly - on prostitution. "The documents describe encounters of ill-fated lonely persons with difficulties in life," as Antti Häkkinen has stated ${ }^{39}$. Yet some information on other kinds of income can be obtained. Mostly these women earned their bread and butter as drinking companions of itinerant lumberjacks. Most of them had worked as maids at some time in their lives and their labor was still needed, at least in haymaking, a task which demanded the entire workforce available. Rovaniemi was a centre where different services were needed. Therefore it is not a surprise that these women earned their living partly from washing and repairing clothes, washing dishes, selling coffee, lemonade, home-brewed beer and tobacco or massaging. These all belong to the sector of the informal economy, a field that is difficult to research because of the lack of sources. ${ }^{40}$ 
This article was earlier published in Ethnologia Scandinavica.

A Journal for Nordic Ethnology. Vol. 29. 1999:

Folklivsarkivet. 


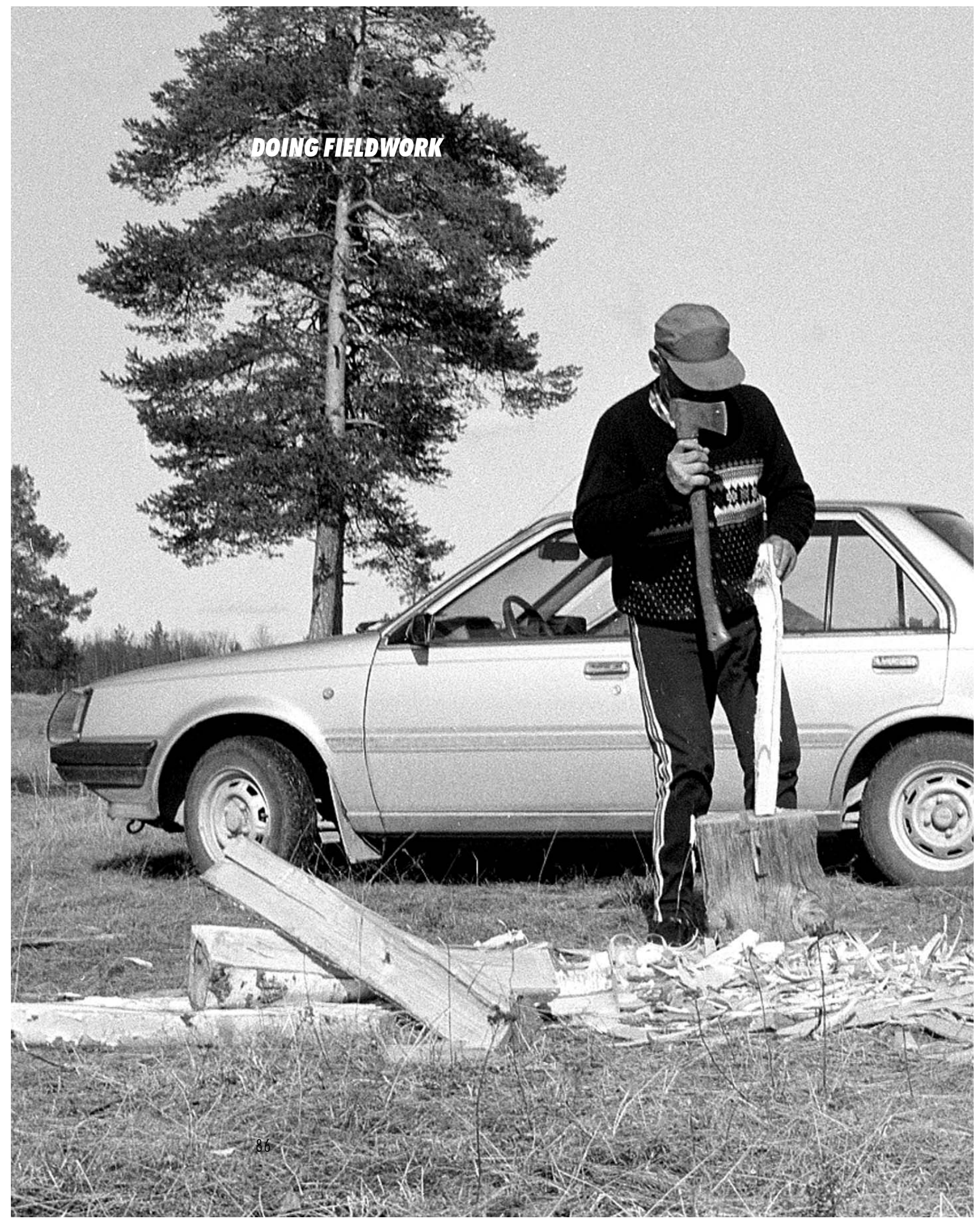




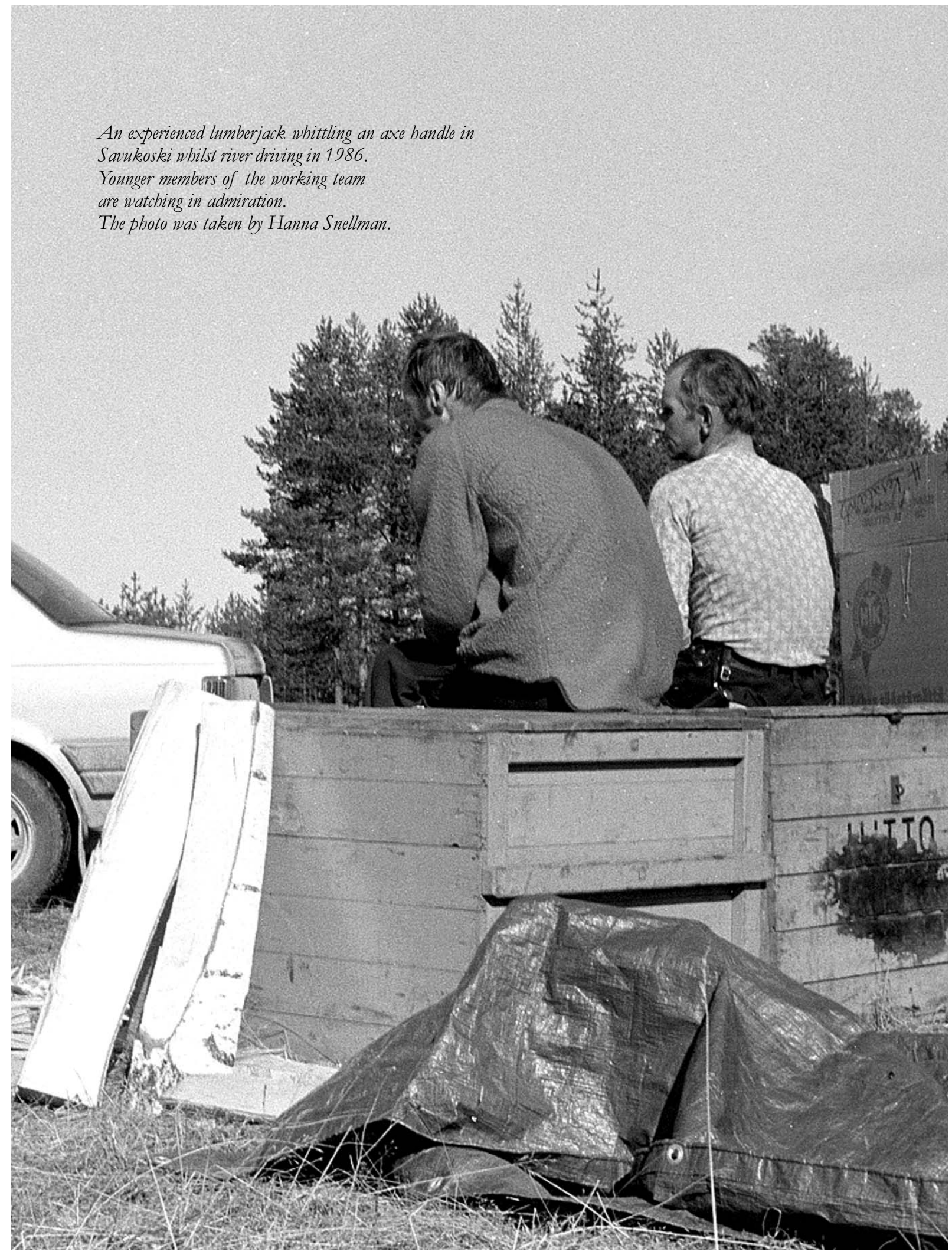


Ethnological research has for a long time been confined strictly to the third person. In doctorial dissertations author's life history and personal connections with the field of study are usually revealed only in the preface of the book: the author may express gratitude to somebody or other for example, a father who is working in the community under study or a mother who was born in to this community - or tell that it has been easy to conduct fieldwork in a community where one is resident. However, nowadays it is a widely accepted opinion that there is no fully objective, unconditional, or absolute truth. The personality, background and even gender and descent of the scholar have a great effect on the results of research, and when the study is based on fieldwork, this is even more so the case. Moreover, intensified interest in reflexivity has led many fieldworkers to see self-exploration as a natural and valuable part of their work. ${ }^{1}$ The same applies to material concerning oral history found in tradition archives: this sort of material is a compromise between remembering and forgetting, and in many cases more the result of the ideas and preferences of the collector rather than the informant. ${ }^{2}$ Therefore, it is important to evaluate the source material from this standpoint.

At the VI Oral History Conference held in Oxford in 1987 I gave a paper entitled "The Myth of Free Men - Lumberjacks in Finnish Lapland". ${ }^{3}$ At that time I had just started work on my doctoral thesis about lumberjacks. Now that I am in the process of finishing this study it is possible to evaluate the source material used in it. ${ }^{4}$ In fact, most of my source material concerns life-histories; informants have interpreted versions of the past for me or for somebody else in words and imagines. In the following I will deal with these words and imagines and discuss the roles I had while doing fieldwork.

\section{A Mission in Life}

In 1986 I documented contemporary floating work in Finnish Lapland for the National Board of Antiquities. During the one spring and summer of year I, a female student of ethnology, periodically spent 24 hours of the day 
with male floating workers: I observed them working, lived in floating camps with them, and ate the same food as they did. I interviewed men about their lives and work at the time. But now it too has turned in to history as well, for floating ended in the area in 1991. There is no loose floating in Finland anymore.

I had done some interviews earlier (1983), but on a larger scale I started collecting life-history material among retired floating and logging workers in 1988. Most of the interviews I conducted myself, but once I was accompanied by students of ethnology as I organized a fieldtrip for students to the area. With few exceptions the interviews were recorded and transcribed. These interviews lasted from anything from half an hour to six hours, and in most cases the informant was visited only once. The reason for this was practical: Lapland is sparsely inhabited and most of the informants lived in isolated farms.

However, there is also other source material available. Logging and floating workers were the very first labor occupations that attracted the attention of Finnish ethnologists. Already in 1959 and 1960 questionnaires about floating and forest work were sent out by the University of Turku. These questionnaires contained questions such as "describe loggers' clothing" or "how did local people stand in relation to lumberjacks?", and informants were asked to answer the questions in writing. It can be argued whether questionnaires consisting of open-ended questions can be used as oral history material or not. ${ }^{5}$ Nevertheless, I have used questionnaires in my research, and tried to find the informant's - not the collector's - mirror image in the answers.

In addition, in 1969 the Tradition Archive of the Finnish Literary Society arranged a competition entitled "Lumberjack Traditions". Again informants were asked to respond in writing, but this time they were not given questions, but simply asked to tell about their lives as lumberjacks. In 1988 a settlement society functioning in Lapland arranged another competition entitled "Logging Camp Traditions". For this competition informants were asked to write their life stories or describe a year of their life. By these various means I have amassed 221 informants in my study, of whom one third have been interviewed. 


\section{In the Box Seat}

When I started my research there was still loose floating in Finnish Lapland, and I was quite familiar with it because of my background. I was born in Lapland, and because of my fathers occupation I had lived most of my life in an official residence of a floating company. I had also done floating work for two summers myself as a student, and during previous summers I had worked in the office of the floating company. My three sisters, my brother and many of my friends had their summer jobs in the floating company as well, and many of my school mates' parents were employed by the floating or logging companies of the area. Therefore, I was familiar with the occupational culture of logging and floating workers even from the start. In fact, much of my life coincided with an era of tremendous change in the forestry of Finnish Lapland. ${ }^{6}$

The fact that I have had the opportunity to sit in a box-seat of this floating theatre has had its advantages, but also its disadvantages. It was for example easy to make fieldwork arrangements, because I was familiar with the area and had known some key informants for years. I was also able to avoid severe culture shock encountered by many fieldworkers. ${ }^{7}$ When I documented contemporary floating, I was actually doing fieldwork in a setting I had myself belonged to a couple of summers earlier, and my earlier work experiences were invaluable on many occasions. ${ }^{8}$ Nevertheless, my background was sometimes a nuisance. Most of my informants knew my father or had even known my grandfather who died in the 1920's, because they both were foresters, and consequently therefore my informants' employers. Without doubt this had its effects upon my fieldwork. Paradoxically, for some I was one of them, a girl from the neighborhood, but for others I was a representative of the elite. Especially during the documentation period my informants were suspicious that I was either employed by the floating company to spy on workers' behavior or that I must be a public health official. Fieldworkers before me have faced similar difficulties. 


\section{Role Problems in Fieldwork}

As Ella Johansson, a Swedish ethnologist, has shown in her doctoral dissertation, the occupational culture of logging workers was masculine in nature. ${ }^{10}$ It was not only masculine, but also male-dominated. In logging and in river and lake floating of Finnish Lapland the workers were male; women were very few and they were employed at womanly tasks, in the office or cooking and cleaning. It was only in the separation of logs that women were engaged in actual floating work with a hook in their hands; this was the work I myself did for two summers. But even here the occupational culture was masculine: women were rough in both their speech and appearance. Female students were an exception, but their presence was yet somewhat problematic.

There were, for example, rules that girls should dress properly; they were not allowed to wear swimming suits on hot summer days. Moreover, while young boys were employed, they were soon educated to "behave as men". To give an example: I remember my 15 -year-old brother coming home after his first day on a floating boat in our home town at the beginning of the 1970's. When I asked him how his first day at his summer job had gone, he told me that his thermos of hot chocolate had been poured over the railing by his fellow workers, because "men don't drink cocoa". His bananas had followed the drink: my brother learnt that men don't eat fruit either. Moreover, I remember from my own work experience that there was pressure on young boys, girls and women to behave in accordance with the norms of older male workers.

An American folklorist Margaret R. Yocom describes her role as a female fieldworker in a logging community in Maine as follows:

In the logging country of the northwestern Maine that I have been visiting for thirteen years now, the worlds of the men and the women stand apart from another in stark relief. — Maine is awash with gender issues. The work worlds of men and women, for example, especially among logging families, are quite separate.

- As I began my fieldwork in Rangeley in 1985, I felt torn between the 
women's world and the men's world. The men's world was dangerous, different, alluring, but I identified more with the women and their struggles to survive and create under pressure. I wanted to go up to the women and shout, "Don't you see how you're being treated here?"

Fortunately, that presumption faded as I realized that my desire to lecture to women came from my own sense of frustration and the way I was being treated by the men of the town, especially the sexual teasing that was very uncomfortable for me. I did not want to admit that all this was happening; I did not want to acknowledge the anger toward the men - some of whom were my informants. And I did not want to admit the feelings of self-blame that the teasing provoked in me. I just wanted to be happily spending my fieldwork time in a pleasant small-town Maine community. - - "It's their way of saying that they like you," a friend of mine suggested. Though I agreed, I told him that I still did not like their way of showing affection."

Attention has also been paid to sexual teasing in the methodological literature. Lois Easterday, Diana Papademas, Laura Schorr and Catherine Valentine call it "hustling" in their article about the making of a female researcher. Particularly in male-dominated settings, where the observer is talking to one male at a time, male-female games come early to the fore. These authors have also found other roles that young females doing research among men usually encounter: the role of the outsider, the gofer, the mascot and the daughter. The female researcher is left out, because she is an outsider; she has difficulty gaining access to the setting itself, because of the fraternity that is common to male-dominated communities. In some settings a female researcher may be cast in the role of "gofer": she is given small errands. Unlike the go-fer, who is expected to do things, the "mascot" is accepted simply for her presence. Older males may also interact with a young female in a manner that can be described as paternalistic. ${ }^{12}$

\section{Girlishly Among Rough Men}

Doing fieldwork among lumberjacks definitely involved being a young female 
in a male-dominated setting. Fellow scholars have sometimes doubted my competence to conduct a study of such a masculine field. ${ }^{13}$ But how about my informants, how did they react to the fact that I was a young female?

In general I did not experience it difficult being "a girl from the university". This was because the way the informants spoke, in a friendly manner put me at my ease, and I did not feel even an urge to lecture them about women's rights. What I found inconvenient was the fact that there were places where I was actually denied access. Sauna is an extremely important part of Finnish culture, ${ }^{14}$ and therefore there was a sauna adgacent to every floating camp. Men went to sauna every evening after work; it was their way to relax and also to get warm after working with ice-cold water. Getting washed was of minor importance. However, I went happily to the sauna on my own. Because one does not have any clothes on in the sauna, I would have felt myself out of place even if the men would not have. But another cornerstone of lumberjacks relaxation, the local bar, was also out of bounds to me, in this case against my wishes. Having a beer after interviewing for 6 hours and after having driven 90 kilometers on a rough road would have been highly acceptable from my point of view, but my informants considered it inappropriate. However, my husband, who visited me during the time I was conducting interviews, was heartily welcomed in their company.

If I had to pick the roles I usually encountered while doing fieldwork, I would have to choose that of daughter and mascot. I was never sexually harassed during the time I was doing fieldwork. On the contrary, the lumberjacks protected me from unpleasant situations. As a result of this I gained access to settings male researchers most likely would have been excluded from. ${ }^{15}$ Men wanted to protect me, so they did not, for example, let me stay alone at night in the floating camp. Therefore, I could easily ask for shelter for the night from their families. It has been pointed out that the personal interest in the researcher can also work to the researcher's advantage. An informant may, at times, reveal more than he otherwise would in an attempt to show how friendly, co-operative, and accommodating he is. ${ }^{16}$ The informants did not always take me seriously, but I used this to my advantage. It was very easy to ask "silly" questions, and the informants were willing to describe everything in detail. However, our communication had 
always a direct bearing on the matters under discussion. As I became more familiar with the subject, interviews turned in to long conversations where I let the informants speak quite freely.

The occupation of lumberjacks has been somewhat romanticized in songs, films and literature, but actually it is also an occupation that has been and still is looked down upon. ${ }^{17}$ Therefore, it is no surprise that I was a welcome quest for many. Somebody being interested in their lives made my informants feel important, and they were willing to be interviewed for hours on end. Moreover, my visit was a change from their everyday routines - I was perhaps the only visitor of the month in an isolated farm.

\section{Conclusion}

Doing research on lumberjacks has been like working on a puzzle: there are pieces from life-history interviews I have conducted among lumberjacks, pieces from lumberjacks' narratives filed away in tradition archives, and pieces of my own life-history as a fieldworker but also as a person born in a certain area and in to certain family. What has made my research rich in yield is the fact that the oral history material I have used has been collected over a long time-span and by different methods. Narratives collected at different times tell a different story, because different facts were emphasized on different occasions. The chainsaw is a good example. In 1960 it was such a newcomer that it was hardly mentioned in the narratives. In contrast, by 1969 when many of loggers had become unemployed as a result of mechanization there was a lot of bitterness about the chainsaw. However, in 1988 the early chainsaws are described in a nostalgic tone. Nevertheless, time is not always a factor. For example, sexual experiences is a theme widely described in the material collected by the Tradition Archive of the Finnish Literature Society (1969), but there are only a few examples of this sort in the material collected by the university (1959 \& 1960) and the settlement society (1988).

The variety of source material has another benefit. Oral history material collected by means of different methods makes the source material more 
complete. Some of my informants had not even been at elementary school and were not far from being illiterate. For most of them it would have been impossible to write about their lives, and yet they were excellent storytellers. Those who had sent their written narratives to archives were also often excellent storytellers, but it was in most cases impossible to interview them. At least some of them died before I was born. However, one must remember that those who respond to requests to write biographies or agree to be interviewed are mostly persons with a life they want to talk about. Social outcasts are rarely found among informants.

This article is based on a paper given at an IX International Oral History Conference in Gothenburg in 1996. 


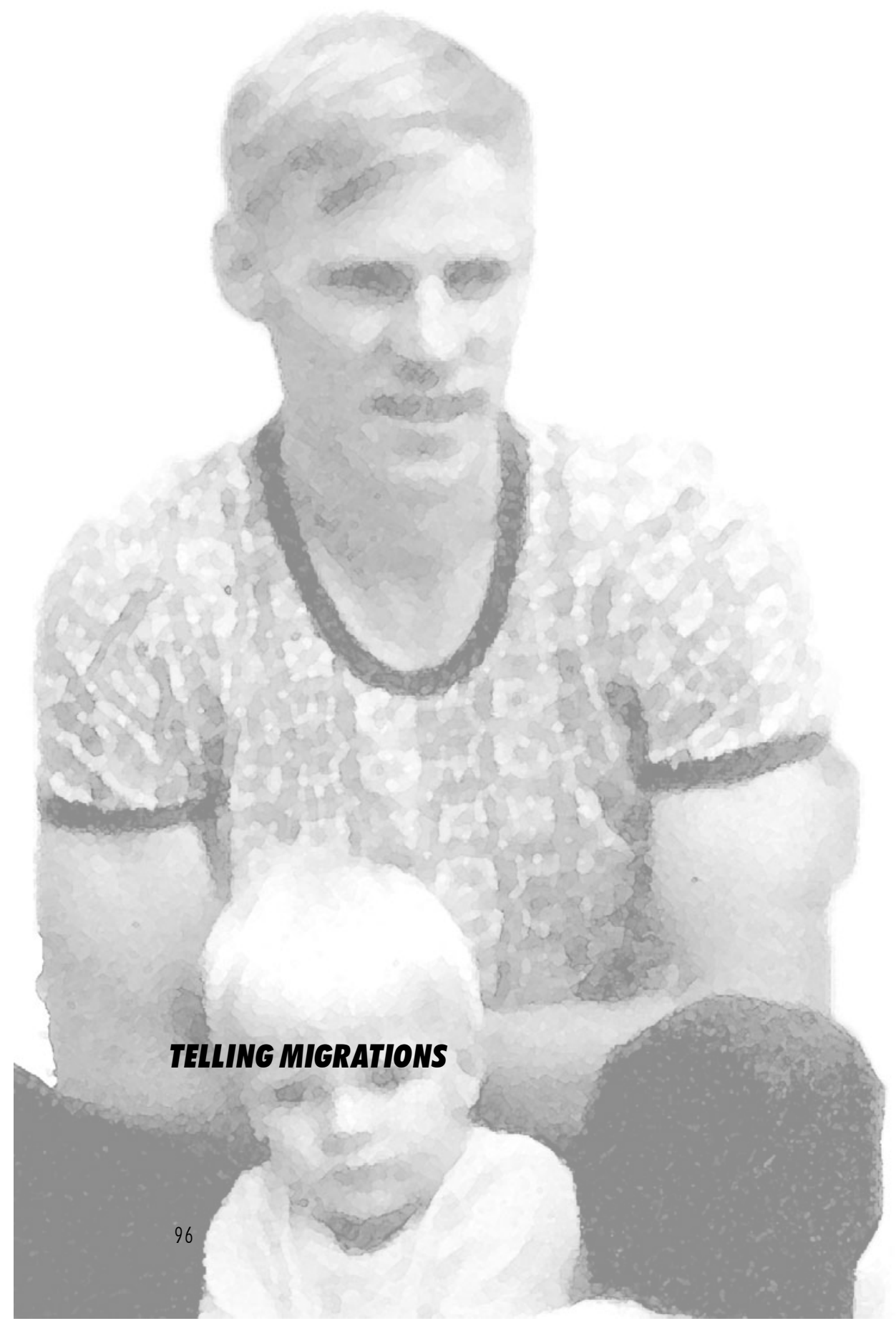


Finnish ethnologists' attempts to periodise Finnish popular culture have shown that the decades after World War Two are perhaps as important a transition period between the old and the new as are the well-known transitional eras at the beginning of the Middle Ages and industrialization in the second half of the $19^{\text {th }}$ century. ${ }^{1}$ Yet so far there has been very little research based on oral history that has considered this most recent era of change. Research about innovations (e.g., mechanization in agriculture and industry) has mainly forgotten the most important target of ethnological research, i.e., the individual and his or her experiences. Mass emigration from outlying villages in northern and eastern Finland to the factories of southern Finland and Sweden - and many times back home again - is a phenomenon typical of the decades after World War Two. Yet it is a subject which - strangely enough, considering the cultural and economic importance of the mass movement for both Finland and Sweden - lacks ethnological and historical analysis.

This paper will be drawing on the results of two oral history projects led by me. The first one, "Gothenburg - Salla's Largest Village?” deals with emigration from Finnish Lapland to Sweden, from a parish called Salla ${ }^{2}$ by the Russian border to the city of Gothenburg via Sweden's west coast. The individuals studied emigrated from northern Finland to Gothenburg. The time span of this study is the second half of the twentieth century, from the 1940 s to the 1990s. The study is entirely based on interviews, mostly conducted by myself. Altogether I have conducted 31 interviews, lasting from one-and-a-half to five hours. The interviews were mostly in the nature of conversations in which I did not have a list of questions to be answered but instead tried to find out what the informants considered important on the topic.

I will also be using interviews conducted in another project, "Forest Workers in a Changing Society", also led by me. In this oral history project we interviewed a thousand forest workers in Finland. Our intention was to get a comprehensive picture of the changes in forestry during the past five decades. By interviewing forest workers we have found out what kind of work has been done in the forests and the changes that have occurred in the everyday lives of the people earning their living in the forests. The focus is 
not on companies and organizations but on individuals. Some of the interviewees have been forced to find other occupations because of unemployment. Some of them moved to Gothenburg. In this paper I will use 14 such interviews conducted by a Finnish ethnology student and seven interviews conducted in Salla among forest workers who stayed in their home parish. All in all, my paper will be analyzing 52 interviews: 29 with women and 23 with men. Many of them (18 in all) were born between 1931 and 1944, which means that they experienced the Second World War. Those (15 in all) who were born between 1945 and 1948 belong to the generation born after the war but facing the consequences of the war, the destruction of Lapland, war cripples and orphans. For the rest, born between 1949 and 1965, the war was of minor importance, but they were born to a much more modern Finland than their parents.

My aim is to try to find the key experiences of Finnish emigrants from Salla to Gothenburg. What were the circumstances that led some people to move to Sweden? I will try to look into the mental processes connected to the decision to emigrate. Even though Finland and Sweden are neighboring countries with a common history, the difference between a parish in the wilds with reindeer herding and forestry as the main sources of livelihood (Salla) and a lively city with homes in the suburbs and occupations in industry (Gothenburg) is striking. In that respect the question of local identity and the concept of home is crucial.

When a British anthropologist, Tim Ingold, did fieldwork in Salla in the late 1970s, he noted the rusting remains of antiquated tractors littering the yards of many deserted houses. He called these vehicles poignant reminders of the social costs of technological development. The tractors had been bought at a time when people talked of the "Salla miracle", when Salla was thought to be a prosperous agricultural district near the Arctic Circle, but abandoned when the miracle was gone. Tractors were supposedly as easy to use as a horse: for farm work in the summer and for forest work in the winter. However, it was soon obvious that ordinary agricultural tractors were not suitable for forest work and therefore they were replaced by heavier equipment not suitable for farm work. Farmers, economically dependent on forest work, were left with bank loans and no means of paying them back. They could only look on as outsiders as 
heavy machines rolled in over their plots, leaving their families, as well as their tractors, unemployed over the winter months. A son, lacking sufficient work on his father's farm, might either become a full-time forest worker himself or leave the area altogether to find a job elsewhere. Many farmers simply sold their entire estates to the forestry companies, sent their cattle and reindeer to be slaughtered, boarded up their houses, and left. One homestead after another was deserted, as in the space of a few years the population dropped from almost 11,000 to a little over 7,000 . Persuaded that there was no future in agriculture, those of working age, particularly of the younger generation, emigrated in their thousands to take well-paid industrial jobs in the south of Sweden. ${ }^{3}$ At that time, those who decided to stay in Lapland said - jestingly, but also bitterly that Gothenburg would be the largest Salla village. However, it was not only Salla, but many other communities in Finnish Lapland that were deserted. In this study Salla acts almost as a metaphor, a symbol of a community economically on the periphery and culturally dependent on its forests.

\section{Rural Depopulation and Migration}

Immediately after the war Sweden began recruiting labor for its fastexpanding industry. In 1946 it embarked on a survey of foreign labor designed to inventory and recruit its workers. The labor authorities were ordered to conduct negotiations with a view to recruiting labor from Italy, Hungary and Austria, and an agreement to the effect was signed in 1947. The labor census and population forecast made two years later jolted the Swedish politicians into taking rapid steps to introduce a new Aliens' Act. Until then, the legislation had been designed to limit immigration, but the demand was now for an Act that would make it easier. A new Aliens' Act was passed in 1954, the year in which a joint Scandinavian labor market agreement was signed and the Nordic countries became a passport-free zone. Residence permits were likewise no longer required, or an invitation. This mutual agreement between the Nordic countries was supplemented a year later by a social security agreement guaranteeing equal rights in the host 
country. Once the new Aliens' Act and labor agreement had come into force, Swedish employers began mass recruiting in even greater earnest. Supply and demand coincided: Sweden needed workers and the rural regions of Finland, Greece and Yugoslavia had plenty of workers but no jobs for them. ${ }^{4}$

In the 1960s the trade unions began demanding immigration restrictions, but the employers were against this. An initiative was nevertheless approved in 1966 by which a work permit could only be granted in Sweden if applied for before entering the country. In 1967 immigration began to be regulated by stipulating that persons from outside the Nordic countries had to have a job, a work permit and somewhere to live before they could enter the country. These restrictions did not apply to the Finns, and the number moving to Sweden grew and grew. The attraction of the Swedish labor markets began to weaken in the mid-1970s: the years of the great migration were over. In a chapter all of their own are those who came back, some of them many times over. ${ }^{5}$

The 1960s in Finland have gone down in research literature as the decade of migration away from the rural regions. Whereas the official statistics for the late 1950s record about 10,000 emigrants, the number had more than doubled by the end of the following decade. The peak year was 1970, when according to the statistics more than 40,000 Finns emigrated. By the end of the decade the figure had fallen to under 15,000. The highest figure for immigrants of Finnish descent in Sweden was recorded in 1980, when they numbered $250,000 .^{6}$

Sven Alur Reinans estimates that instead of the half million or so Finns who officially immigrated to Sweden between 1945 and 1994, the true figure was 700,000-800,000. Yet only some of them, an estimated quarter of a million, took up permanent residence there. ${ }^{7}$

The majority of the Finns moving to Sweden in the post-war years settled in the Stockholm region and the Tornio river valley. In the 1960s the Finns headed further afield, especially to the industrial towns of Central Sweden in the region between Gothenburg and Stockholm. In 1998 there were most Finnish-born immigrants $(22,287)$ in Stockholm and second most in Gothenburg (9,727). This represented 3.1 percent of the population of Stockholm and 2.1 percent of that of Gothenburg. The jobs they found in 
Sweden were mostly in industry. In the years of large-scale migration the immigrants usually had a low level of education and they were young. ${ }^{8}$ The typical immigrant was, in the light of previous research, thus a person with an elementary education from one of the large age cohorts and a remote rural region.

In 1980 Gothenburg had an estimated 28,000 or so Finns among its population. In around 1960 they had been the biggest immigrant group in the city. In 1962 Gothenburg was home to 3,213 Finnish citizens. This major multicultural city also had other immigrants at an early date: Norwegians, Danes, Germans and Hungarians. The statistics for 1970 give 3,825 Finns as immigrants. Thus in the year in which, according to the statistics, the population of Salla fell by six percent, that of Gothenburg grew by one percent.'

\section{The Decision to Emigrate}

The studies of Finns in Sweden almost without exception look into the reasons for emigration. Jouni Korkiasaari reports that enquiries conducted among Sweden-Finns in the 1970s revealed that economic factors such as unemployment, the poor employment situation in Finland, the better job opportunities in Sweden and the higher wage level in Sweden were among the main incentives to emigrate. The majority of the respondents quoted an economic factor as their primary reason for emigrating. Some had followed a friend's example, or been prompted by a desire for adventure or change. Among the random reasons was having nowhere to live or poor housing conditions in Finland. ${ }^{10}$

Jari Kuosmanen, who obtained a doctorate at the University of Gothenburg in 2001 on the subject of Sweden-Finns, adopted a qualitative approach in examining the motives for emigration. In a study within the discipline of social politics he interviewed 28 Finnish men born between 1920 and 1960 and living in Gothenburg. The majority of them had immigrated to Sweden in the 1960s and 1970s. The interviews yielded the following reasons for emigrating: unemployment, the assumption that life would be better or easier in Sweden, the need to get away from life in Finland, a desire for adventure or change, a change in the work opportunities 
for seamen, study, and love. ${ }^{11}$

Similar reasons are given in the interviews I made in Gothenburg, but the assumption that life would be better in Sweden is the primary one. Many were motivated by the hope of a better life: better job opportunities, better wages or better housing. ${ }^{12}$ Unlike those who clearly gave unemployment in Finland as their reason for emigrating, their decision may not have been dictated by necessity. The people in the category headed "love" by Kuosmanen had probably followed their husband or wife to Sweden even they though did not personally want to emigrate. There were occasional mentions of a desire for adventure, disappointment, youthful defiance, and even a desire to get away from life in Finland.

For many the move to Sweden had not been long thought-out; the decision may have been made very quickly once a job had been confirmed. For young girls the job was often as a babysitter in a relatives family, and they would stay in this job until old enough to get a better-paid one in a factory. The babysitter was almost a member of the family, since she lived in the family whose children she was looking after. ${ }^{13}$ Boys were more likely to be offered a job through the labor exchange. ${ }^{14}$ The majority nevertheless departed for Sweden without any definite job to go to, confident that something would turn up. With one exception the interviewees stressed that they only intended to work in Sweden for a time. None of them had planned to settle permanently in a new country. And again, even though an interviewee had lived in Sweden for 40 years, the dream of returning to Finland was a focal topic in the narratives of the Gothenburg Finns.

\section{Migration Chains}

Our attention is caught in analyzing the migration narratives by the tendency to stress not the reason for emigrating but with whom and to whom the narrator moved. Although there is no point in subjecting the interview made for this study to quantitative analysis, there is no doubt that the majority of the interviewees had moved to Sweden either with or to join someone. It may thus be claimed that both chain and group migration were characteristic features of the emigration to Sweden from the province of Lapland in the 
1960s and 1970s. In chain migration a person follows a familiar person such as a relative to a new country. Many of the problems related to emigration are in this case smaller than for others. The emigrant knows in advance about the new country and region, s/he gets assistance in finding a job and somewhere to live, with the language, and money before the first payday. Most important of all, however, is the fact that s/he has ready social contacts with people who speak the same language. We speak of group migration when two or more persons emigrate together. In order to maximize their sense of security, many Finns immigrated to Sweden in a group, and what is more, to a person they knew. On being asked their reason for immigrating to Sweden, the majority of the interviewees said they already knew someone living there. The conditions they were leaving behind did not necessarily feature very large for them, and nor did they have any very great expectations for the future. The important thing was the person they were going to.

In the following the interviewees themselves describe the background to their move to Sweden. For reasons of privacy, they all appear under pseudonyms.

Kaija said it was easy to emigrate because waiting for her in Sweden were three brothers and a sister, and another sister was going with her. Many others likewise said that leaving was easy. Keijo's two older sisters were living in Sweden, and when one of them came home for a visit when he was 16, he decided to go back with her. ${ }^{15}$ Ritva and Raija likewise followed their sister's example and went to Sweden when they were $16 .{ }^{16}$ Raimo, another 16-year-old, asked about jobs at the Haaparanta labor exchange and was advised to try the Saab factor at Trollhättan. But, in his own words, he did the wise thing by "popping down to see his brothers in Eskilstuna", got a job there and spent his first two years in Sweden in their brotherly care. Reima, too, went off to Gothenburg with his big sister and her family. His sister had moved there a year before and persuaded not only Reima but other sisters and cousins to come as well. ${ }^{17}$

Four interviewees specifically mentioned a relative who had been in Sweden since being sent there as a child in the war as the person who had given them the idea of emigration. ${ }^{18}$ Considering that children were sent from Lapland expressly to Gothenburg, I cannot help thinking that the first to emigrate there, in particular, may well have had ready contacts in Sweden. 
Alma, who moved to Gothenburg with her husband and two children in 1970, recalled their decision to emigrate as follows:

Then I wrote to my...uncle lives, he was evacuated to Sweden as a child in the war, and my aunty too, she's lived in Sweden all her life... so then I wrote to my uncle, asked if there was any work there in Gothenburg, so I could come over. And then a moment later he, a few weeks later I got a letter saying there was work, just come on over. So then my husband went first and me a month later with the kids. - My sister's crowd went at the same time. A few at a time like, we didn't know much about it, like there were masses of people going, but we'd heard that people were going. That there was work to be had and the wages were pretty good. But I can't say there was a boom, everyone going off... or at least I wasn't aware of it. It was just the way things were at the time that set us off. ${ }^{19}$

Alma's little brother followed a year later:

There was quite a string of cars [when we moved]. There were cousins and ... cousins and... cousins, cousins, cousins and ... two cars and we had two, three cars. They were over [in the home village] for the summer holidays, and I went with them, they'd gone there the previous year. - Suppose they had to go, there was nothing for them there. Farming didn't pay and there was no longer any work in the forest. It looked as if there wouldn't be anything in the future. ${ }^{20}$

Every family had someone who had gone off first. Akseli and Ruut are brother and sister, and the first to go was Akseli, in 1967. His narrative of the move is typical in the sense that the decisive moments have become polished with the passing of time, maybe because the story has been repeated so often:

I was made redundant, but then I got a temporary job with the TVH [road and waterways authority]. I'd been there five days, with the TVH at Kemijarri, up at Kallaanvaara, they were doing the road there right by the lake, doing the banks, spreading gravel, and I was shoveling it. There I was when they told me ... I think it was Friday, Friday it must have been, no Wednesday, because that weekend, I mean Friday would have been the last day, they told me Friday would 
be my last day, there was no need for me to come back next week. And there was no work going anywhere else. Sometimes I was unemployed, sometimes I was in a job for a bit. And there was the rent to pay and everything and all sorts of things I needed to buy, and Olavi just happened to drop by, you must know him, and Kalervo, too, they were both from Kemijäriv. I knew them pretty well... we were all into sports at the same time. They were driving past and stopped me. Stopped to say how are things Akseli. Says I, dash it, I'll be out of a job in two days' time and I've got nothing new in sight. Say the boys, they're off to Sweden to look for work. Me, when are you going, they're off already on... well, like, can I come with you? Well why not, jump in, and me, I've got nothing but my rubber boots and I hadn't got any better clothes with me but... hang on a sec and I'll cover my shovel by the road there, on the bank of the ditch, then I'll come back sometime and return it. I shoved the shovel into the bank and kicked the sand over it. ${ }^{21}$

For Akseli, the decision to leave his former life and immigrate to Sweden culminates in the shovel he was using when he made the decision but which he would not need in his new life. Corresponding objects with a great symbolical and emotional charge feature in many other migration narratives, too. For Auno the symbolic object was a chainsaw. The logging at one site had just ended and there was no prospect of any more when Auno, inspired by his pals, set off for Sweden. He left his chainsaw in the shed at home, thinking he would no longer need it in his new job:

I came in March 1969, I was right out logging in the forest. There was a meter and a half of snow and going to Sweden was all the rage. The lads from the village came round and I told them I'm off. I hung the chainsaw up there in the shed and it's no doubt still there unless someone's removed it. We came to Haaparanta by bus and there I bought a train ticket, I've still got it, the train ticket. 149 crowns to Landskrona and I'm still here. ${ }^{22}$

Soon after Akseli went to Sweden he was joined by his four brothers and two sisters. ${ }^{23}$ For his sister 17 years younger, the fact that her brothers and sisters were there was an obvious reason for immigrating to Sweden. The meaningful object in her narratives is shoes, or rather the lack of them: 
I came here to Sweden when I was 16, when I left school in 1970. And I was here about a year. But then I, I didn't like it and I didn't feel at home here, and I never had any friends because there were lots of ... Like my sister had five children, my brother had three children. It was endless looking after the children. I didn't do much apart from looking after the children. I had no freedom of my own or anything. I did one shift at work and another shift looking after the children, so I had no time for anything else, or... I really didn't like it there and I thought I must get away, I can't stand it here. Then I left in the spring. It must have been May when I moved, or rather I went back to Finland.

- I did the course [a clerical course in Tampere], paid for it myself with money I'd saved. Then I spent some time working in Muonio in the bus station office. Then I went to the exchange and I was there two years. I really liked it there. And naturally I'd have liked to continue there, but it so happened that I was on my summer holiday... my brother was over here on holiday from Sweden. So he says to me come back with us. I was free to go, I had nothing to keep me. It was my summer holiday and off I go, and I remember I didn't even have any shoes of my own with me when I jumped into the car and thought what the hell, I'll just be visiting, I don't need any shoes in summer. I came here, and then my money began to run out. I thought not to worry I could work for a week or two. I called them at work and told them I'll be back in a week's time. I spent that week at work and earned more than I got in a whole month at the exchange. You won't catch me going back to Finland. ${ }^{24}$

Almost all Akseli's brothers and sisters followed him to the new homeland, and so did his wife and children. The decision to immigrate to Sweden may not actually have been such a spontaneous affair as it later seemed. It was clear from the start that Akseli's young wife and two children would follow him as soon as things were straight in Gothenburg. It was almost the rule for the family to follow on a few months later, when a home had been found and the husband's job was confirmed. ${ }^{25}$

An emigrant might be followed by not only his or her own family but 
by other relatives and friends as well. The narratives often have a touch of gold fever to them; people just had to go to Sweden like everyone else. At a time when Lapland was plagued with unemployment and jobs were very uncertain, work alone was worth its weight in gold. ${ }^{26}$ "Going to Sweden was all the rage", said Auno in describing his sudden decision to set off for Sweden with the lads from the village in 1969. He, too, was followed by his fiancée a couple of months later. ${ }^{27}$ His fiancée already had an older sister in Sweden and her younger sister emigrated with her in the same year. ${ }^{28}$ Emigration to Sweden was really in full swing at the end of the 1960s. Anneli, another person who emigrated from Salla in 1969, said in an interview that all the villages in Salla were emptied in that year, "the people from all the villages, they had to leave". Anneli went to Gothenburg with her husband and their six children. Her husband's brother had gone there a year before, and they already knew other people in their future homeland. "We had to go. We knew people in lots of places, they phoned and said come on over", Anneli recalled of her decision to emigrate. They did not, however, sell their homestead and it is still owned by the family, for use - in typical fashion during visits to Finland and ${ }^{29}$ in case they ever decide to return. ${ }^{30}$

The person(s) with whom the emigrant shared the experience was just as important as the person(s) they followed to Sweden. The majority of those interviewed had immigrated to Sweden with their husband/wife and children. ${ }^{31}$ A few had immigrated to Sweden with their parents, brothers and sisters. ${ }^{32}$ It was also common to emigrate with one's spouse or future spouse $^{33}$ or with friends ${ }^{34}$. In other words, the people with whom people emigrated belonged to the same category as the people they followed. It is therefore not surprising that many immigrated to Sweden with an older brother or sister. ${ }^{35}$ There might sometimes be a whole gang of relatives and friends emigrating at the same time. ${ }^{36}$

Few of the interviewees had immigrated to Sweden alone, and even then they usually knew of someone they could stay with. Raili was 16 when she moved to Sweden. She, too, had an older sister already living there, but she had to travel alone, which was not so easy when it meant traveling from the northern shores of Lake Inari in Lapland to the North Sea:

And I only did up to the ninth form [in school], and then I left, you see, I left 
and came here. So I was sixteen in the spring and in the autumn, just before Christmas, I came here to Sweden. - My sister needed help, she'd got a little boy, a boy of two. She needed help with looking after him and... I must say I thought I wouldn't mind, see, she'd been over from Sweden and she was wearing really nice clothes, and you know, things like that... mm, so I did it [made the decision] rather out of curiosity. At least as far as I was concerned it was partly out of curiosity that I came here. I didn't have a proper job, just looking after my sister's little boy. - Dad was never at home and I met Mum when I was already on my way with all my bits and pieces. I met my Mum and she says... you poor thing, how on earth will you find your way there, you've never even seen a train. And I was going by train. I had all the tickets, my sister had sent me the tickets so I could go. Mum must have been at work, otherwise how would I have met her in the road... we just met. So there wasn't much in the way of goodbyes. I just went off and I've been going ever since. It's true I'd never seen a train, but I managed fine. By post bus to Rovaniemi of course and then on to Haaparanta by train and then straight down from Boden, it brought me right here to Gothenburg. ${ }^{37}$

The typical emigration narrative combines a description of conditions in the homeland with chain and group migration:

A cousin of mine got a job over there at Skövde and wrote to my brother saying things are good here. He was much older, my cousin, see. And he'd gone to work over there at Skövde with a pal. So we [my brother and I] thought, he was out chopping firewood, why don't we go too? Dad was a bit, well, weepy sort of, 'cos you see we always used to do everything at home. Then we left and went over there to Skövde. And we couldn't find any work. So in 69 we came back to Finnspong, over there near Norrköping. There was... we'd been logging, there wasn't much in the way of work there in Lapland, so we left, us two cousins and us two brothers. Then there was another boy with us from the same village. ${ }^{38}$ 


\section{Conclusion}

Nowhere in Europe was the structural change after World War II as rapid as in Finland. The transition from farming and rural occupations took place much later here than elsewhere. Finland's agricultural policy was reformed in the mid-1960s, and when the former subsidies to unprofitable small farms ceased, thousands of people suddenly found themselves unemployed in the rural regions. Following the reform of the taxation on income from farming in 1968, the incentives to take land out of productive use and to slaughter cattle in 1969-70, there was even greater pressure to leave the countryside. The number of farms had grown by 120,000 between 1941 and 1950 as a result of government measures to resettle evacuees and men returning from the front. Large families were living on small farms at a low subsistence level. Many small farmers had to eke out their living with casual seasonal work outside the farm, and as harvesting became more and more mechanized, it was no longer possible to earn a sufficient extra income from forest work either. ${ }^{39}$

The structural change of the rural regions hit the northern and eastern parts of Finland, where the employment effect of forestry had been greatest, particularly hard. Logging was until relatively late a labor-intensive seasonal occupation. By the beginning of the 1950s the tools used in forestry had lagged clearly behind those of other forestry countries. The harvesting chain was still labor-intensive and relied on muscle power; and there had been few innovations in a hundred years. Trees were felled with handsaws and transported first by horse and then by water. When the mechanization of harvesting finally came, it was both quick and dramatic. The first chainsaws were seen in northern Finland in the early 1950s, they were already common by mid-decade, and by the beginning of the 1960s all forest workers had a chainsaw. Tractors began to take the place of horses on farms in the early 1960s and in the forests in the mid-1960s. By 1970 horses were rare at forest sites and forest tractors common. Floating was not, with the exception of sorting, mechanized, but the stream floating calling for a large labor input gradually died out, as did loose floating as a whole. ${ }^{40}$

Mechanization meant hard times both for the men employed all year round in forestry and floating and for the small farmers. Since other forms 
of economic activity also decreased as the number of forest workers fell, the indirect impact of mechanization was considerable. ${ }^{41}$ An example of those hit are the shops, taxis and cafés whose clients were mostly forest workers. Whereas there might still be over 160,000 men employed in commercial cutting at the busiest time in January in the early years of the 1960 s, the figure fell in the course of ten years to somewhere around 30,000. The severing of the link between small farming and forest work meant that many small farms were no longer viable. Many a small farmer had bought a farm tractor thinking he could use it about the farm in the same way as he had used a horse for paid work at a logging site and work on the farm. The farm tractor then became obsolete when the more powerful and efficient forest tractors came on the market and the farm tractor was often left in the yard to rust. Whereas in 1950 more than 250,000 persons were making a living off farms of less than five hectares, by 1980 the number had fallen to only 16,000. Floating continued to provide seasonal work, but the end of stream floating and the reduction in floating as a whole meant fewer opportunities to earn money in the remote country regions. Concurrently with the reduction in the work available in the rural areas, the large age cohorts born after the war reached working age. ${ }^{42}$

Pervading Finnish rural society is an austere and powerful work ethic. Bolstered by a strong tradition of Evangelical Lutheranism, it insists that the only road to a good life is through unremitting physical and mental toil, for which the motivation must come from within. Hard work constitutes the basis of both one's self-respect and of one's rating in the community. ${ }^{43}$ Until the 1950s the country youngster in northern Finland knew that once he had completed his compulsory schooling, he would be able to work as his father before him: in the forest. Girls could correspondingly expect to find work as cooks at the logging camps or assistants in cafés until they got married, when their job - looking after the children and cattle - would be in the family circle. As the labor demand decreased, youngsters could no longer rely on this career path, yet there were no new opportunities within the region to replace it. When unemployment and the fear of it encountered the ideal of work and managing on one's own, the result was stalemate. However much people wanted to earn their place in the community by working hard, this was no longer possible. For many, emigration to Sweden meant a chance 
to work, to justify their existence by being good workers. Consequently, the Finns were welcomed as workers in Swedish factories. They would toil without complaining, because they had been taught since childhood to honor work above all else in life. In analyzing the causes and consequences of emigration, oral history material provides a means of making interpretations in which the focus is on the subjective motives and experiences of the people themselves.

This paper was presented at the XII International Oral History

Conference in Pietermaritsburg, South Africa in 2002. 


\section{THE FINNISH WORKER IN SWEDEN}

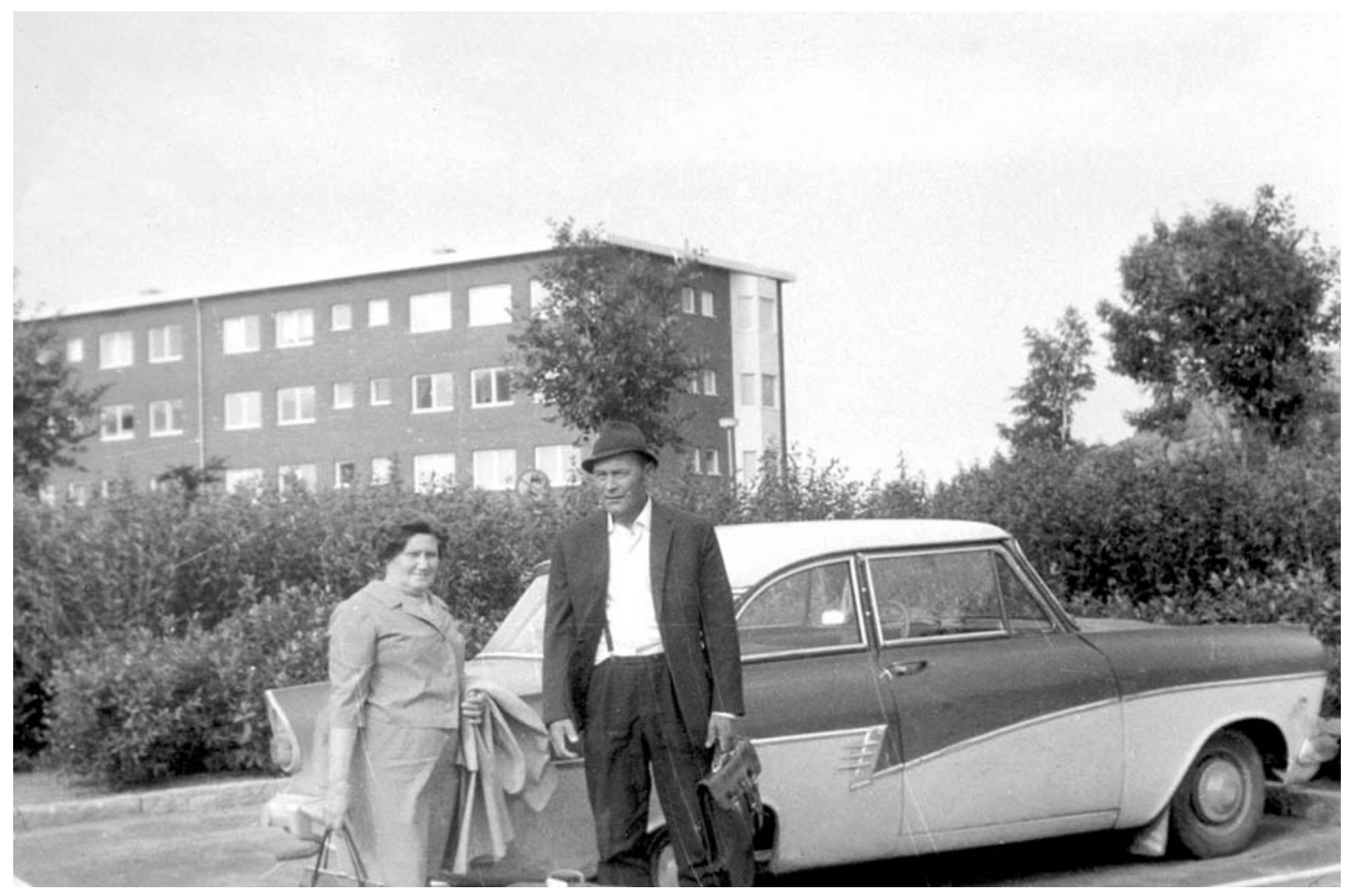


We workers are, or at least we have been, rated like the Swedish krona: very low. And unfortunately, we workers ourselves have come to accept this poor status without putting up much opposition. Because whenever there's any talk, whatever the context, about life at work and professions, someone will always ask the idiotic question (even in middle age still): 'So when are you going to start studying? A person like you could really make something of yourself.' Faced with this, most of us, I'm sure, react in the same way: we stare flabbergasted at the person who asked the question, our mouths hanging open, and the natural retort never gets voiced. We simply must learn to answer this stupid, offensive question at the speed of lighting. We should, for example, ask: 'Did I hear right? What exactly do you mean? Make something of myself?' Am I not something already? Listen, you, I'm a metal worker. I've been on the job for ten years and I'm very proud of it. My job requires more skill than most of the jobs where people don't need to wear overalls. So I don't need to make anything of myself because I am something already, something bigyou don't seem to appreciate. I'm a working man, and most of the welfare all the other members of society are able to enjoy as well rests on the shoulders of us working men and women. We're not picky. OK, we're happy to share with others the fruits watered with the sweat from our brows. But we also demand that we be respected, that the work we do be respected, that people appreciate the fact that we workers, by giving our physical and mental resources, are building this society and are the pillars holding it up. It's a job for which we sometimes have to pay for with the loss of a finger, or an eye or some other part of the body, with arthritis, ruined lungs and other internal organs, and if we're unlucky, even our lives.' 
It was with these words that a top lathe operator from Eskilstuna described his self-image as a Finnish worker in Sweden in 1987. He was one of the writers who submitted a biographical entry in a competition about metal worker tradition to the Archives of the Finnish Minority in Sweden.

This article debates the way Finns saw themselves as workers in Sweden and the distinctions made between Finns and Swedes at work. I shall also be examining the role of party politics as reflected in the activities of Finns who immigrated to Sweden in the 1950s and 1970s. ${ }^{2}$ My observations are based on interviews conducted by me in Västerås in 2005 and replies to the metal-workers' tradition competition in 1986-1987. ${ }^{3}$

\section{Slave Suit in Olofström}

Pertti Toukomaa, a school psychologist, described the status of the Finns in Olofström, a town of 18,000 inhabitants in southern Sweden, in 1972 as follows:

Above all, my concept of humanity, the meaning of human dignity changed during the year I spent in Olofström. Almost every day while I was there, I really did experience what it felt like to be of lower status, a second-class citizen. It is not therefore surprising that the Finns in Sweden commonly called themselves 'white niggers'. Admittedly my relations with my colleagues on the local school board were beyond reproach, and I did not notice any signs of superiority in their attitudes to me, but as soon as I came into contact with the majority in the streets, shops, government offices, etc., I felt I belonged to a contemptible minority.

One of the salient features of the town is the factory siren, the sound of which regulates the rhythm of daily life. The shift changes at $2 \mathrm{pm}$. Either side of this, for about an hour in all, the main street seethes with life. Pedestrians, cyclists and people in cars. The dominant colour of the street scene is blue: most people are dressed in blue overalls and cap. 'Slave suit', is what the Finns call it. On the cap, in big letters, are the letters 'Volvo' [the town's biggest employer].

At other times the street scene in the centre of town is like that of any other 
little town. The predominant language is Swedish. One hears surprisingly little Finnish in the streets and shops. The reason soon becomes clear: the Finns mostly speak to one another in whispers, as if ashamed to reveal their nationality...

An immigrant town such as Olofström has very little to offer its Finnish population apart from work and somewhere to live. Swedish is the only language spoken in the government and local offices; no one there speaks Finnish. The teaching in school is in Swedish, even if the majority of the pupils are Finnish, as in many of the Vilboken schools. - The amusements are confined almost exclusively to dances and visits to the cinema. - Apart from the Finland Society, only the religious organisations and communities cater for Finns and put on events in Finnish. - But the trade union, for example, (the LO), has no Finnish-speaking divisions at all. ${ }^{4}$

The people interviewed by Toukomaa do not paint a very flattering picture of the relationships between Swedes and Finns. The Finns criticized the Swedes above all for being smug and prejudiced, for looking down on the Finns, for pressurising them, excluding them, treating them unfairly and underestimating them. They also complained about the high prices, high taxes, the lack of services in Finnish, the indifference of the trade union and the 'racist policy' at work.

When asked in what way Sweden failed to meet their expectations, the Finns mentioned wages, the physical strain of work, human relations, and being a foreigner. They considered it particularly unfair that they did not have the same opportunities as the Swedes for changing jobs or promotion. The work was physically strenuous and there was no scope for development. "Once you can speak the lingo, you realise the Swedes are almost all shit," said one respondent in reply to a comment from another Finn that "it's difficult to find work corresponding to your abilities because the Swedes get preference and think they're cleverer." The trade union also came in for criticism for not acting on behalf of its workers. One respondent crystallised the biggest fault as "the killing pace at work and the laid-back attitude of the trade unions on the shop floor". Many of the Finns regarded themselves as excluded. "The Swedes treat the Finns like dirt," said one of Toukomaa's 


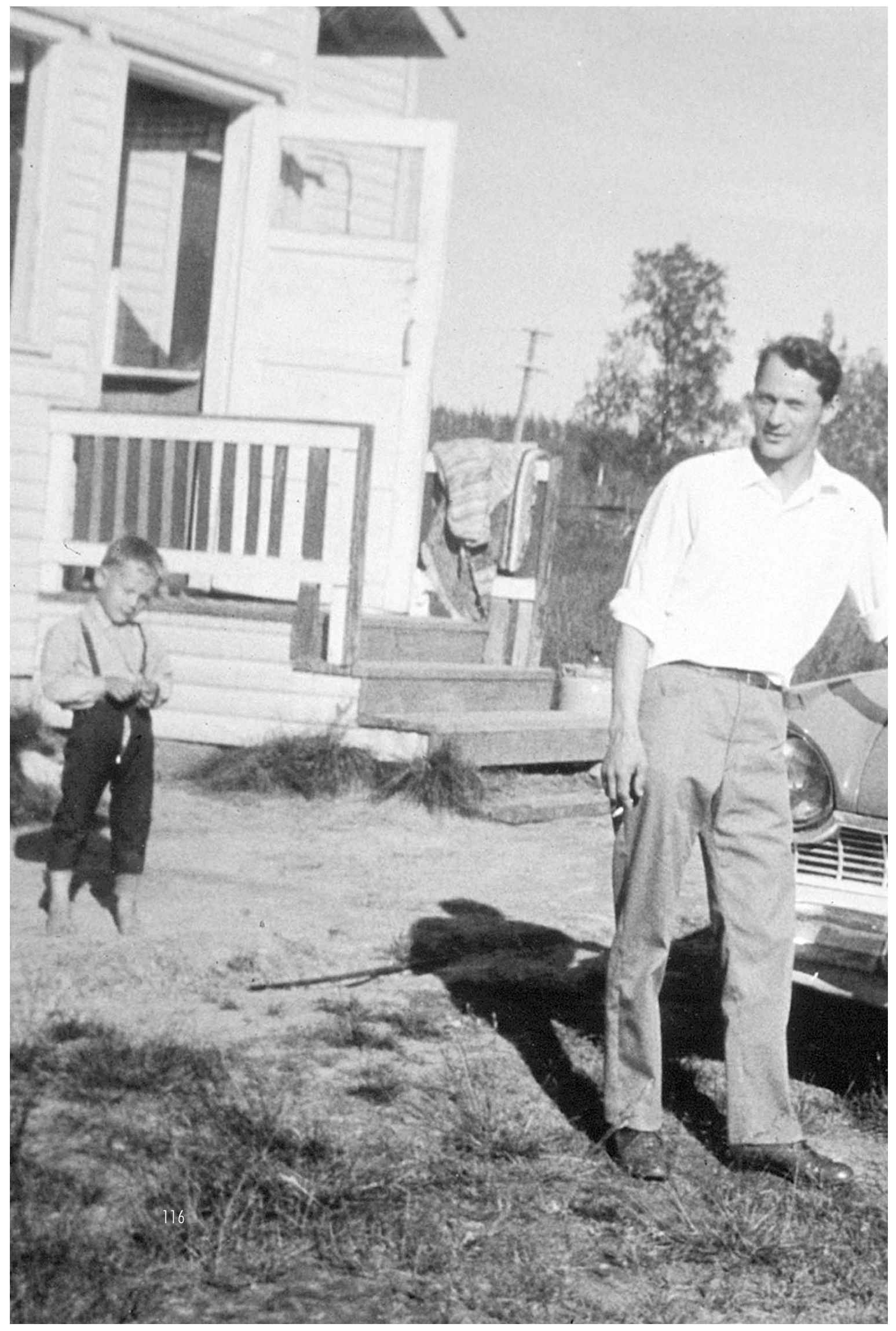


It was typical to have your picture taken with your newly acquired car. A first generation

Finn from Gothenburg visiting his home

village in Salla, and his parents visiting him in his new home in Gothenburg.

The photos in this article were taken in the 1970s by Viljo Saariniemi.

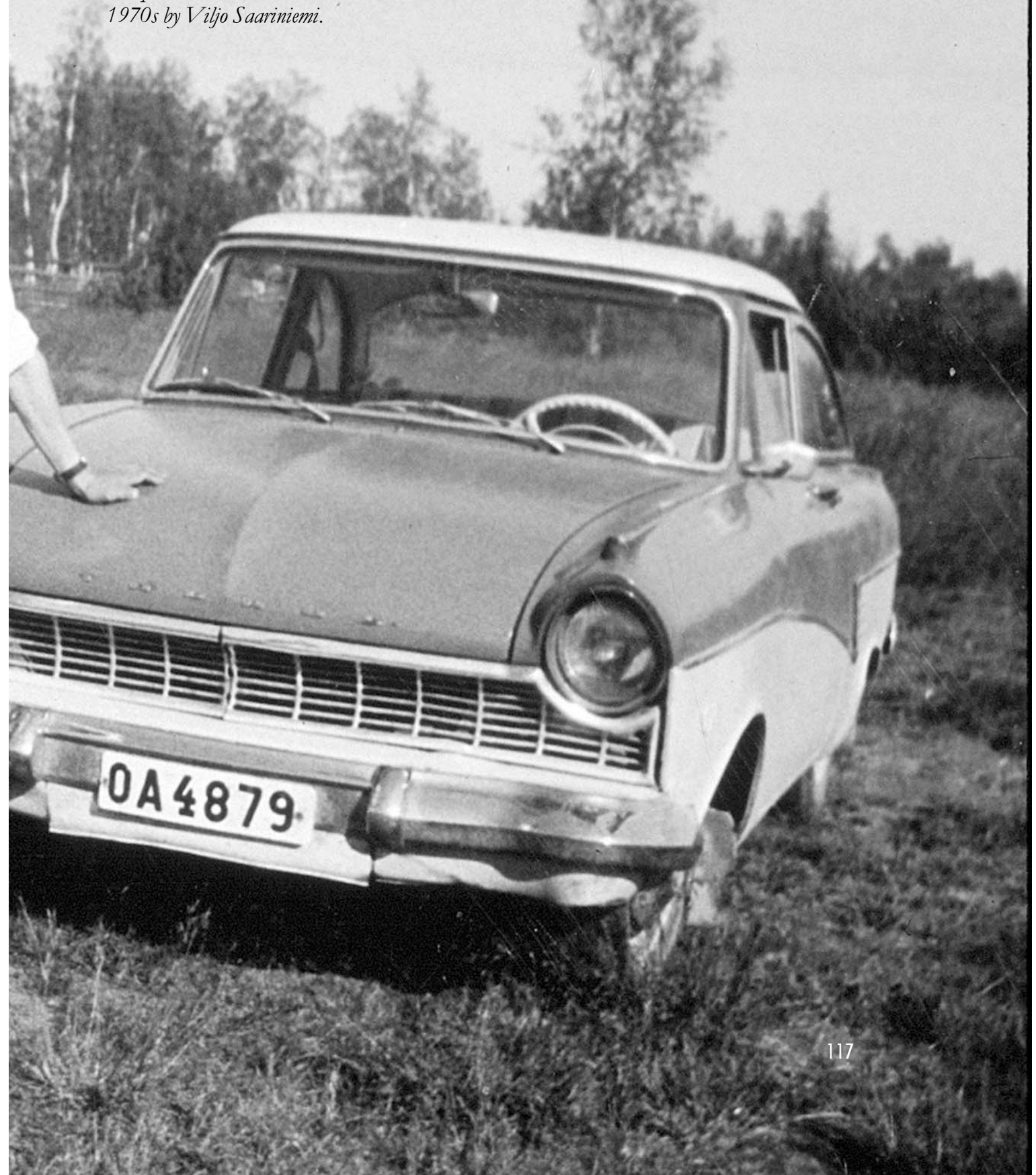


interviewees on hearing another say that "immigrants are not fully accepted because the Swedes cannot yet stomach the idea that anyone apart from them could live in their country". ${ }^{6}$

The Finns' low social status stands out in the replies. The common cultural background has not, it seems, made it any easier for the Swedes to accept the Finns. One respondent said that the Finns at work were "lower than the dogs worshiped by the Swedes".?

\section{Butt of Jokes in Virsbo}

Surveys similar to that above and conducted in the 1960s and 1970s have been described as "misery tales" , and the report by Toukomaa is no exception. The picture formed by ethnologists of the Finnish community in Sweden is not, by contrast, quite so bleak.

In the early 1970s the Department of Ethnology at the University of Jyväskylä, the Nordiska museet and the Department of Geography at the University of Umeå undertook a study of two Finnish communities in Central Sweden: Virsbo in the province of Västmanland and Upplands Väsby north of Stockholm. The reports covered the Finns' diet and customs in Sweden and jokes told about Finns. ${ }^{9}$ Virsbo and Upplands Väsby were chosen for the study because they were felt to be highly typical. The majority of the Finns immigrating to Sweden in the early 1970s had, after all, settled in the industrial regions of southern and central Sweden. ${ }^{10}$ For some reason only the reports on Virsbo have been published.

Of the 2,000 inhabitants of Virsbo, between Västerås and Fagersta, 28 percent were Finnish citizens in 1974. Featuring on the pages of the report are Finns eating rye bread and baking buns and eating the regional and seasonal foods traditionally found at home in Finland. Their attitude to the Finnish foods was not, according to the report, in any way nostalgic; the foods were simply part of everyday life. ${ }^{11}$ The Finnish immigrants did not visit Swedish homes and they were not in the habit of eating out, so they did not even know what the Swedes ate. The lack of contact was not, it seemed, due to language, since the Finnish immigrants whose native language was Swedish did not mix with the Swedes either. Rather, the lack of contact was 
due to a difference in mentality: the Finns were used to dropping in on friends spontaneously, without waiting to be invited, whereas the Swedes expected to be invited. ${ }^{12}$ In other words, the Finns brought their agrarian roots with them.

The same mentality difference was pointed out by a Finnish woman living in Västerås in 2005: if she wants to meet a Swedish friend, she must first get out her diary. But she could call in on a Finnish friend at any time. ${ }^{13}$ Although the dropping of formalities, such as the 'polite' mode of address in government offices, etc., has been one of the ideals of the welfare state, some Swedish customs are still alien to the Finns even after decades of living in Sweden. ${ }^{14}$

The jokes about Finns told by the Swedes are one of the topics of the research report on Virsbo. The Finnish jokes are usually about modern conveniences and their unfamiliarity to the Finnish immigrants: the Finns drilled a hole in the parquet to make the Christmas tree stand upright, or they used the bath to salt the Christmas ham. The Finns, being used to outdoor toilets, did not (it was joked) know how to use a WC. When, after a few days, the toilet bowl was full, they called a plumber. Finns living next door to each other drilled a hole in the wall between the flats so they could share the same telephone. The Finns' violence and heavy drinking were also the subject of the Swedes' jokes. To give an example: Two Finns were having a party together. They opened their bottles of liquor, drank them in silence and passed out. The next morning they continued partying. One of the Finns opened another bottle and said "Cheers", to which the other replied, "Look, are we here to drink or to chat?"15

A third major topic is the sexual performance of Finnish men compared with that of the Swedes. The subject might be addressed at the level of jokes in the following way, for example: A Finn and a Swede were competing to see which could have it off with more women in the space of one night. They lived next door to each other and agreed that by morning, each would write his score on the door. On returning home after their nocturnal escapade, the Swede wrote I I I on his door in the way that loggers count tree trunks to indicate that he had been with three women that night. The Finn came home a little later and was shocked: "I lost by two", exclaimed the Finn. ${ }^{16}$

Stories claimed to be true were also told about the "stupid, primitive 
Finnish immigrants". At Fagersta, one Finnish man is reported to have removed the parquet by the window in the living room so that he could plant flowers there. The same man was said to have sawn a hole in the kitchen door so his wife could keep an eye on the children in the living room more easily. Finns were said to have made saunas in a cupboard or the kitchen of their flats. The message of both the jokes and the rumours is clear: the Finnish immigrants are simple, a bit stupid, say little, have a tendency to drink, are aggressive, but sexually vastly superior. ${ }^{17}$

When Swedes living in Virsbo were asked to describe their images of Finns, they said they believed the Finns were more aggressive and drank more than the Swedes. They had also noted the Finns' poor command of Swedish, but also that the Finns were hard workers. The Swedes on piece work did not necessarily like the efficient Finns. They also disapproved of the Finns' eagerness to buy things, and especially to change their cars. ${ }^{18}$ The stories told about Finns should not, however, be regarded merely as a negative phenomenon, for humour also serves as a means of relieving tension within the community and of clearing the air. At work, particularly, the Finns upset the prevailing status systems, and this did not pass without discord. ${ }^{19}$

\section{Too Hard-working or too Lazy in Västerås}

A study by Swedish sociologists of the lives of young Finns in Västerås in the late 1970s provides yet another picture of the Finns in Sweden. In 1978 Västerås had close on 120,000 inhabitants, of which nearly 5,000 or four percent were Finns. Of all the foreigners in Västerås, 56 percent were Finns. According to the Swedish researchers, there was a clear "Finnish colony" in Västerås. Most of the Finns there aged 20-25 were employed in industry or services. The biggest local employers, ASEA and Nordiska Metallaktiebolaget, accounted for the majority. Of those included in the study, 38 percent said they were happy living in Västerås, $52 \%$ moderately happy and eight per cent unhappy. Three percent of those interviewed either could not or would not answer the question. Many said Västerås was a boring, old-fashioned town where there was nothing for young people to do.

The young Finns in Västerås can, according to the study, be divided 
into three categories. Some of the youngsters of Finnish descent identified themselves as Swedes (the majority had, after all, been born in Sweden), and they felt that it was the Finns' own fault if any problems arose between Finns and Swedes. They accused the Finns of being unwilling to learn Swedish and of having unacceptable lifestyles, of drinking heavily and riding round town in big American cars. The second category consisted of young people who had no clear views on Finn-Swede relations. In the third category were those who felt they would never be accepted by the Swedes however hard they tried. In their opinion, the Swedes looked upon the Finns as "Finnbastards, alcoholics and social drop-outs or as threatening to steal the Swedes' jobs". In other words, they were either too lazy or they worked too hard. ${ }^{20}$

The Finns in Västerås have also been addressed by Finnish sociologists, and the topic of two doctoral dissertations. The first was in sociology by Vilho A. Koiranen in 1966, on the integration of Finnish immigrants in Sweden. Koiranen drew his research material from Stockholm, Eskilstuna, Västerås and Kolsva, spending nine months in the field. One of the themes of his research was the Finns at work. According to him, the Finns had the same statutory rights as the Swedes on the Swedish labor market: the same wage, the same pension rights, the same sickness and unemployment benefit, child allowances and the same maintenance allowances. Even so, the Finns did not feel they were equal to the Swedes. They took little part in the social and political life of Sweden. They had not formed associations of their own with political objectives in Sweden, and nor did they take part in the Swedish associations with political ambitions. They belonged to the trade union partly because, according to Koiranen, membership was almost obligatory in many jobs. Having once joined the union, either voluntarily or under pressure, they were in most cases very passive members. ${ }^{21}$

The doctoral dissertation in sociology published by Magdalena Jaakkola in 1984 again focuses on Västerås. One of the articles in the dissertation deals with the ethnic organisation of the Finns in Sweden. Either Koiranen had closed his eyes to political activities or a lot had happened in two decades. According to Jaakkola, the various parties in Sweden organised activities in Finnish and the Finns in Sweden had formed their own associations or divisions, especially in the left-wing parties. The majority of the Finns in Sweden in the 1970s were blue-collar or lower white-collar workers, and 
most of them, to quote Jaakkola, "appear, according to a number of studies, to support and vote for the Social Democrats". Emigration to Sweden had for many also meant a shift towards the Social Democrats. Jaakkola reckoned that the transition from agrarian occupations to work in industry no doubt explained the swing in allegiance from the Centre (agrarian) to the Social Democratic Party. The smallness of the Swedish Communist parties and the fear of being branded may, according to Jaakkola, explain the increasingly Social Democratic tendencies of former Communist supporters. ${ }^{22}$

\section{Boundaries}

\section{...in Research}

The journey from Olofström via Virsbo to Västerås may, in the light of the above, also be understood as a journey to three different disciplinary approaches: those of psychology, ethnology and sociology. The ethnological perspective produces different material from the psychological, and the time difference also accounts for the different research perspectives. Each discipline has its own unwritten laws and traditions that determine the focus of attention. In other words, different disciplines are concerned with different things.

The object for research, the people, in the discipline, ethnology, which I represent, was for a long time defined as the agrarian population. Until the 1960s, the definition of folk culture did not recognize any of the other inhabitants of the rural regions, such as the clergy, artisans or the landless. Nor were town-dwellers regarded as 'folk' in ethnological research. Inspired by Swedish research and with the collaboration of Esko Aaltonen, Professor of sociology at the University of Turku, Ilmar Talve, Professor of ethnology at the same University introduced a broader concept of folk. ${ }^{23}$ But though the field of research grew wider, certain things, such as the political workers' movement or the political parties, were still avoided. Their existence was not contended, but nor were they analysed. An ethnological monograph on the annual celebrations of the Finns in Sweden published in 1975 makes no mention of May Day, for example, even though this must have been celebrated in the research localities as the workers' own day. ${ }^{24}$ In my own 
doctoral dissertation (1996) on the timber floaters on the River Kemi, I specified my research topic by saying that in my interviews I touched on party politics only in cases where the interviewees themselves so wished. ${ }^{25}$

Although ethnology would appear on the surface to have avoided anything hinting at politics, this is not the whole truth. The discipline has from time to time been harnessed to political objectives. Nazi Germany went to extremes in ordering ethnologists to idealise the nebulous past of the Aryan peasant. ${ }^{26}$ The recording of oral workers' tradition begun in Sweden in the 1940s was part of the building of the 'folkhemmet' (the 'folk home' alias the Swedish welfare state), in which all members would be equal and in which all would have equal right to their own history. ${ }^{27}$ The studies of tufted rya rugs by Finland's first Professor of ethnology, U.T. Sirelius, were translated at the government's expense into several languages in the 1920 s in a desire to demonstrate the originality and artistry of the newly independent Finns. ${ }^{28}$ Back in the 1960s the Swedes were already talking, in the spirit of Fredrik Barth, of political ethnology in which politics was defined as influence. ${ }^{29}$ In Finland the concept has not been used, at least on a wide scale.

\section{...and Experience}

From the 1950s to the 1980s the Finns in Sweden were Workers with a capital W. The life stories collected among immigrants typically begin with the words "I came from an ordinary worker's home". 30 The journey to Sweden seldom meant a step up the social ladder, since the Finns were employed in manual labour. In 1956, of the Finnish citizens living in Sweden, 43 percent were employed in industry. By 1964, 60 percent of the corresponding section of the population were employed in industry or mining, and by 1970 the percentage had risen to 69. The Finns were employed above all in foundries, car factories, shipyards and other metal-working undertakings, and in the rubber, textile, clothing and paper industries. ${ }^{31}$ The proportion of blue-collar workers has since decreased, and many of the Finns living in Sweden do not like having attention drawn to the agrarian background of the Finns in Sweden or their dominance in industrial occupations. The reason for this is not necessarily that they do not respect 
the working-classing background of the Finnish communities but rather that they want to dissociate themselves from the vicious circle of sheathknife, liquor and 'sisu' attached to the Finnish industrial communities. ${ }^{32}$

Another explanation put forth for the Finns' political passiveness is that a rumour persists among the Finns that political activeness, and especially membership of political organisations is forbidden for the Finns in Sweden. ${ }^{33}$ An ethnology student from Helsinki came across this same rumour while interviewing Finns in Upplands Väsby around New Year 1969-1970. According to one interviewee, it is not acceptable for Finns to be politically active in Sweden. Some of the men, the interviewee's husband included, had plans for founding a club for old war veterans, but the interviewee claimed it was prohibited. Paradoxically, the interviewee said, the Finns are obliged to pay their trade union membership fee, part of which goes to support the Social Democratic Party. Another informant, who had worked as a political correspondent in Finland, reported that he had not had any part in Swedish politics because it was forbidden. He had been asked to stand as chairman of the Young Social Democrats but had refused. ${ }^{34}$

People substantiated the rumour by quoting the 'Undén Tractate' that was reputed to prohibit political activities among foreigners in Sweden. ${ }^{35}$ Professor Ilmar Talve, the ethnologist of Estonian descent mentioned above who had escaped to Sweden in 1945 recalls in his memoirs that the Swedes were afraid the refugees would take political steps in Sweden "and it was therefore prohibited in the refugee passport". Foreigners were, according to Talve, nevertheless allowed to found ideological associations. ${ }^{36}$

The aim of the agreement named after Östen Undén, for many years Foreign Minister of Sweden, was, according to earlier research, to prevent the forming of a Baltic exile government in Sweden after the war. ${ }^{37}$ There is, however, no mention of this in the Swedish research into Undén. His biography does vaguely allude to the fear of a Trojan horse in post-war Sweden, but there is no mention of foreigners being forbidden to take part in political activities. The name of Östen Undén is admittedly associated with the Balts: after the war, the Soviet Union demanded that 167 Balts be extradited from Sweden, and this was done. Since Undén was Foreign Minister, he played a central role in the extradition and was severely criticized in the press. ${ }^{38}$ 
Ever since the early days of the workers' movement it has been the practice in Sweden for the trade unions to be firmly anchored on the Social Democratic workers' party. The members of the Swedish Trade Union Confederation (LO) are, via the affiliates system, registered as party members. The party membership fee is thus included in the union membership fee and collected by the trade unions. Hence many a Finn became a member of the party without even realizing it, and many an immigrant was later surprised to learn that he or she was a member of the Social Democratic Party. ${ }^{39}$ A handbook in Finnish called "Suomalainen Ruotsissa" (The Finn in Sweden) targeted at immigrants in 1969 and 1976 describes the work of the trade unions. According to it, a private member of a trade union can, on lodging an objection, refuse membership of the Social Democratic Party. ${ }^{40}$ According to a survey conducted in 1984, foreign nationals working in Sweden were just as often members of a trade union as Sweden nationals, but fewer were members of political parties. ${ }^{41}$

In the 1970s Finnish immigrants were regarded as anti-union. The reasons given were their agrarian background and youth on emigrating. They had not been used to union activities while at home. ${ }^{42}$ Or if they had, their experiences had not necessarily been favourable. Kalle reported in an entry to a competition that at home in Ostrobothnia in Finland more than ten workers had been given the sack from one firm on joining the trade union. When, in their new jobs in Sweden, Finns were instructed to pay a certain sum of money every month to the trade union, the men took fright: "What should we do? What's the union like here? What if we get the sack when we've just got a job? Better ask the foreman - so we tried in our poor Swedish to ask whether we could join the union. He waved his arms about and talked and we got the impression it was all the same to him." ${ }^{\prime 3}$

The oral material also reflects union opposition. An electrician living in Märsta recalled his early days in Sweden at the Volvo factory in Olofström. Having started work at the factory, he heard that the pace was stepped up in the autumn because it was impossible to change jobs just before the onset of winter. "The damned screws come round every autumn just before winter. They know the guys can't change jobs in the winter", Erkki recalls. He was given his cards because he refused to accept the change in the piece-work rate that would have meant doing more work in order to earn the same 
income. He felt the union had not supported him: "I was told to leave at once before even the dust had time to settle. They all kowtow, the big nobs and the little nobs. The union men dance to the same tune." ${ }^{\prime 4}$

Not all had such a negative image of the unions, however. Sirkka, who worked for L M Ericsson, said a man from the union had made sure she joined the union as soon as she started working at the factory in 1971. According to her, the union worked well. It held courses for workers and informed them of major issues. ${ }^{45} \mathrm{~A}$ union representative might also provide assistance on matters only loosely connected with work, such as finding a place for a child in day care. ${ }^{46}$

Their inability to speak Swedish was for many an obstacle not only to paying their membership fee. Those who did learn Swedish were often active in the union. Inkeri, who worked at the SKF factory in Gothenburg, decided to learn Swedish at once on immigrating to Sweden. Only a year after arriving there she found herself interpreting at work and thus got involved in the union. ${ }^{47}$ Some had already been active in the union at home in Finland. Jouko, also at SKF, was invited to join the union after he began work there. He was already expecting to hear from the union as he had signed his transfer papers on leaving Finland ${ }^{48}$ Heikki, a worker at Sandviken, had been an active member of the Metal Workers' Union at home in Finland, and he continued to be active in Sweden. ${ }^{49}$ As their Swedish improved, the men took a more active part in union affairs and helped influence the start of activities in Finnish.

Being an active member of the union was not always easy. Juho joined a study circle dealing with the collective labor agreement. He soon noticed, as delegate for his place of work, that he did not know enough about the agreement, to say nothing of the union organisation and legislation. He therefore signed on for a one-week LO course and later other LO courses. His colleagues ragged him on returning to work after the courses about taking an extra summer holiday. ${ }^{50}$

During the evenings at the course, the idea was voiced in several quarters of setting up union divisions operating in Finnish. ${ }^{51}$ Representatives of the Social Democratic Parties of both Finland and Sweden were present when a Social Democratic club of the Stockholm Finnish-speaking trade union was founded in 1965. By 1982 there were 82 Finnish-speaking Social 
Democratic divisions in various parts of Sweden. The majority of them were founded in 1975-1977, i.e. immediately after immigrants were granted the right to vote in local elections in 1975. The Finnish-speaking Communists began to get organized at a meeting in 1971 that was attended by leaders from the Communist Parties of both Sweden and Finland. The first Finnish-speaking divisions were founded in Gothenburg, Södertälje and Stockholm. The majority of the Finnish-speaking divisions of the Communist Party were founded during the election campaigns for the Finnish Parliamentary elections in 1975 and the Swedish local elections in 1976. The other parties have displayed little Finnish-speaking interest and have not had any divisions especially for Finnish speakers. ${ }^{52}$

Many of the experiences of the Finns living in Sweden who entered for the metal-workers' tradition competition concerned social relations at work. The entries display a certain contradiction. Some emphasise solidarity between workers across nationality borders, while others speak of unfair treatment at work. In most cases the Finns feel they have been treated unfairly precisely because they are Finns, but there are also reports of the opposite. The Finns suffered in many ways for their inability to speak Swedish: "The man setting the piece-work rates was very scathing about our demands, and he said one reason why we weren't entitled to the same rate as the others was that it took us longer in the tool stores because we couldn't speak Swedish properly. - Then in the afternoon I was told the rate had been lowered even further and the "miscalculation" would be rectified." 53

\section{Conclusion}

The studies by Finns usually underline the large number and significance of the Finns working in Swedish factories. The studies by Swedes look at work places as multicultural communities in which immigrants' country of origin is of lesser importance. ${ }^{54}$ According to Billy Ehn, the first Swedish ethnologist to study immigrants, the concepts held by immigrants of the Swedes are as stereotypical as the Swedes' concepts of immigrants. The immigrants, Finns included, claim that the Swedes look down on them, that they dislike foreigners, that they keep to themselves and are spiritually impoverished..$^{55}$ 
Immigrants from other countries are the subject of similar jokes to those told about the Finns in Sweden. ${ }^{56}$ The stereotypical concepts of the "national character" of one's own or one's neighbouring nation are not, however, based on reality. ${ }^{57}$ True, nations act in different ways, as was evident from the comparison of Swedish and Finnish visiting customs. These are, however, acquired customs, not innate national traits.

On listening to the Finns' narratives of their experiences as immigrants, I cannot help wondering what experiences the immigrants in Finland relate. I would not be surprised if they had a similar tendency to talk in low voices in the streets in order to avoid unpleasantness, and if they felt excluded at work. The Finns living in Sweden have themselves expressed the feeling that people in Finland could benefit from their experiences. As long ago as 1971 some Finnish politicians in Sweden published a book called "De finska invandrarnas problem" (The Problem of the Finnish Immigrant) in order to join in the debate in Sweden on immigration policy. In the Finnish edition published the following year the authors reported that many of the wishes and demands stated in the book had been incorporated in Sweden's immigration policy. What is interesting is that they gave the following as their reason for publishing the book in Finnish: "Finland will undoubtedly be receiving immigrants and will have to solve many of the problems that have either already been solved in Sweden or that will have to be solved in the near future." ${ }^{\prime 58}$ 
This paper was presented in Finnish at a conference organized by the Finnish Society for Labour History in 2004. 


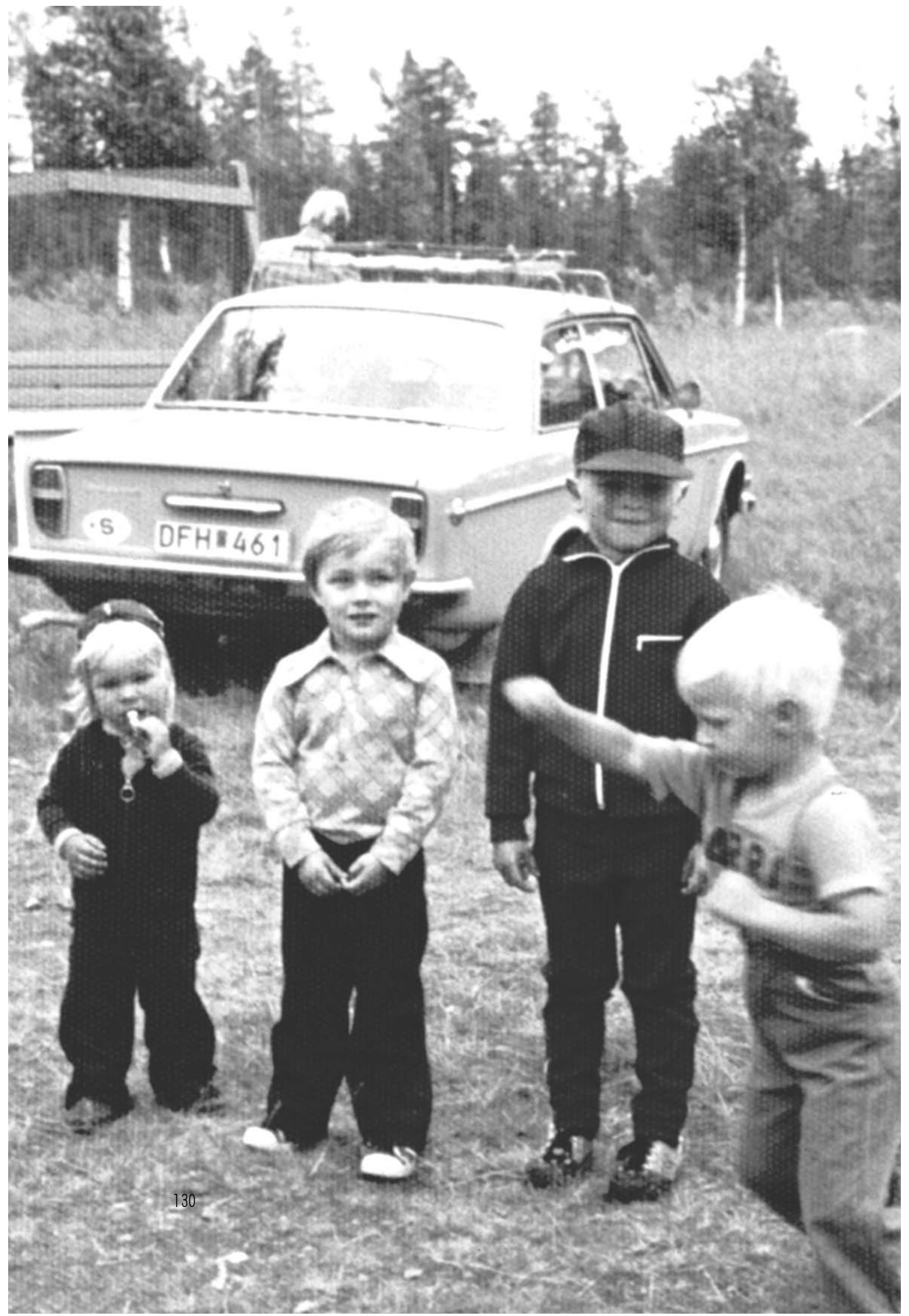




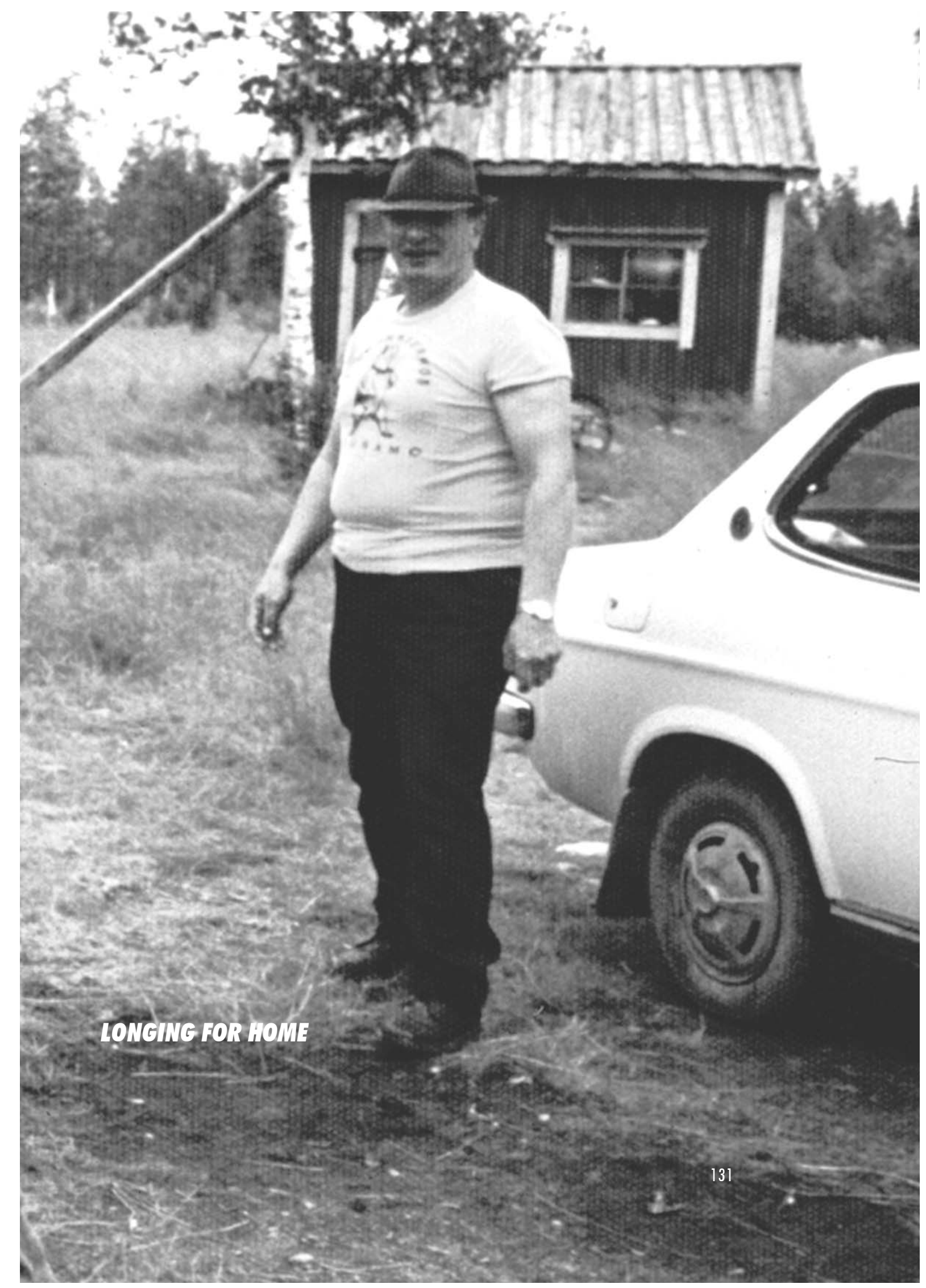


Structural change has been a marked feature of Finnish history since the Second World War. Not until around 1980 were there more Finns living in towns than in the country. The 1960s have come to be known in research literature as the decade of rural depopulation. The migrants headed mainly for the industrial towns of southern Finland or for neighbouring Sweden. ${ }^{1}$ The flow of migration to Sweden from Salla, on the eastern border of Northern Finland, was so strong in the 1960s and 1970s that the locals joked that Gothenburg, a major industrial city in southern Sweden, had within a matter of years become Salla's biggest village. In 1970, for example, more than six percent of the population of Salla moved to another Nordic country, and the other municipalities of Lapland likewise came high in the migration statistics. ${ }^{2}$ Although the figures for the individual municipalities were not large, migration to Sweden meant a considerable population drop in Lapland. The consequences were made all the more dramatic by the fact that the migrants were those of the best working and child-bearing age.

In 1980 Gothenburg had an estimated 28,000 or so inhabitants of Finnish descent. Of the just under half a million at the beginning of the 1990s, five percent were Finns. In the absence of source information, it is not possible to say categorically what part of Finland the Gothenburg Finns originally came from. It may be assumed that a considerable proportion of them came from northern Finland; 40 percent of the Finns migrating in the late 1960s were, after all, from the provinces of Lapland and Oulu. ${ }^{3}$

My previous research was concerned with the experiences of persons who migrated to Gothenburg from Salla and other municipalities in the province of Lapland in the 1960s-70s. I am examining the environment in which they grew up in Finnish Lapland, and the way this background was reflected in their lifestyle in their new homeland. I was further looking into their key experiences of being a Gothenburg Finn. ${ }^{4}$ One of these experiences is the topic for this paper: vacations in Finland. The focus is on the thoughts and experiences at individual level, and in my analyses I will be trying to piece together their worldview. ${ }^{5}$ The study is based almost exclusively on interview material. I have at my disposal 62 interviews, half of which I made myself. The interviewees had migrated to Sweden at different times. 
The social networks of first generation Finns in Sweden were tight. First cousins born in Sweden had the opportunity to meet their grandparents, aunts, and uncles during summer vacations.

Picking cloudberries, going to sauna, and frying sausages were typical holiday activities.

The photos were taken in the 1970s.

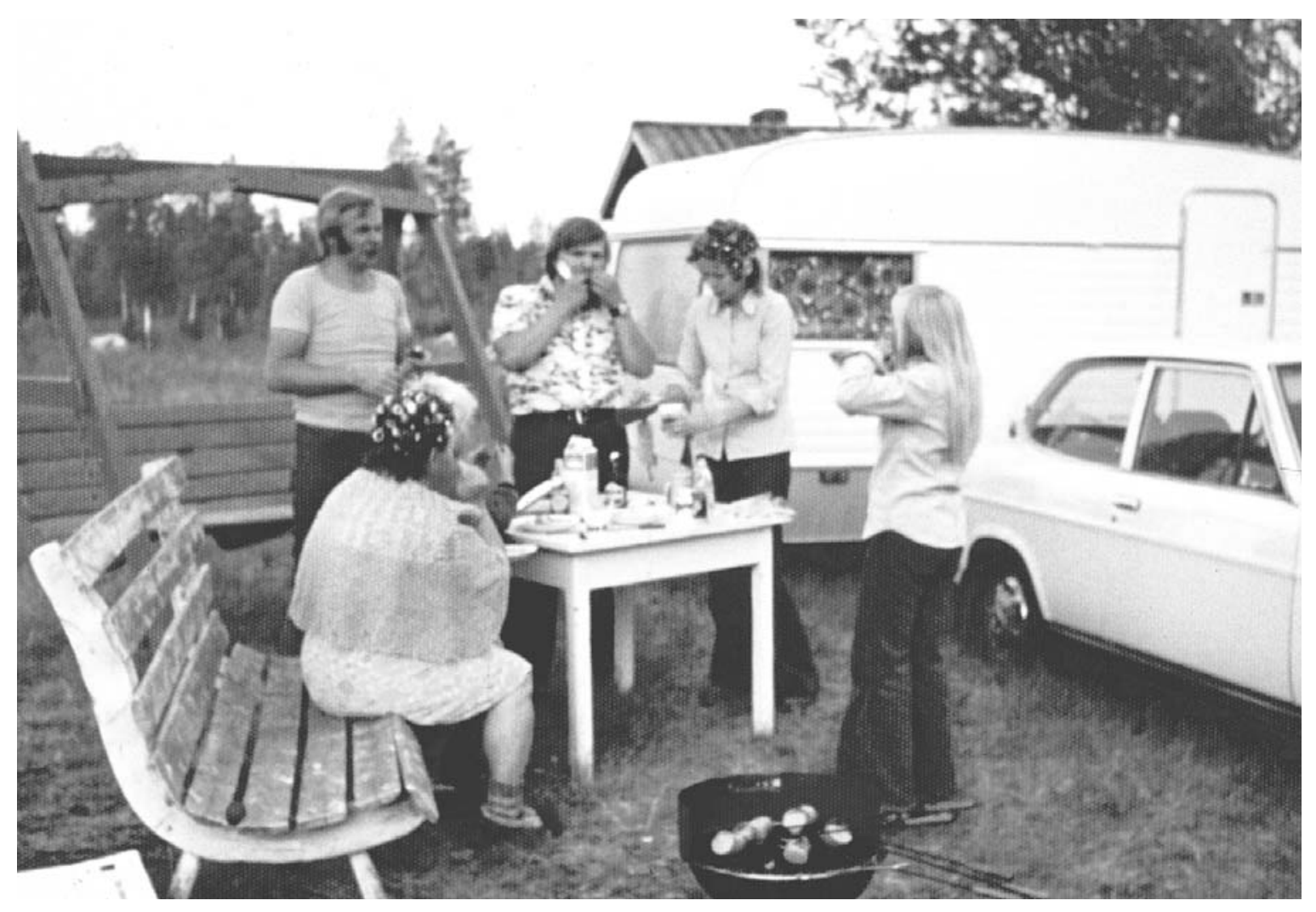


The one who had spent the longest uninterrupted period in Sweden had gone there in 1955 and the most recent in 1979. The majority of the interviewees had migrated to Sweden between 1962 and 1974, and 1967-1970 were peak years. Although I did not know the year of migration when I fixed the interview, the data well represents the peak years in the statistics. The same applies to the age of the interviewees on migration: the youngest woman had migrated to Sweden without her parents when she was 14, and the oldest at the age of 37. The ages of the men on migration varied between 16 and 39. Most of the interviewees had been under the age of 25 when they migrated to Sweden.

In addition to the interviewees, I have used material in the press, oral history collected by The Archives of The Finnish Minority in Sweden in Stockholm, and the diary of and letters received in Sweden by a young girl who migrated from Salla to Gothenburg.

\section{The Permanence of Temporality}

All the interviewees with a couple of exceptions stressed that they never intended to stay in Sweden. The idea of temporality is a major element of the migration narrative. "I'll just stop for a while and then go back" is how many described their mood when they first went to Sweden ${ }^{6}$. As a rule, they hoped to earn a lot of money in a short time and then return home. "Migration to Sweden spread like at the flick of a fan" is how Auno recalled her sudden decision to go to Sweden with some of the boys from the village in 1969 . They all intended to make only a short stay and then to return home: "We thought we'd just visit, make a packet of money and then come back like everyone else". Employers were used to people going off to Sweden "just for a visit", so they might promise their employees a job to come back to if they did not like it there. "We both had jobs, but we came over sort of just out of curiosity. And at work, back home, the boss said you go over in your summer holiday and then come back", is how Aaro recalled the mood in which he set off.

On departing for Sweden, the majority thought they would be returning before long. But many never did. "It must be years [since I gave up the idea of going back]; the last time must have been when we moved here [their 
house]". His wife continues: "It's just come about gradually, always just a bit longer. Then when the children start school, then we'll have to go back at the latest, but I don't know what...why we didn't go back then. And then I had a good job at the glass factory by the time the girls were born". "We've been here ever since. Reckon we no longer have the gumption to go back," adds Auno. Research literature uses the term 'permanence of temporality' for this phenomenon. The idea of returning is typical of first-generation migrants; but with time, temporary nevertheless becomes permanent. ${ }^{7}$

Many stopped dreaming of returning when their parents had either died or moved away from their home region. They ceased being homesick. As their children, or at the latest their grandchildren, were born and grew up, the new country came to be looked upon as home. Even so, many of those interviewed still treasured the annual vacation in Finland. The migrants returning to their former native region for their holidays are an interesting group. In a way they are tourists, but they are tourists at home.

\section{Ulla's Diary}

Ulla, who kindly lent her diary as material for research, was 15 when she migrated to southern Sweden from a remote village in Salla. She had finished her compulsory schooling at the end of May and been confirmed at the end of June, 1969. The summer and autumn were spent at home, helping about the house, with the hay-making and as a domestic help. Being a domestic help did not appeal to her, and by September she was noting in her diary that she would have to look for a job. She was already mulling over the idea of migrating in October, as a domestic help at the school: "Oh if only I could get a job somewhere else. It would be fun to go with Tuula." It is evident from the entries for November that the girls used the telephone in the village shop to reply to a job advertisement, but the diary does not say what the job was. On December 20 Ulla writes: "Guess what! I'm off to Sweden with Tuula and my big sister. Just think!"

The story of how Ulla came to migrate at 15 is in many ways typical: she goes with her older sister and her best friend to stay with a cousin's family. The idea was that one of the girls would remain as a domestic help 
with the cousin's family and the other two would go and work in a factory. The decision to go would appear to have been made quickly, because according to the diary, Tuula's father did not even know they were going. He may have been away at a logging camp, because their departure came in mid-December, while the cousin and family were on vacation in Finland.

We set off on Monday. Came here with Tauno and Jukka. I cried when we left. Ensio (Tuula's father) didn't know Tuula was going. He's sure to be angry. So the journey over was fun. We laughed and sang a lot. Jukke's really nice. I'm staying at Irma's. The men are out at work.

Life in Sweden was not, however, quite as pleasant as Ulla and her pals had expected. After three days there, Ulla wrote in her diary, "Nothing's been as good yet as the journey over." She was a domestic help in her cousin's family, so she had both a job and a roof over her head. Also living in the same house were two other families. It was the end of December, and Ulla hoped she could "stick it out until the summer". In other words, she had no intention of staying permanently. Even so, she was depressed:

This house is SO cold and such a dump. It's not at all nice here. Posted home a letter and some cards. We've been to the bank and the shops. There are 2 other families living here. - The children are absolutely impossible. Eero wipes his snotty nose on the cushion. Yuck! I'm so glad the girls didn't leave, so I wasn't left here on my own. How am I going to cope with these kids? Goodness knows. - I do hope I can go and live with the girls, and if only the place was WARM.

Ulla spent eighteen months in Sweden, but she never really enjoyed it. The subtenants living in the same house partied until well into the night, and Ulla could not sleep - she was, after all, expected to sleep in the living room, where the party was going on. Once she was sexually harassed by a neighbor visiting the apartment. The girls who came over from Finland with her were in a different town, so Ulla was lonely. She felt she could not handle the work expected of her, and she even went hungry. Meditating on the course her life had taken, she bitterly regretted going to Sweden. She likened herself to the bleak Northern countryside and said that it was difficult being uprooted: 
Time goes on, every day the same! Never a free Saturday or Sunday. Yrjö's now got an accordion and I've had a go on it, too. Oh how lonely I am. I've written home as well. And I've been writing up my old memories of our hut in the forest to pass the time. It makes me feel better at once and long to be in the wilds. Tomorrow I'll be 16. This is the fifth year since I started writing to you. What a lot I've been through, first childhood, school, a few months hanging around at home and now - now I'm testing my wings on the winds of the world - without Mum to support me. And without any friends (for the time being). I don't know whether I'll come back to Sweden if ever (God willing) I get home. What a way to leave - suddenly snatched away from home - the homeland. Life completely changed. From my dear, quiet home village to the big wide world. How can anyone turn at once into a hard city creature, selfconfident and independent? And try to be grown up as well? It's not easy. It's difficult for youngsters, too; it makes me frightened and weepy. And they can't understand why I don't get to know the girls who call here. I don't see how I can. They've got different interests, and a different outlook on life, I reckon. I simply can't, or maybe I don't want to. I'm a bit of a dreamer and to top it all shy. They're lively and talk a lot. Hm! Whereas I'm gloomy and don't say much. Reckon I'm like the bleak countryside of Lapland. I don't like larking around or big places where you have to talk to lots of people. I don't enjoy parties, they make me so tense. You're expected to be so sophisticated. No, I'm better suited to the forest hut, a beautifully peaceful place where you can be free with your friends, any way you like. You don't need to be sophisticated or tense. Maybe I'm just so deeply rooted in my home region that I can't cope here. But I reckon there's nothing anyone can do.

Being a domestic help was hard work, at least in the family where Ulla was. In addition to her loneliness, she complained about the lack of free time. The working days were long, and the parents wanted her to look after the children at the weekend, too. Relations with the employer became strained, partly because both parties felt they had been let down: Ulla because she was not able to live with the same family as her sister and friend, and her employer because the girls would rather work at the factory than as a domestic help.

After the initial culture shock, the reports of homesickness gradually give 
way in the diary to accounts of places visited. Ulla has nothing to do with any Swedes, but she does mix to some extent with other immigrants. Her dearest wish is no longer to go home but to get a job at the factory and to move in with the other girls: "If only God would help me get a job at the factory and let me live with the girls." Her prayer was answered, and she also found a boyfriend: "Kari and I have been going out for some time. We even went to Finland at Easter (all 6 of us!). I nearly stayed there and would have done if I didn't like Kari. It was lovely going home. The village looked different."

Ulla went home to Salla again for her summer holiday, as did the others. All the interviewees recalled that in the early years in Sweden, particularly, they went to Lapland for their summer holidays. "We just had to go to

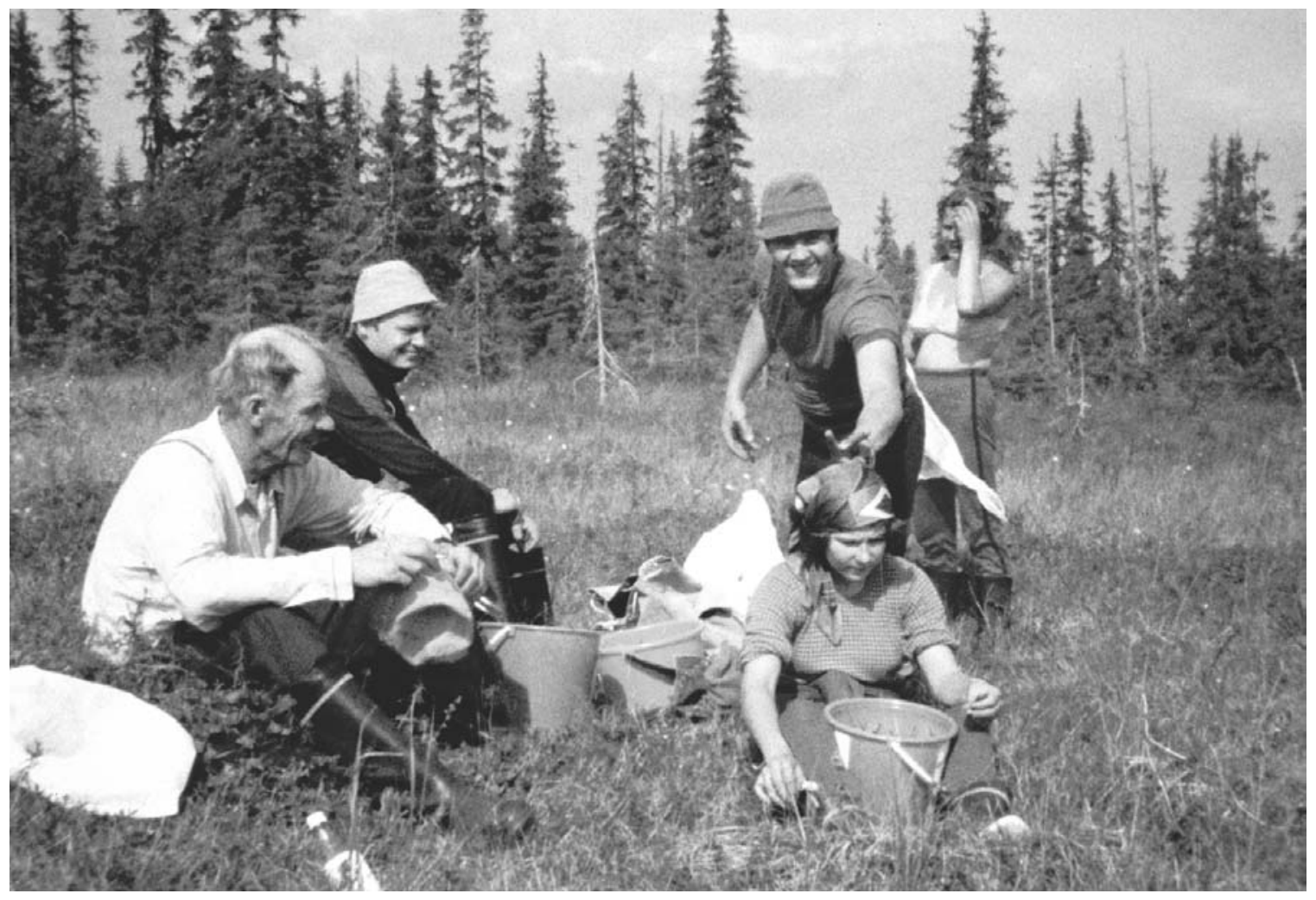


Finland" was the standard answer in the interviews. It was as if the new year began at Midsummer." Ulla wrote in her diary that she was once again "in this revolting Skene". The summer holiday with her boyfriend in Salla had been "wonderful". The time was spent swimming, at the hut in the forest, visiting, and at the café. Ulla went back to Salla again the following Christmas and Easter.

\section{"Must Get Back to Finland"}

Homesickness comes in many guises, one of which is a longing for the native countryside. The interviewees said that even after decades away they still longed for the light summer nights in Finland, the snows of early spring, the silence, the autumn colours and the wilds. In other words, they longed for the natural phenomena for which Lapland is specifically famous and which Gothenburg lacks. Even after thirty years, Reino still finds it hard to leave Sodankylä and return to Gothenburg after his summer holiday: "But even so, the longing remains. I don't know really what it is. What is it I miss? Is it, is it my relatives, or is it Lapland itself, the place where I was born?" "I must say I sometimes long for a bit of peace and quiet. When I first came here, I really enjoyed it when I got there, right up north. You couldn't hear a single car, and you could go off down to the river and fish. You'd light yourself a fire and brew some coffee there on the river bank. The only sound there was the rippling stream", said Keijo, who had been living in Sweden for forty years.

It is interesting to note the different way in which Finns who had migrated from Ostrobothnia to South Africa felt for the scenery of their old and new homelands. For those interviewed by Ulrika Wolf-Knuts, the cold Finnish winter was the best remedy for any homesickness suffered in Africa: for them, the South African countryside was paradise. Homesickness meant missing their parents, brothers and sisters. ${ }^{10}$ Nor did all the people I interviewed idolise the countryside of Lapland. Some also said they were satisfied that the winters in Gothenburg were not cold and that there were no mosquitoes in summer. They did not, however, extol the Gothenburg countryside particularly. Some of the interviewees pointed out that in some 
winters it was possible to ski in Gothenburg and to go tobogganing with their children pastimes familiar to them from childhood. Nor was a longing for the Finnish countryside a key experience of migrants from Lapland only, since similar sentiments were expressed by interviewees from Kainuu and North Ostrobothnia, too.

The core feature of the summer vacation narratives is a heroic drive to Lapland without a single stop to rest or eat. The vital thing was to get to Lapland, and fast.

You can imagine how we always looked forward to the summer holiday. It was always the...just as little kids look forward to Christmas, so we always looked forward to summer and the summer vacation, when we could go back. You know, we'd pack the cars up the same night and we'd drive to Sodankylä, you know, we wouldn't eat and we wouldn't sleep. So we could be there the whole four weeks.

Seeing their parents, brothers and sisters was for many the primary motive for travelling to Finland. They missed their mother and father, and letters and phone calls could not bring them sufficiently close. During the summer holidays, particularly, there might be many visitors at their grandmother's, and this made the stays so memorable. Alma's family would first visit relatives in Raahe before going on to Rovaniemi and Salla. The return journey would take them via Kuopio and Imatra. Salla was the main destination; there might be more than twenty summer visitors there, all working in Sweden. The cousins born in Gothenburg met one another each summer in Salla. Some would sleep in the house, others in a caravan or tent. According to Alma's brother, the time in question, the 1970s, was the best time of his life.

\section{I still get wistful when I recall how the summer holiday would come and the whole crowd would come; it was quite a to-do. The whole village had people over.}

The migrants did not, however, return to Finland merely to see friends and relations, but also to do things they could not do in Sweden. Many felt that their childhood environments were the only ones where they could really 
relax and enjoy the countryside. During their annual vacation they therefore fished and picked arctic cloudberries. A sauna bath beside a lake was the crowning glory. During the summer holiday they wanted to tramp the familiar wilds, the likes of which were, they claimed, not to be found in either Gothenburg or Sweden. During a five-day holiday Akseli once drove all the way from Gothenburg to Salla just to spend the night in the familiar wilds:

I set off after work down at Volvo's and drove all the way to Salla without a single shut-eye. What would that be -1,800 kilometres. I slept the next day after I got here in the morning, early morning, I was here in Salla before noon. Then I got up and when I'd had a bite to eat, had a meal, I threw my rucksack on my back, stowed an axe and some grub in my rucksack and off I went, off up to Vilma Fell. I skied ten kilometres or so into the backwoods, chopped down a dead pine tree and spent the night there. Then the next day I skied back and set off to drive back to Gothenburg. It was that sort of visit. I needed it, being able to spend the night by the glow of the burning pine. I just went and recharged my batteries, as it were.

For Raili's family, fishing and picking berries were among the highlights of the summer trip. It was also easier to go out dancing than in Gothenburg, because there was someone to look after the children:

We went fishing, and we went berry-picking. It was pretty important for us to go berry-picking, we had to have our berries, arctic cloudberries. And we would go dancing. I always felt the month passed so quickly, we couldn't be there the whole month, and it went so fast that we hardly had time to do anything. And if it happened to be cloudberry time, then you could spend weeks tramping in the cloudberry forests.

While home on vacation, the migrants would recruit others. Like Ulla, many of the interviewees had literally been fetched from home to work in Sweden. Good workers at the Volvo factory, for example, were even urged to bring over relatives in the days when labour was scarce. The same phenomenon can be observed among the Turkish immigrants in Gothenburg, or the Yugoslav immigrants in Stockholm. Magnus Berg, in his doctoral 
dissertation about second-generation Turks in Gothenburg, uses the term kamratrekrytering (peer or pal recruiting) in describing how the majority of the first-generation Turkish men found their way to Sweden. Most of the recruiting was done during the vacations ${ }^{11}$.

The interviewees were young, and they mostly spent their summer holidays with their parents. Many were soon in a position to buy a caravan; this was useful during their vacations, too, when many of their brothers and sisters descended on their parents at the same time. Others bought a summer cottage in their home region, or used their former house in Finland as a summer cottage. There they could live in the way familiar from childhood. A potato patch, for example, and a sauna were key elements of a lifestyle regarded as Finnish.

\section{The Home as a Stage}

One thing I noticed in making the interviews was that almost all the interviewees had a collection of souvenirs of Lapland conspicuously placed in their homes. Typical examples were souvenirs made from reindeer skin or bone, gold pans, Lapp dolls, and woven raanu wall hangings. There might also be such relics of bygone days as a rake reminiscent of a meadow economy or a curdled-milk pan from a former dairy. These items were usually placed in the hall, i.e. the most public part of the house. If the home is regarded as a theatre, then the hall and living room are the stage. The objects are displayed as an entity; they are symbolically placed in a frame. ${ }^{12}$ Ulrika Wolf-Knuts likewise mentions the Finnish ornaments in the homes of Swedish-speaking Finns in South Africa, but she does not specify exactly where they were placed. ${ }^{13}$ The fact that similar interior elements occur in the homes of people unknown to one another supports the claim put forward by Marianne Gullestad that home decoration has a grammar of its own that is commonly observed. ${ }^{14}$ Päivikki Suojanen speaks of the language of the American-Finn home. ${ }^{15}$

The souvenirs in the homes of the Gothenburg Laplanders indicate the home decorator's rural Lapland background, and probably also childhood memories. Eva Londos, in her studies of Swedish home interiors, has aptly 
noted that it is possible to read the life story of the owner (or his/her partner) from the walls of the home. The wedding, confirmation and other photos are a visual document of significant people and events. This same narrative is supported by the paintings and objects on display ${ }^{16}$. The fact that the conspicuously placed objects are associated specifically with Lapland (reindeer herding, the Sami ethos, gold panning and other indigenous occupations) tells of a desire to underline their owner's origins in Lapland. Strength is drawn from a traditional way of life now past in the society of the present. ${ }^{17}$

On the other hand, the treasures also tell of holiday trips chiefly to the former homeland, in this case Lapland. In the family albums are photos of souvenir stalls along the roads to Lapland. It is in a way paradoxical that the symbols of Lapland for the Finns who migrated young are, in the new homeland, ones that are clichés: tourist souvenirs.

This article was earlier published in Touristic Construction and Consumption of Culture(s). Papers of the $8^{\text {th }}$ Finnish-Hungarian

Ethnological Symposium Lakitelek, Hungary, August 25-31, 2003. Eds. Miklós Cseri er Zoltán Fejös er Zsuzsa S zarvas. Budapest 2004: Hungarian Ethnographical Society. 


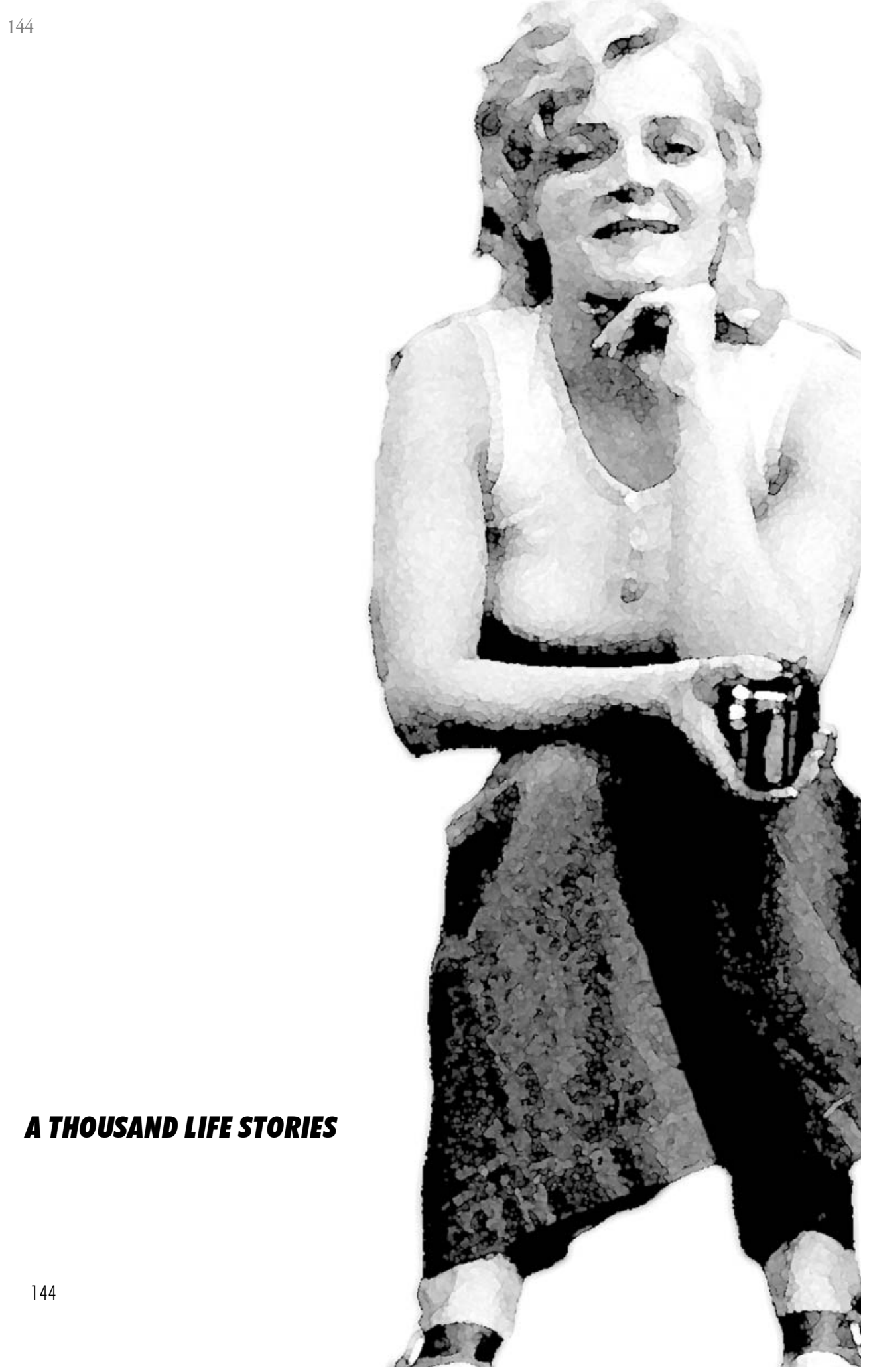


Interviews have been a strong element of Finnish ethnology ever since the discipline was first established; unlike their historian colleagues, ethnologists have not, however, had to justify their use as source material. Ethnologists are not asked whether interviews constitute good or bad materials, or whether or not they tell the truth. Interviews are taken so much for granted that Finnish ethnological research seldom sets out to listen to people whose voices are not otherwise heard. ${ }^{1}$ Interviews have simply been regarded as a unique source of material about everyday life. My perspective combines the ethnological tradition accepting the use of interviews as a matter of course with the strivings of the oral history movement to act as a megaphone for the persons for study, as a means of amplifying the quiet voices of the interviewees. Immigrants, for example, have been regarded in research of oral history type as persons whose voices deserve to be amplified.

In 1999-2002 I was in charge of a project called "Forestry Professionals in the Changing Society" run by the Finnish Forest History Society during which interviews were made with 1,053 forestry professionals. Oral history had been collected among forest workers in Finland since the 1950s, but the collections had focused on people engaged in physical labour: lumberjacks, timber floaters - and men. The project wanted to collect the oral history of white-collar workers in the forest sector and women as well. Compared with, say, North America, forestry was mechanized very late in Finland not until after the Second World War. This means that we can collect oral history on the impact of mechanization on the everyday lives of forestry professionals from the very earliest days. People likewise still remember the advent of women in the industry, be they logging camp cooks or forestry officers with a university degree.

We now have 2,500 hours of oral history on tape, giving us about 22,000 pages and four shelf-meters of transcribed interviews for the use of researchers at Lusto, the Finnish Forest Museum. The material paints a comprehensive picture of the changes taking place in the forest sector over the past five decades. The perspective is ethnographical: the focus is not on companies and organizations but on subjective human experiences. In addition 


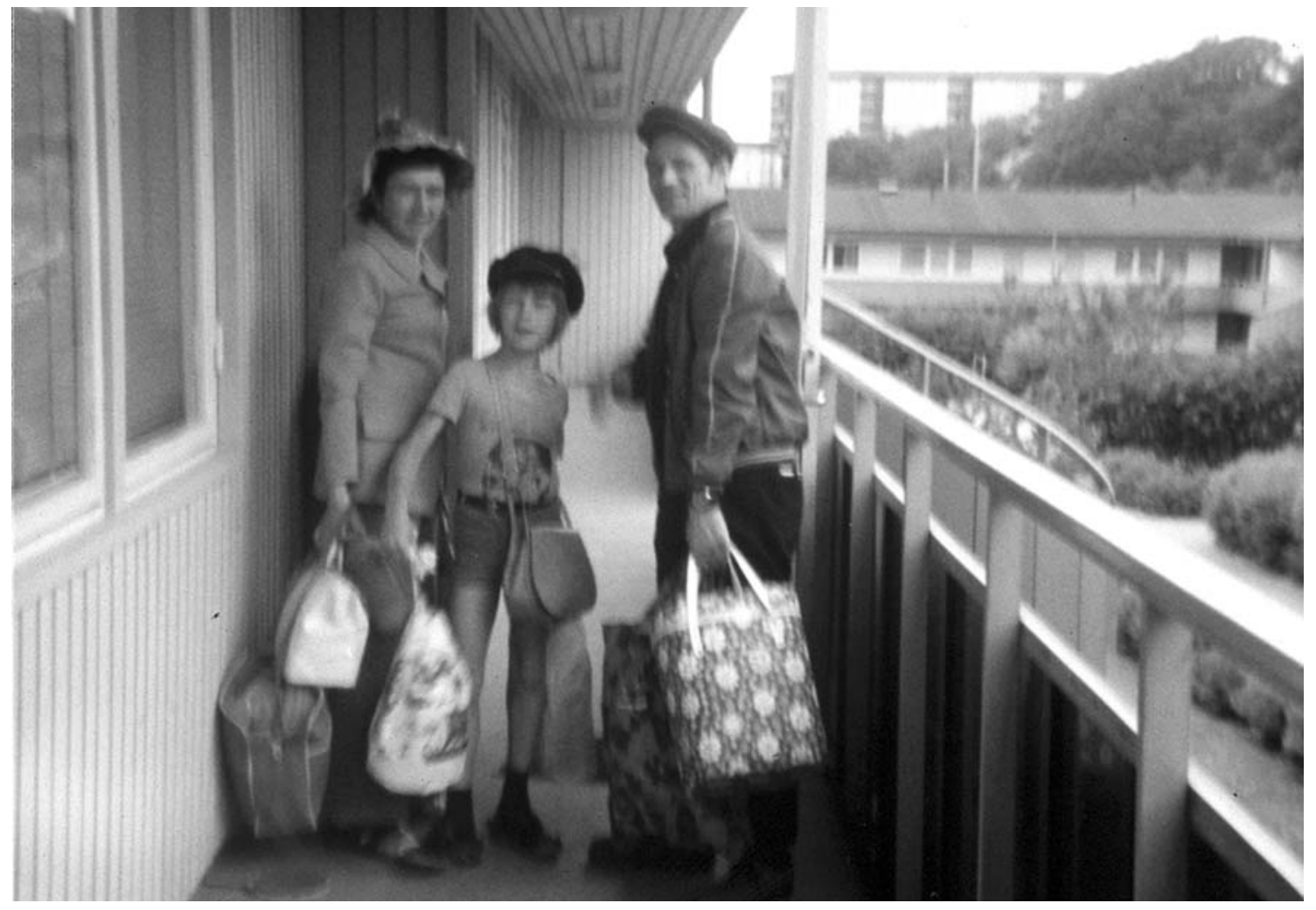


Homes in the suburbs of

Gothenburg were different from

childhood homes on the farms in

Lapland.

The photos were taken in the

1970 s in Gothenburg and Salla.

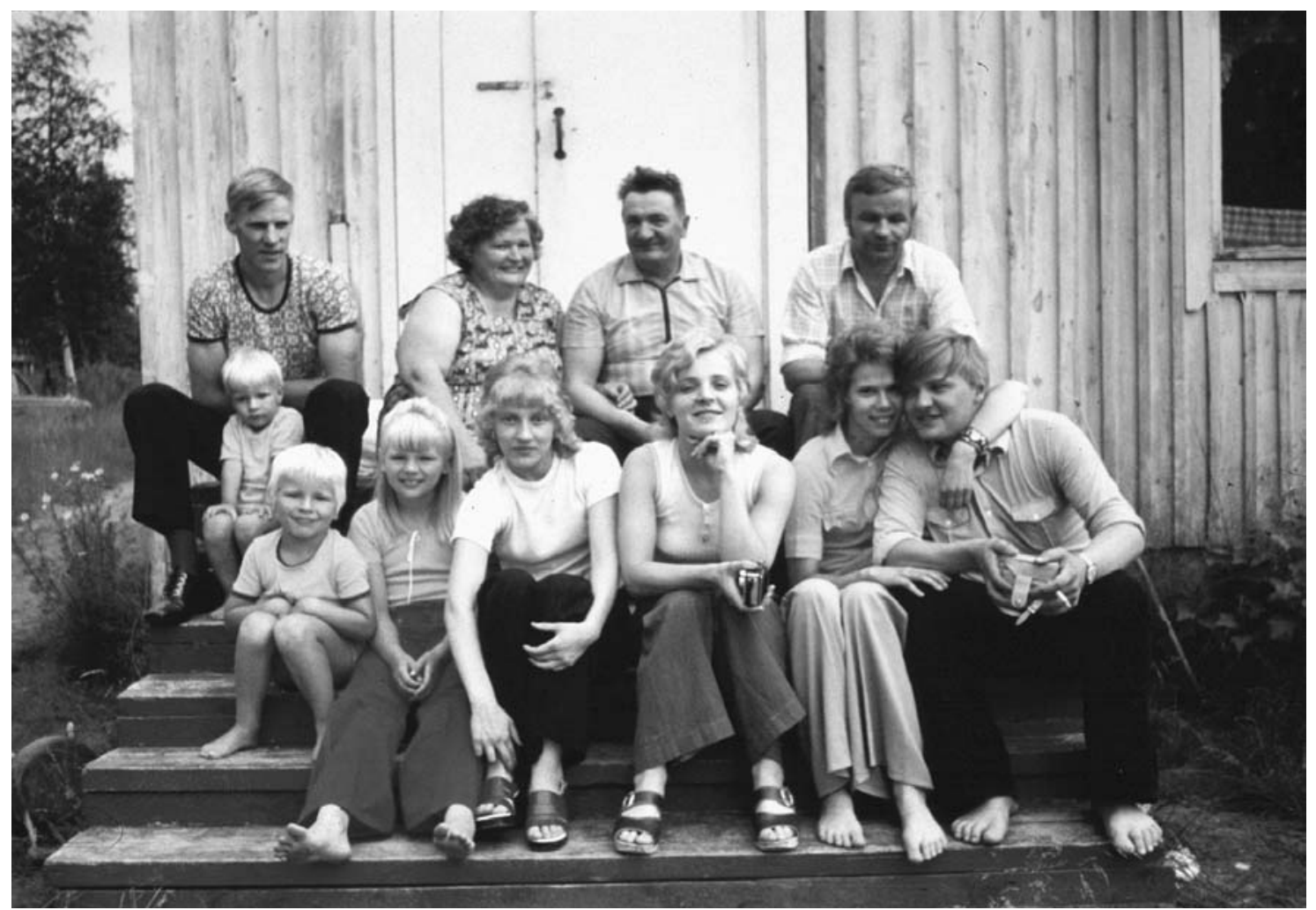


to the work itself, the changes taking place in it and the unemployment that sometimes ensued, the interviews also covered other walks of life such as everyday family life. The economic trends in the forest industry have forced whole families to move both to other parts of Finland and abroad. The crosssectional material collected in different parts of Finland is an excellent corpus for use in examining post-war Finnish society and the way it has changed. Never before in Finland have interview materials been collected on quite this scale. ${ }^{2}$

A large number of interviews is never as such an objective in ethnology - the narrative of a single person provides a window on a whole society at a specific time and in a given place and social group. The need for geographical coverage and to cover as many occupations as possible alone made the collection of such extensive interview materials essential. It also says something about the importance of the forest economy in Finland. A broad corpus of material permits far-ranging research. I am at the moment supervising several research projects on this extensive material, including four doctoral dissertations. ${ }^{3}$ I have also used a tiny fraction of the material in my own research into Finns in Sweden. ${ }^{4}$

Since the project also wished to interview people who are, for some reason or another, no longer employed in the forest sector, it seemed natural to look for interviewees in the industrial centres of Southern Sweden. As forestry became mechanized in the 1960s and 1970s, many former forest workers went to Sweden and found jobs in factories. Similarly, many a little sister or cousin followed in their wake, in accordance with the principles of chain migration, finding work either as a domestic servant or in some other job. As jobs in forestry became scarcer, so business in general declined and the Swedish labor markets became increasingly attractive, especially for people, both men and women, in eastern and northern Finland. ${ }^{5}$

\section{Background}

Recent research has tended to question the view that urbanization and industrialization have brought about a radical change in the significance of the family and traditions in society. In his study - now a classic - "The Making of the English Working Class", E.P. Thompson claimed that 
industrialization affected the family economy, upsetting the traditional relationships between spouses and other members of the family and separating work from "life". According to him, members of the family were, with the coming of industry, torn away each day at the sound of the factory siren. Researchers of the Chicago school report that migration from the country into the towns tore people up by their roots, far from their established social networks based on kinship. Many scholars have demonstrated that adapting to the industrial way of life, to an urban home and work in a factory alienated migrants, in particular, from their own traditions. Yet studies reporting that entire families were recruited by factories, and that industrialization as a whole in fact depended on families moving from country to town and from one country to another have a very different story to tell. For the traditions brought by the immigrants from their homeland appear to have served as a major means of adapting to the new homeland. Relationships with the extended family, rather than being severed, in fact often became stronger in the new cultural environment. ${ }^{6}$

Ethnological research into migration has used the metaphor of the suitcase or wardrobe. Emigrants metaphorically pack their cultural heritage - their memories and experiences - in a suitcase, and duly unpack them in their new homeland, storing them away in wardrobes and drawers. As time goes by, other things are also put away in the same wardrobes and drawers, as the immigrants gradually adapt to the new way of life by combining elements of the old and the new. ${ }^{7}$ The most recent migrant research thus speaks of multiple identities in postmodernist vein. Continuing the wardrobe metaphor, we could liken identities to dressing in layers rather than to individual, interchangeable garments. ${ }^{8}$ In dealing with the second and third generations, we can no longer speak of immigrants, but the transgenerational nature of traditions and their importance is still of the utmost significance.

The mass post-war emigration from Finland to Sweden provides excellent substance for debating the effects of industrialisation and urbanisation on the family and individual. What happened when, at a single stroke, people moved from a rural environment and small farms to factories and city suburbs? What were the implications of no longer being able to spend their free time as they were accustomed: picking berries in the forest, fishing and hunting? What were the implications of no longer working at 
home and spending the day carrying firewood, water and slops, tending the cattle and looking after the children?? True, migration within Finland from country to town had involved a change of lifestyle, but the change must have been more dramatic in migrating from one country to another. ${ }^{10}$

In this paper I wish to examine the adaptation to their new homeland of women emigrating from Finnish Lapland to Gothenburg in Sweden in the 1960s and 1970s. My main question is: how was their background in Lapland reflected in their new way of life? What values and attitudes did they carry with them in their imaginary suitcases, and how did these values and attitudes help them in adapting to their new cultural environment? ${ }^{11}$ How was their regional and Finnish ethos manifest in their new homeland - or was it in any way visible? At my disposal I had interviews with 38 women from northern Finland. ${ }^{12}$ In order to emphasize the individual-oriented perspective of ethnology, I will, however, be concentrating mainly on the life of one woman, Heljä, in Sweden. ${ }^{13}$ Examination of the various stages in her life provides a broader insight into the emigration process and settling in a new country.

\section{The Lapland Mentality}

The environment in which the interviewees grew up in Lapland was marked by physical labour. Since the work done by children was of real economic significance, learning the necessary skills at an early age was considered an important element of children's upbringing and socialization. The children worked hard and applied themselves to the job, and in return elicited praise from their parents and other adults. They also worked at the expense of their education. Attendance at school was, for many, both difficult and costly due to the long distances alone. Nor did the children as a rule receive much encouragement at home to attend school. The women repeatedly said in their interviews that they "got all their schooling" after their church confirmation, i.e. at around the age of 15 . Few had had an opportunity to continue in middle school after elementary school, to say nothing of a vocational or senior secondary school. Money or distance was not the only problem, however, since disparaging attitudes to education might also present an obstacle. Even after the Second World War, especially in the rural regions, girls' lives were 
ruled by various authorities and hierarchies. ${ }^{14}$ The aim was to start earning as young as possible. In large families, the older children also had to make room for their younger siblings at a very early age, because there simply was not room for them all at home. Mothers might still be giving birth to their youngest while their eldest children were becoming parents. ${ }^{15}$

According to a number of studies, the future of the family farm is the primary consideration governing and structuring the agrarian way of life. Farmers who have assimilated the continuity ideal usually say they grew attached to their farms and occupation while still a child. ${ }^{16}$ The Finnish word for "peasant" literally means "farm boy" and thus bears gender implications. Hence, the responsibility for the future of the farm lies expressly with the male members of the family, even though women have, at least according to the law, had equal rights to continue a family farm ever since the late 19th century. Judging from my own material, I would say it is not simply a question of a male mentality moulded over dozens or even hundreds of years, or simply of a farming mentality, but of the continuity that accompanies the agrarian way of life in general. In the absence of any other opportunities, youngsters living in the country got used at a very early age to the idea that when they grew up, they would continue to work in the same environment as their parents'. For women, this meant being in charge of a household, be it the home farm, a small farm or, say, a logging camp. The rapid change in society in post-war Lapland nevertheless put paid to many a young person's dreams for the future. Few had a chance to follow in their mother's footsteps, as the woman responsible for the running of the farm household or a logging camp. However, this need not be viewed purely in a negative light. It is clearly evident from the defiance expressed by the interviewees towards their parents that the change was also welcome. It brought alternative opportunities. The only way to make room for oneself in a socially confined community was to move away.

\section{Heljä}

One option open to many a young person in Lapland in the 1960s and 1970s was to go to Sweden. Heljä, a girl from Sodankylä, was one such 
emigrant. She first went to Sweden in 1970, when she was only 14. She was the eldest of five children in a family living in a remote little village. Her father was a reindeer herder and her mother tended the cattle on the home farm. Heljä was in the ninth grade at school when she decided to go to Sweden, having completed her compulsory education at the end of grade eight. When an uncle living in Sweden called at the home farm during the Christmas break and offered her a job helping in his household, she decided to leave school and go to Sweden with him. Four weeks later she was nevertheless back in Finland. During those four weeks she had already lived in two places with her uncle's family. - The Finns in Sweden did a lot of moving from job to job in the early 1970s.

Although Heljä had sworn she would never return to Sweden, fate had different plans. Soon after returning home, she fell in love with a boy from her village and with him went off to work at a fish factory in Norway. On returning to Sodankylä, she got a job in the school kitchen, but her boyfriend, who wanted a job as a logger, was, like his father, unemployed. His brother was over visiting from Gothenburg and persuaded the youngsters and the third of the brothers to go back to Sweden with him. Heljä was 17 at the time and, like many of those interviewed, stressed that they intended to go to Sweden "just for a visit", not to settle permanently. ${ }^{17}$

\section{Manifestations of the Lapland Background in Sweden}

Over in Sweden the young immigrants, like Heljä's boyfriend, found jobs in factories, where they were greatly valued as workers. The interviewees felt they were appreciated at work, and researchers have noticed this too. ${ }^{18}$ The harder they worked, the more they were praised. Just as they were used to winning the approval of their parents by working hard, so they won the approval of their employers - even in their new homeland. For the Finns unable to speak the language of the country, outdoing the Swedes in the workplace hierarchy was extremely gratifying. In this respect the men's experiences differed from those of the women. However hard women worked, they were not appreciated and remunerated at work in the way the men were. Even so, the women also felt it was important to prove what 
good workers the Finns were. The downside to the myth of the "Finnish workaholic" maintained by the Finns was their tendency to become incapacitated for work long before they reached the official retiring age. ${ }^{19}$ Inkeri, one of the respondents to a collection of metal-workers' tradition conducted by the Archives of the Finnish Minority in Sweden, reported being assigned the very worst job in the factory but feeling honour-bound to show them just what a Finn will put up with. ${ }^{20}$ This experience was not, however, confined to the Finns alone, or to immigrants in Sweden, for it was a fate also shared by other immigrants doing manual labour. ${ }^{21}$ It is no coincidence that, for example, a book describing Italian immigrants in Canada is entitled "Such Hardworking People". 22

The interviews demonstrate that hard work gave meaning to life. There are two sayings that kept recurring in the interviews: "we're here to work, not to talk" and "if a Finn can't do it with his hands he'll do it with his feet". ${ }^{23}$ No wonder, therefore, that Finnish workers were much soughtafter in Sweden. The Finns had been brought up to respect work and did not make any great demands of their working environment. ${ }^{24}$ Their inability to speak Swedish prevented many from taking an active part in the trade union. ${ }^{25}$ In this respect they differ from the Finnish immigrants in North America famous for their involvement in politics. ${ }^{26}$ At least one difference between North America and Sweden is that the Finns in Sweden were newcomers to a "ready" trade-union movement. Maybe the Finns were not always welcome, and it was easy to pass them over due to their poor command of Swedish. North America did not have a ready union culture in the same way, and since there were so many immigrants, even a poor command of English was sufficient.

Another thing to which the immigrants from Finnish Lapland in Gothenburg had become socialized in childhood was the unofficial "social security" or mutual aid. The Finns would thus help fellow-countrymen to find a job or somewhere to live on arrival in Gothenburg. In their childhood homes the interviewees had been used to giving even strangers food and a bed for the night. The severe climate alone forced people to look after one another. Out in the wilds, where it might be dozens of miles to the nearest neighbor, it was impossible to shut the door on strangers, to say nothing of relatives, who were looked after as a matter of course. And there had been 
many opportunities for this in a Lapland ravaged by war. ${ }^{27}$

The immigrant's first home in Gothenburg was usually a bed in the apartment of a Finnish relative or workmate. The Finnish community had such a strong feeling of solidarity that people would also take in non-relatives. There was a built-in principle of helping fellow-countrymen to get started in their new environment. The arrangement would, however, never be for long; just to tide the newcomer over. There were no strict rules to what constituted family, and strangers might be taken in even when space was limited. As a rule, the Finns had got used to living in cramped conditions at home and in the logging camps and did not necessarily even wish for a room of their own. Back in Finland, "home" had not, for many, meant just a farmhouse and yard but the whole village. Nor did the family necessarily consist of nuclear members only. Close relatives living nearby might, for example, be classed as members of the family, and there might also be nonrelatives living in the same house. The siblings who had left home often seemed more like strangers than cousins of the same age living near one another. Staying with relatives in Gothenburg was thus a continuation of a practice to which they were accustomed. Helping relatives and neighbors was taken for granted. The privatizing associated with an urban way of life is a relatively recent phenomenon among the Finns of Gothenburg.

All tried to find a home of their own as soon as possible. For many it was vital if their girlfriend or family were to follow them to Gothenburg. Finding somewhere to live is not easy for someone who cannot speak the language, but here again the Finns helped one another. The typical housing history of the Finn in Gothenburg began with a temporary lodging with relatives or friends or in a hostel. This would soon be replaced by an apartment of his or her own, either rented or possibly purchased. ${ }^{28}$ Heljä's housing history followed this pattern: she spent the first few months in Gothenburg living secretly in her boyfriend's room at the Volvo hostel. They spent two short periods working in a neighbouring town but returned to Gothenburg. A two-roomed flat in a block owned by Volvo represented more permanent accommodation. Next, as the family grew, they moved to a larger flat and bought a home of their own, but they always remained in the same city suburb. Both found jobs at the Volvo car factory in Gothenburg. ${ }^{29}$ 


\section{Domestic Servant}

Like Heljä, many women first found work in Sweden as a domestic servant in a Finnish family. Until recently, virtually no attention was ever paid to the working conditions of these young girls migrating to Sweden. ${ }^{30}$ Nowadays the debate over domestic servants stresses the different social status of employer and employee. Only a very wealthy person can employ a servant. The Finns working at the car factory were not particularly wealthy and they belonged to the same working class as their servants.

The maid's job was to do the cooking and cleaning and look after the children. Many girls were literally plucked from their homes while Finns working in Sweden were visiting Lapland on holiday. The decision to go to Sweden was sometimes made after very little reflection, as Heljä's example illustrates. ${ }^{31}$ For a young girl, a job as a maid in Sweden, often in a family she knew, meant a chance to make a safe transition to Sweden. It was often agreed that the girl would work as a maid until she reached the age of 18 . She would then be eligible to work in a factory and earn a good wage. When, in due course, the girl who had gone to Sweden as a maid became independent and had children of her own, she too might return to Sweden after her summer holiday in Finland with a maid, promising the girl that when she was 18, she would help her find a job and a home of her own. This is what Heljä did. ${ }^{32}$ The interviewees who had gone across to Sweden to look after their siblings' children recalled that the maid was kept very busy, but that it was an interesting time. If the employer was not a close relative, the experiences were often less favorable. The working days were long, the girls had no free time, even at the weekend, and they did not always get enough to eat even. ${ }^{33}$

The Finns already living in Sweden wanted a maid from their home region, for a number of reasons. The most important was perhaps that the day-care system was not so well developed in the 1970s that it was possible to get a place in municipal day care. The Finns wanted a Finnish speaker to look after their children, partly because they did not intend to settle permanently in Sweden. They therefore wanted to ensure that their children would be able to speak Finnish should they ever return. Many also enjoyed the company of a little sister from Finland. A maid did not cost very much, 
usually just board and lodging and a little pocket money. Once municipal and Finnish-speaking day care became more common in Sweden, maids were no longer recruited in Finland to look after children. ${ }^{34}$ Little by little people also wanted their own privacy.

\section{Double Day under a Glass Ceiling}

Women are seen as suffering from the glass ceiling and double day effects. An invisible glass ceiling prevents them not only from getting ahead in their careers but in other ways as well. The double day effect literally means two working days: one in paid employment and the other at home. Heljä described her working day as a mother with two children working shifts as follows:

You can imagine how dusty it was [working at the Volvo car factory]. When I left work I, when I blew my nose, it was gray slime. My eyelashes were gray, my clothes were, everything was. At that time the machines didn't yet have suction fans. - -

I remember the last years when I was at Volvo's and my hand was hurting. It ached so much I was sometimes in tears. I had to take Treo tablets all day. Then when I got home, I can clearly remember it. There were stairs up to our flat. And by the time I got to the top stair, it was just as if I'd been drinking lead. I hadn't an ounce of energy left. He went off to work, and I was left with our son. I simply didn't have any strength left. Of course the surroundings, all that dust and noise. - Then the nights, because we worked shifts, the alarm went off at half three. The bus went at ten to five. I'd get to bed at about eleven in the evening. Didn't leave me with many hours' sleep. I ached all over. Appointment with the doctor, sleeping pills to make me sleep. The last five years I spent taking pain killers by day and sleeping pills by night. How on earth did I manage to look after the family and everything? How did everything get done? Then all of a sudden I just said if this is all there is to life, then you can keep it. So then I went to see the Volvo nurse and I began, I told her I just can't do it, this is not the job for me..$^{35}$ 
The majority of the interviewee families still observed the division of labor between men and women familiar from childhood. The mother did the cleaning, laundry, cooking and washing up. Ideally, she also baked and made the children's clothes. This was to some extent a financial necessity, but it also sprang from the values assimilated in the childhood home. For the mother, going out to work, which often meant physically strenuous shift work in a factory, combined with running the home meant a life of drudgery. Many mothers felt they were not giving their children sufficient attention: the working days were long, so they could not spend enough time with their children, and even when they were at home, they had all the household chores to see to. The feeling of inadequacy was further aggravated if the mother either did not have time or was not able to bake and cook as well like a "proper wife and mother". ${ }^{36}$

Judging from the material collected for the purposes of this study, the Finns in Gothenburg do not appear to have taken a particularly active part in society - if anything, on the contrary. Rather than a glass ceiling, it would in their case possibly be more appropriate to speak of glass walls. In this respect they differed from their counterparts in Canada. For the Finnish women in domestic service in Canada tended to be described as independentminded, stubborn and strong, and they made active efforts to improve their lot. Other nationalities were far more passive. ${ }^{37}$

The reason for the passiveness of the Finnish domestic servants in Sweden may have been their youth and the fact that it was taken for granted that, on reaching the age of 18 or becoming more familiar with their new country, they would give up their jobs as maids and seek better-paid work. Inability to speak Swedish has usually been regarded as the explanation for the Finns' passiveness, but the reasons were undoubtedly more complex. ${ }^{38}$

The fact that these Finns tended to remain outsiders in Swedish society is somewhat surprising, seeing that many came from politically active homes. Although they had, as children, been accustomed to marching in the May Day procession, for example (the majority came from left-wing homes), in Gothenburg they were content simply to watch the marchers. ${ }^{39}$ The turnout of the Swedes of Finnish descent in elections both in Sweden and Finland has traditionally been low. ${ }^{40}$ They cannot, however, be characterized as passive; their activeness just took a different form. Catherine A. Cavanaugh 
and Randi R. Warne say of Canadian women that they "have attempted to influence, use and transform formal and informal institutions or, alternatively, to create counter-institutes to more effectively meet women's needs and advance their agendas". ${ }^{41}$ The social activeness of the Finnish women in Gothenburg is likewise visible in the everyday round and the informal institutions designed to ease it.

The day-care arrangements of the Finnish children were the outcome of two factors: the absence of a well-run day-care system and their parents' wish to keep up their Finnish with a view to their possibly, even probably returning to Finland. If both parents were working shifts, they usually did different shifts; this meant they needed an outside career for only a short time when the shifts changed. Older siblings might look after their younger brothers and sisters, and neighbors would often help one another. Neighbors would also be relied on when the children were at school and needed an adult's presence before or after school. Since the Finns liked to live near one another in the same part of town, there was no shortage of Finnish neighbors willing to help. It was always possible to find a Finn who, for a small consideration, would look after children - in Finnish.

Not all worked shifts, or else they wanted the family to spend some time together. One answer was then to hire a young girl, often a close relative from Finland, to come and work as a maid. Another alternative was to find a local child minder. Many of the Finnish mothers were glad to mind neighbors' children all day while the parents were at work. One woman might have several children in her care, each coming for a different period of the day. The system suited all, because it meant a mother looking after her own children at home could earn some money and the parents of the child in day care had a Finnish-speaking child minder in a familiar environment. The day-care arrangements reinforced the sense of belonging together of both the family and the Finnish community.

This day-care arrangement was by no means a unique manifestation of the northern sense of community in Gothenburg. Franca Iacovetta gives an account of a very similar system among immigrants in Toronto and Isabel Dyck in Vancouver. ${ }^{42}$ Dyck uses the interesting concept of "neighborhood space" to describe the determined efforts of women in the suburbs to make their daily lives easier: "If a woman is able to establish a 'safe place' - 
often through child-centered networks - that fulfils her criteria of both tending and caring about her children, she is in effect able to extend her domestic workplace into neighborhood space, which, however, is carefully controlled. Controlling neighborhood space is an important means by which women may allay their value dilemma and practical difficulties they encounter in combining home and wage labor." ${ }^{\text {43 }}$

The Finns have also been very active in promoting education in Finnish in Sweden, and in this the part played by parents has been of paramount importance. Had it not been for the active role played by Finnish parents, the command of Finnish of Swedes of Finnish descent would probably be poorer. Parents have also repeatedly shown themselves to be prepared to defend school teaching in Finland when the need arises. ${ }^{44}$

\section{Two Homelands}

In her recent doctoral dissertation in folkloristics, Susanne Österlund-Pötzsch addresses the serviceability of the concept of ethnicity in contemporary research. The concept has, she says, been used so much and in such different contexts that it has, like the concept of culture, become "risky" or at least difficult in the process. The concept of ethnicity functions better as a tool for research when given a qualifier. The concept of symbolic ethnicity launched by Herbert Gans interprets the significance of the cultural heritage of the country of origin as being symbolic, rather as nostalgia for one's roots. ${ }^{45}$

At the time of the interviews, many had been living in Gothenburg for far longer than in Lapland. Yet Lapland, as a place, still occupied a focal position in their minds. Many missed the scenery even after decades in Gothenburg. Above all they longed for the elements of the landscape that were missing in Gothenburg: the wilds, the silence, the light summers and the snows of early spring. ${ }^{46}$ The significance of landscape to identity and the images attached to it has been debated by researchers representing several disciplines. The narratives of emigrants attach people, social relations and cultural orders to the landscape that place the narrator in the landscape in different ways. ${ }^{47}$ The Gothenburg Finn homesick for the scenery of Lapland is in fact also homesick for the social environment of Lapland, the way of 
life and the opportunities, the past, which no longer exist. In the words of Mauno Häyrynen, a researcher who has addressed the Finnish landscape, "the process of urbanization gradually turned the Finnish countryside into an object of nostalgia, a place of origin left behind, only to be returned to during summer holidays". ${ }^{48}$

The Finnish immigrants in Gothenburg nevertheless found in the landscape a key to adaptation. In discovering the hilly forests and lakes of the region around the city, more familiar to them than the Gothenburg seascapes, they also discovered a place where they could relax. The weekends would be spent hiking and camping. Many of the associations founded by Finns in Gothenburg focus on fishing, hiking and the sauna. Nowadays many have a summer cottage. ${ }^{49}$ During their first few years in Sweden, they nevertheless spent all their summer holidays in Finland. Then as the number of close relatives gradually dwindled, their visits grew infrequent and "discovering" the countryside around Gothenburg became all the more important. ${ }^{50}$ The Finnish and Lapland element has become increasingly symbolic. Yet certain foods associated with special days in the year are still important, and many want souvenirs in their homes to remind them of Finland and Lapland.

The Gothenburg immigrants from Lapland say that the city has gradually become "home". Many finally stopped dreaming of ever returning to Finland, often when the grandchildren came along. Yet by no means all of them intend to apply for Swedish citizenship. ${ }^{51}$ The interviewees also raised the subject of dual citizenship and minority status for Finnish. Both were topical issues at the time of the interviews, but the practical implications were not yet known. ${ }^{52}$

\section{Conclusion}

The school bell and the factory siren have not separated the Finns from one another in the Finnish suburbs of Gothenburg; if anything, the opposite has applied. The yards, clubs, Finnish associations, dance halls, shops selling Finnish food and the church are concrete meeting places for the Finns. The media supply information about events and create a sense of Finnish 
community. The local radio stations, in particular, have enhanced this sense of solidarity among the Finns of Gothenburg. They are also a channel for sharing and producing collective memories and stories, in Finnish, about Sweden. ${ }^{53}$

When I began my study of the Finns from Lapland living in Gothenburg, I had a rather naïve image of Finns toiling and suffering in sooty factories. I thought they would be lonely. My image was partly due to the ancient, 150year-old concept of an easy-going country life as opposed to the hard life of the city, Gemeinschaft vs. Gesellschaft. It was also partly moulded by the studies of Finns in Sweden made in the 1970s, such as the report on Olofström by Pertti Toukomaa in 1973. These reports, mainly stories of deprivation and misery, describe the Finns in Sweden as "white blacks" forced in public to speak in a whisper so that no one will discover their language. ${ }^{54} \mathrm{I}$ soon realized on making my first interview that the Gothenburg Finns are not unhappy; rather the opposite in fact. When asked how it felt to move from a little village in Lapland to a city suburb, one interviewee replied that it had been great. No longer did she have to spend all her time lugging firewood and water in or slops out, and the children no longer had earache because of the draughts. A bath tub more than made up for the absence of a sauna. Her answer surprised me, since I had expected her to say she missed the feeling of space in Lapland in the way I once did on moving from Lapland to Helsinki. I learnt that while one may miss the landscape of childhood, this does not necessarily mean that one would want to live there. - At least if this is not possible. 


\section{FOR THE ROAD}

1 Gerholm 1993, 11-12; Löfgren 1996, 49.

2 Talve 2004, 280, 284.

3 Andersson 2003, 200-204, 212; Biography and Society 1981, 3; Van Maanen 1988, 18-19.

4 Löfgren 1996, 53; Miller 2000, 4-6.

5 Löfgren 1996, 42; Miller 2000, 7.

6 Miller 2000, 8.

7 Inspired by Daun's memoirs (2003) I visited Båtskärsnäs on 27th December 2005. There was not even a trace of the sawmill, Båtskärsnäs was by no means a ghost town or abandoned.

8 See Löfgren 1996, 76.

9 Miller 2000, 6.

10 See Hallberg 2001, 153-155, 183-186

11 See Kalela 1984a; Kalela 1984b; Kalela \& Manninen 1985.

12 Bertaux \& Bertaux-Wiame 1981.

13 See the end of each article for information about earlier publications. I am grateful to previous publishers for the opportunity to print the articles again.

14 Van Maanen 1988, xv.

15 See Löfgren 1996, 36-38.

16 See Van Maanen 1988, 82

17 Gerholm 1993, 9.

18 See Hallberg 2001, 103-108.

19 See Snellman 1999.

20 Gerholm 1993, 19.

21 Miller 2000, 13.

22 The title of my project is "Dimensions of Sway - the Meaning of Social Networks for Finnish Migrants in Sweden". The project is financed by the Academy of Finland. The decision of the Academy of Finland n:0 211152.

23 Miller 2000, 120.

24 See Van Maanen 1988, 9.

\section{REALITY AND ROMANCE AS HISTORICAL PORTRAYALS}

\section{NOTES}

1 See Oulu Provincial Archives: Kemi Oy Archive. Meinander 1952.

2 Itkonen 1976, 42

3 Oulu Provincial Archives: Kemi Oy Archive. Linkola 1939, 215.

4 Tradition Archive of Finnish Literature Society. Lumberjack Traditions 1969. 
5 University of Turku: Department of Sociology. Niemelä 1982, 65

6 University of Turku: Department of Sociology. Niemelä 1982, 4-5.

7 Antrila 1974, 35

8 Junttila et.al. 1974, 10.

9 Suomen virallinen tilasto XXXIIIIV, 6.

10 Heinonen 1984, 126-128.

11 Oulu Provincial Archives: Kemi Oy Archive. Meinander 1952, 122.

12 Church records of the community of Sodankylä. Register of marriages 1881-1915.

13 Peltonen 1991.

14 Peltonen 1991.

15 See Jansson 1984

16 Heinonen 1984, 9

17 See Calder 1974; Wright 1977

18 Dary 1981, 275-334.

19 E.g. Films: Two lumberiacks 1954.

\section{SYMBOLS OF POWER AND NOSTALGIA}

1 Professor IImar Talve discussed the subject in his inaugural lecture in 1963. Talve 1963, 138

2 E. g. Talve 1961; Talve 1978; Eenilä 1965, Niemi 1970; Snellman 1988; Snellman 1989; Snellman 1990.

3 For example, the University of Turku (Department of Sociology) in 1959, the Finnish Literature Society (Folklore Archive) in 1969 and the University of Helsinki (Department of Ethnology) in 1989.

4 See Material Anthropology 1987; Nason 1987, 58-59.

5 Oulu Provincial Archives: Kemi Oy Archive. Berättelse öfver flottningen af stock i Kemi elf under femårsperioden 1901 05,5 .

6 Oulu Provincial Archives: Kemi Oy Archive. Linkola 1939, 293; Oulu Provincial Archives: Kemi Oy Archive. Meinander 1952, 164; Itkonen 1976, 144.

7 Further details of the buildings of floating workers dwellings are given in e.g. the following: Snellman 1914, 217-219; Skogarbetarnas levnads- och arbetsförhållanden... 1916, 389; Talve 1961, 282; Ropponen 1985, 78; Ylinen 1980, 28; Lehonkoski 1987, 48, 56; Paasio 1951, 38; Niemi 1970, 136; Purhonen 1960, 113-114.

8 As Mats Ahlund and Lasse Brunnstöm have stated: "Den enklaste, organiserade bolabssamhållstypen är lagret. Bolagslagret kan vara ett medvetet utladt provisiorium eller ett komplett men ändå rorligt minisamhälle som används i samband med exploaterinfgen än en råvara". (Ahnlund \& Brunnström 1987, 11-13.)
9 Snellman 1914, 218.

10 Oulu Provincial Archives: Kemijoki Floating Association Archive. Buildings owned by the Kemi River Floating Company in 1969

11 Oulu Provincial Archives: Kemiijoki Floating Association Archive. Files of the floating camps.

12 Mäkilä 1987, 32.

13 On the occupation structure of the population of Lapland see Massa 1983

14 On the development of the forest industry in Lapland see Ahvenainen 1984; Itkonen 1976.

15 The empirical data in this chapter are given in more detail in my unpublished paper, see University of Helsinki: Department of Ethnology. Snellman 1990.

16 Not all the camps follow the pure row-house layout. The following is a more detailed account of the various types of camp. The simplest camp consisted of a single square room, possibly with a corner divided off by a flimsy partition for the cook. The same room was used for cooking, eating, sleeping and spending free time. Camps such as this were built, for example, on shores of rocky rapids requiring constant supervision and the presence of a few men. If necessary a larger group of men might be called in to work near the camp, but the number of people spending the night there was always small. (See e.g. Pälsi 1923, 136.) Most of the camps had several rooms, the use of which was more widely differentiated than in the one-roomed camps. The buildings were also larger. The layout of the camps was either that of the pure row house with two or three rooms in a row, each with their entrance from a corridor-like veranda, or that of a room and entrance hall, less frequently two rooms with a hall in between. In the basic room-andentrance-hall a small veranda led to an entrance hall which had a door into a living room running the width of the building frame and a foreman's room behind the entrance hall. The camps built at the beginning of the century were influenced by the row house plan in that both the living room and the entrance hall had their own entrances from a corridor-like veranda. Next to the hall there might be a little room for the cook. This type of building was thus differentiated in the same way as the row house type. One variation on the two-roomed dwelling was the camp with a living room on one side of the entrance and the hall room behind it and two bedrooms on the other side. The living room took up about half the entire building area. See University of Helsinki: Department of Ethnology. Snellman 1990, 100-118.

17 Bedal 1976, 176.

18 Oulu Provincial Archives: Kemiioki Floating Association Archive. Kemi River Floating Company Board of Management. Meeting 26.5.1933. 
19 Since there were no telephone lines in northern Finland, the logging companies had to build their own. In 1874 the Senate gave permission for a telephone line to be built from Tornio to Rovaniemi. This line had branches to Karihaara and Laitakari, where the Kemi Oy sawmills were situated. In 1904 the Senate also gave Kemi Oy permission to build a telephone line from Rovaniemi to Kemijärvi and in 1909 to Sodankylä. (Oulu Provincial Archives: Kemi Oy Archive. Documents on the building of the telephone lines.)

20 The temporary timber dwellings continued to be important in providing shelter for the men engaged in stream and river floating until the Second World War, when their place was increasingly taken by army tents. The simplest form of shelter has neither a roof nor walls and the beds were no more than conifer branches. Heat was provided by a camp fire consisting of two dead tree trunks one on top of the other (fi. rakovalkea). Such fires could be lit anywhere, so rest stops could be established wherever was most suitable from the work point of view. If the men had to spend longer periods at the same work site, a shed with a sloping roof (fi. laavu) was built in addition to a camp fire. The shed was covered with either conifer branches or a tarpaulin. If there were several groups of men spending the night round the same fire, two sheds were built facing one another, with the fire in between. This made a 'floating shelter' (fi. uittokota). Sometimes these shelters were made of logs if they were to be used for a longer period. See University of Helsinki: Department of Ethnology. Snellman 1990, 56 63; The National Board of Antiquities: Collections of the Workers' Culture Project. Documentations of floating on the Kemi River in 1986/ Hanna Snellman.

21 Alapuro \& Alestalo 1973, 89-90; Härö 1984

22 E.g. Perä-Pohjolainen 11/1887; 42/1889; 52/1889; 139/ 1904; Suomen Virallinen Tilasto xxxii 1923; Snellman 1914; Leutschaft 1927; Sohlman 1927.

23 A quotation from an annual report reflects the atmosphere at the turn of the century:" Vi anse oss ännu börja påpeka svårigheterna med arbetsfolket i de trakter den bolagets affärsbedrivfes, i det hittills icke lyckats få mera än en obetydlig del av folket att quarstå såsom en ständing, pålitlig arbetarestom. Större delen har kommit och gått, arbetat en tid, strejkat en annan och har mäst ersättas av nytt ovant folk, vilket allt självfallet fördyrat arbetskostnaderna." (Oulu Provincial Archives: Kemi Oy Archive. Berättelse öfver travarubolaget Kemis verksamhet år 1895.)

24 Oulu Provincial Archives: Kemijoki Floating Association Archive. Files of the floating camps.

25 Oulu Provincial Archive: Hanna Snellman's Archive. Interviews.

26 The National Board of Antiquities: Collections of the Workers' Culture Project. Documentation of floating on the Kemi River in 1986/Hanna Snellman.
27 Two investigations into the social conditions of lumberiacks and floating workers were made at the beginning of the century according to Scandinavian example: see Snellman 1914; see Suomen Virallinen Tilasto xxxii 1923.

28 The National Board of Antiquities: Collections of the Workers' Culture Project. Documentation of floating on the Kemi River in 1986/Hanna Snellman.

29 The influence may have some from military barracks. In Sweden barracks with side corridors were among the most common types of military barracks from the 1860s to the 1950s (Berg 1981, 49).

30 For a history of salmon fishing on the River Kemi see Vilkuna 1974.

31 Oulu Provincial Archives: Kemi Oy Archive. Linkola 1939, 293.

32 Oulu Provincial Archives: Kemi Oy Archive. Meinander 1952a, 167

33 Sirelius 1906, 253-268.

34 Cf. e.g. churches and workers' community halls.

35 Junttila \& et.al. 1974, ground plans.

36 Suomen Asetuskokoelma 159/1928.

37 Andersen 1932, 12.

38 Kortfattad handledning... 1921.

39 See Rosander 1990.

\section{THE SURPRISE OF SIMILARITIES}

1 See e.g. Fjellström 1970; Nilson 1975; Tuomi-Nikula 1989.

2 A:son Palmqvist 1984.

3 Erixon 1956, 56-68.

4 Signe Betsinger as quoted in A:son Palmqvist Lena 1984, 64.

5 Claire Selkurtt as quoted in A:son Palmqvist Lena 1984, 64.

6 Jordan \& Kaups 1989

7 See Carlsson 1964, 43-63; Sejersted 1980, 170, 194.

8 Sejersted 1980, 192.

9 Oulu Provincial Archive: Kemi Oy Archive. Linkola 1939, 37; Sejersted 1980, 182

10 Oulu Provincial Archive: Kemi Oy Archive. Linkola 1939, 38.

11 Oulu Provincial Archive: Kemi Oy Archive. Linkola 1939, 48.

12 See Sejersted 1980; Werner-Hansen 1970.

13 Oulu Provincial Archive: Kemi Oy Archive. Linkola 1939, 148

14 See Jensen 1945, 33

15 Brown 1934, 12, 54

16 Skogarbetarnas levnads- och arbetsförhållanden...1916, 196,398

17 Siirtolaisuuden ja maassamuuton tutkimus 1984, 11. 
18 Hunnisett 1989, 6; Siirtolaisuuden ja maassamuuton tutkimus 1984, 17; Ljungmark 1991, 8.

19 See e.g. Roinila 1992, 15.

20 See University of Helsinki: Department of Finnish. Horila 1936; Talve 1961; Snellman 1990, 3.

21 Pelkonen 1989, 14-18.

22 Oulu Provincial Archive: Kemi Oy Archive. Linkola 1939, 109

23 Sejersted 1980, 192.

24 Skogarbetarnas levnads- och arbetsförhållanden...1916, 18; Rehnberg 1953, 147, 149, 150.

25 Lento 1956, 138, 140

26 Wackerman 1949, 67-68.

27 Church records of the community of Sodankylä. Register of marriages1881-1915.

28 E.g. Sejersted 1980; Werner-Hansen 1970.

29 E.g. Antila 1974.

30 Skogarbetarnas levnads- och arbetsförhållanden 1916, 150-152, 169, 197-200; Snellman 1990, 190-191, 202.

31 Rehnberg 1953, 147.

32 Mørkyed 1978, 38.

33 Skogarbetarnas levnads- och arbetsförhållanden... 1916, 38; Bryant 1923, 71; Ahnlund \& Brunnstöm 1987, 12; Minnesota Historical Society: Roots: Timber, 26.

34 Jensen 1945, 38; Minnesota Historical Society: Drake 1989, 3-9.

35 The National Board of Antiquities: Collection of the Workers' Culture Project. Documentation of floating on the Kemi River in 1986/Hanna Snellman; Oulu Provincial Archives: Hanna Snellman's Archive. Interviews.

36 Snellman 1990, 263

37 Bryant 1923, 61-63

38 Correspondence with Dwight Gessie in August, 1989

39 Further details of the building of long camps in northern Finland are given in e.g. Junttila \& et.al. 1974.

40 University of Turku: Department of Sociology. Eenilä 1967, 215

41 See Snellman 1992, 20

42 Jensen 1945, 88

43 University of Turku: Department of Sociology. Niemelä 1982, $4-5$.

44 Andersen 1932, 12

45 Kortfattad handledning... 1921.

46 Suomen Asetuskokoelma 1928.

47 Bryant 1923, 70, 76; Skogarbetarnas levnads- och arbetsförhällanden... 1916, 398.

48 See Snellman 1989.

\section{THE CHALLENGE OF DIFFERENCES}

1 Connerton 1989, 73-74; Gjesdal-Chiristensen 1979; Humphrey 1974; Löfgren 1982, 36-39; Rapoport 1976, 1317; Rapoport 1990, 9; Waterson 1991, xv-xvi, 167-168.

2 See Ehn \& Löfgren 1982, 49-51; Hellspong 1987, 33; Lönnqvist 1989; Nurmi 1989, 84-90; Nylen 1962, 88, 110; Siivonen 1993.

3 Lundin 1991, 34; See Nurmi 1989, 148; Peterson 1993.

4 See Connerton 1989, 10-12; Jacobson 1993, 96-97, 102103, 114-115; Lundin 1991, 35

5 See Lehtonen 1994, 136.

6 Lehtonen 1982, 609; Talve 1983, 456.

7 See Leimu 1976, 87, 94-96.

8 Lainio 1981, 53-56.

9 Eenilä 1965, 179-180.

10 See photographs in "Suomen vapaussota kuvissa 1", s. 83, $119,147,163,183,185$; "Suomen vapaussota kuvissa 2", s. $18,19,31,34,35,36,39,63,227,263$; Roudasmaa $1986,29,33,43,51,62,95$.

11 Talve 1961, 283

12 Karonen 1995, 30.

13 Hagberg 1976, 124.

14 See Kilpi 1989, 38.

15 See Pöysä 1997, 89

16 See Korhonen 1985; Leimu 1977, 78; Pälsi 1923, 173; Talve 1961,285

17 Tradition Archive of Finnish Literature Society: Lumberjack Traditions 1969; Valonen 1952, 137.

18 Immonen 1996, 210.

19 Talve 1961, 285

20 Pöysä 1997, 176.

21 See Frykman 1993, 21, 23, 117, 131.

22 Kuusanmäki 1966, 537.

23 Haatanen 1968, 193.

24 See Snellman 1996, 144.

25 Borda \& Lundin 1986, 67-69, 82.

26 See Brück 1984, 76; Ehn \& Löfgren 1982, 53-55; Gudeman 1986, 6-9, 17, 21-22; Sörlin 1981, 223. 


\section{SAD HISTORIES}

1 Gustavsson 1980, 31-32; Lehtonen 1995, 177.

2 Apo 1984a, 9-10; Apo 1984b, 153

3 Gerholm 1993, 19.

4 Frykman 1977.

5 This article is based on a paper presented at the Second European Social Science History Conference in Amsterdam, 7th March 1998.

6 See Snellman 2005.

7 This paper is an experiment inspired by Carlo Ginzburg's article "The Inquisitor as Anthropologist", published in Clues, Myths and the Historical Method 1992. Ginzburg writes: "The analogy which is the subject of this brief essay struck me for the first time several years ago in Bologna while I was attending a colloquium on oral history. Historians of contemporary European societies and distinguished Africanists and anthropologists were debating the different ways of dealing with oral evidence. Suddenly it occurred to me that even historians of early modern Europe - a noncontemporary society which has left enormous amounts of written evidence - sometimes use oral sources, or, more precisely, written records of oral speech. For instance, the judicial proceedings of lay and ecclesiastical courts might be comparable to the notebooks of anthropologists, recorded centuries ago."

8 See Johansson 1994; Snellman 1996

9 Snellman 1996, 56-75.

10 Enbuske 1997, 88-89.

11 E.g. Ahvenainen 1970; Enbuske 1997; Snellman 1996.

12 Snellman 1989.

13 Matti Enbuske from the University of Oulu has kindly provided me with this information.

14 Snellman 1996, 187

15 Heikinheimo \& Ristimäki 1956, 17

16 Häkkinen 1995, 70.

17 On war orphans (altogether about 20,000 after the Civil War) see Pulma 1987, 126-136.

18 Oulu Provincial Archives: Juridical Archive of Rovaniemi Sign. CIIlc:2.

19 Snellman 1996, 192-198.

20 Oulu Provincial Archives: Juridical Archive of Rovaniemi. Sign. Cllle.l.

21 Häkkinen 1995, 20

22 Oulu Provincial Archives: Juridical Archive of Rovaniemi. Sign. CIIlc:1.

23 Oulu Provincial Archives: Juridical Archive of Rovaniemi. Sign. CIIlc:2

24 Häkkinen 1995, 120, 171

25 Oulu Provincial Archives: Juridical Archive of Rovaniemi. Sign. CIIlc:2
26 Oulu Provincial Archives: Juridical Archive of Rovaniemi. Sign. Cllle:1.

27 Oulu Provincial Archives: Juridical Archive of Rovaniemi. Sign. CIllc:2.

28 Oulu Provincial Archives: Juridical Archive of Rovaniemi. Sign. Clllc:2.

29 Oulu Provincial Archives: Juridical Archive of Rovaniemi. Sign. CIIIc:2.

30 E.g. Tradition Archive of Finnish Literature Society: Lumberjack Traditions 1969.

31 Tradition Archive of Finnish Literature Society: Lumberjack Traditions 1969

32 On the system, see Pulma 1986, 113.

33 Oulu Provincial Archives: Juridical Archive of Rovaniemi. Sign. CIIIc:2.

34 Oulu Provincial Archives: Juridical Archive of Rovaniemi. Sign. CIIIc:2.

35 Gray 1971, ix

36 On prohibition (1919-1932), see Peltonen 1997, 96.

37 On similar unlicensed saloons in Helsinki, see Häkkinen 1995,57

38 On the vicious circle of prison, hospital and alcoholism, see Häkkinen 1995, 112, 171, 178-182, 188-189.

39 Häkkinen 1995, 9.

40 On the tasks of women in a rural setting, see Isacson 1994, 58-62.

\section{DOING FIELDWORK}

See e.g. Gerholm 1993; Kalela 1991; Yocom 1990.

2 See Lönnqvist 1989, 31

3 See Snellman 1989.

4 The dissertation was published in 1996. See Snellman 1996.

5 See Gaunt 1991

6 My research was part of a Nordic project known as "Cultural Processes in Nordic Forest Regions".

7 See Women in the Field 1986, 10-11; Furnham \& Bochner 1994.

8 See Applebaum 1981, 17.

9 See Sariola 1954, 11-13.

10 See Johansson 1989; 1990; 1994.

11 See Yocom 1990.

12 Easterday et.al. 1986

13 Of similar experiences, see Gustavsson 1993, 48.

14 See Edelsward 1991.

15 Easterday et.al. pay attention to this advantage, too. See Easterday et.al. 1986, 66.

16 See Easterday et.al. 1986, 66.

17 See Snellman 1989 


\section{TELLING MIGRATIONS}

Talve 1990, 413.

About Salla, see Ingold 1984; Ingold 1988.

Ingold 1984, 119 - 123.

4 Korkiasaari 2000, 146-147.

Korkiasaari 2000, 149.

Korkiasaari 2000, 158, 164.

Reinans 1996, 66.

8 Korkiasaari 2000, 159, 169, 174.

9 De Geer 1980, 3, 6.

10 Korkiasaari 2000, 152.

11 Kuosmanen 2001, 89-96.

12 Informants born in 1931, 1932, 1933, 1937, 1939, 1940, $1941,1944,1945,1946,1947,1948,1949,1951,1953$, $1954,1955,1958,1959$.

13 Informants born in 1946, 1949, 1951, 1951, 1953, 1958.

14 Informants born in 1941, 1959.

15 Informant born in 1946.

16 Informants born in 1951 and 1953.

17 Informant born in 1953

18 Informants born in 1932, 1939, 1944 and 1953.

19 Informant born in 1944.

20 Informant born in 1953.

21 Informant born in 1937.

22 Informant born in 1944.

23 Informant born in 1937.

24 Informant born in 1954.

25 Informants born in 1932, 1933 and 1939.

26 Informants born in 1931, 1939 and 1949.

27 Informant born in 1944.

28 Informant born in 1946.

29 Informants born in 1945, 1948, 1949, 1949, 1953, 1953.

30 Informant born in 1932.

31 Informants born in 1932, 1932, 1937, 1937, 1939, 1944, $1945,1947,1947,1948,1949$

33 Informants born in 1937, 1951, 1954, 1957, 1965.

33 Informants born in 1939, 1946, 1950, 1951, 1955, 1958.

34 Informants born in 1937, 1941, 1941, 1944, 1948.

35 Informants born in 1945, 1948, 1949, 1949, 1953, 1953.

36 Informants born in 1944 and 1945.

37 Informant born in 1951 .

38 Informant born in 1945.

39 Korkiasaari 2000, 140-141.

40 Snellman 1999, 202.

41 See also Hansen 1998.

42 Korkiasaari 2000, 141; Rannikko 1999, 216; Snellman 1999, 197.

43 Hoikkala 1999, 399; Ingold 1984, 132-133.

\section{THE FINNISH WORKER IN SWEDEN}

1 The Archive of the Finnish Minority in Sweden: Metal workers' tradition. Sign.2/87.

2 My article is part of an ongoing studies financed by the Academy of Finland and is entitled "Dimensions of Sway the Meaning of Social Networks among the Finnish Migrants in Sweden". The decision of the Academy of Finland no. 211152.

3 Snellman 2003, 27.

4 Toukomaa 1973, 1-2, 5-6.

5 Toukomaa 1973, 39-40.

6 Toukomaa 1973, 45-46.

7 Toukomaa 1973, 49.

8 Suutari 2000, 36.

9 Rosengren 1975; Velure 1975.

10 Bordegård 1978, 125.

11 Rosengren 1975, 25-26.

12 Rosengren 1975, 21.

13 Interview in Västerås 18.2.2005/Hanna Snellman.

14 Ahrne \& Roman \& Franzén 2000, 38.

15 Velure 1975, 6, 8

16 Velure 1975, 8.

17 Velure 1975, 6-7, 9.

18 Velure 1975, 10-12.

19 Teräs 2001, 47-48.

20 Steen 1980, 104, 127-130.

21 Koiranen 1966, 71-74.

22 Jaakkola 1983, 101.

23 Talve 2004, 280, 284.

24 Tyrfelt 1975.

25 Snellman 1996, 30.

26 Lehtonen 2004, 5-11.

27 Nilsson 1999, 98-114.

28 Lehtonen 1972, 162; See also Löfgren 1999, 22-117.

29 Daun 2003, 96.

30 Mahilainen 1987, 23-26; Snellman 2003, 55.

31 Korkiasaari 2000, 174-175.

32 Ågren 2002, 122-142.

33 Tammenoksa 1972, 52, 56.

34 University of Helsinki: Department of Ethnology. Oral History Collections. Sign. 139.

35 Ylärakkola 1972, 82.

36 Talve 2004, 234

37 Korkiasaari 2000, 213; See also Ylärakkola 1972, 82.

38 Möller 1986, 189, 240-262; Talve 2004, 226-227.

39 Tammenoksa 1972, 47-67, 48; Korkiasaari 2000, 135200. 
40 Suomalainen Ruotsissa 1969, 21-24; Suomalainen Ruotsissa 1976, 27-28.

41 Tema invandrare 1984, 112-113.

42 Hormia et al. 1972, 34-35; Tammenoksa 1972, 47; Knocke 1986, 168-170; See also Leiniö 1979, 68

43 The Archive of the Finnish Minority in Sweden: Metal workers' tradition. Sign.22/87.

44 The Archive of the Finnish Minority in Sweden: Metal workers' tradition. Sign.3/87.

45 The Archive of the Finnish Minority in Sweden: Metal workers' tradition. Sign.8/87.

46 Lusto Finnish Forest History Museum: Interviews in Gothenburg; Knocke 1986, 181

47 The Archive of the Finnish Minority in Sweden: Metal workers' tradition. Sign.39/87.

48 The Archive of the Finnish Minority in Sweden: Metal workers' tradition. Sign.16/87.

49 The Archive of the Finnish Minority in Sweden: Metal workers' tradition. Sign. $55 / 87$.

50 The Archive of the Finnish Minority in Sweden: Metal workers' tradition. Sign.73/87.

51 The Archive of the Finnish Minority in Sweden: Metal workers' tradition. Sign.16/87; sign.55/87.

52 Jaakkola 1983, 101-106.

53 The Archive of the Finnish Minority in Sweden: Metal workers' tradition. Sign.16/87.

54 Ehn 1989, 92-107.

55 Ehn 1989, 227-240.

56 Klintberg 1989, 171-181.

57 Frykman 1999, 120-160.

58 Ruotsin suomalaiset 1972.7.

\section{LONGING FOR HOME}

1 Löytönen 1999, 57-60.

2 Korkiasaari 2000, 157

3 Suutari 2000, 41

4 Snellman 2003.

5 See Löfgren 1996, 77-87.

6 Lusto Finnish Forest History Museum. Interviews in Gothenburg; Oulu Provincial Archives: Hanna Snellman's Archive. Interviews.

7 See Berg 1994, 95; Kettunen-Hujanen 2000, 167; Szabó $1989,23$.

8 The diary entries were written between September 24, 1969 and April 15, 1971. Ulla's Diary.

9 The Archive of the Finnish Minority in Sweden: Oral history collections. sign. 50/87.
10 Wolf-Knuts 2000, 46, 54, 66, 67 .

11 Berg 1994, 67, 76

12 Londos 1993, 31, 34

13 Wolf-Knuts 2000, 138.

14 Gullestad 1984, 87.

15 Suojanen 1996, 107-108.

16 Londos 1993, 39, 184.

17 See Wolf-Knuts 1995, 21

\section{A THOUSAND LIFE STORIES}

1 See Klippenstein 2000, 200.

2 Metsäammattilaiset metsätalouden muutoksessa 2002.

3 A doctoral dissertation in ethnology by Leena Paaskoski at the University of Helsinki on the changing professional culture of degree foresters, a doctoral dissertation in ethnology by Katri Kaunisto at the University of Helsinki on forestry professionals in a changing forest economy, a doctoral dissertation in cultural anthropology by Tiina Suopajärvi on the relationship with nature of white-collar workers in the forest sector, and a doctoral dissertation in sociology by Tuija Alariesto at the University of Lapland on structural change in the forest sector on Lapland.

4 Snellman 2003

5 See Snellman 2002.

6 Hareven 1982, 1-5.

7 Blandsverige 1988, 10.

8 See Österlund-Plötzsch 2003, 17-18.

9 See Salmi 1996, 212-213.

10 See Kortteinen 1982; Ahponen \& Järvelä 1983.

11 This article is part of an ongoing studies financed by the Academy of Finland and is titled "Dimensions of Sway the Meaning of Social Networks for the Finnish Migrants in Sweden". The decision of the Academy of Finland no. 211152.

12 The interviewees were born between 1931 and 1965 .

13 The interviewees have been assigned fictitious names.

14 See Hoikkala 1999, 401

15 Snellman 2003, 57.

16 Silvasti 2001, 97, 103

17 Lusto Finnish Forest History Museum: Interviews in Gothenburg.

18 Arbetets etniska delning 1994, 47, 58, 65

19 E.g. Lusto Finnish Forest History Museum: Interviews in Gothenburg.

20 The Archive of the Finnish Minority in Sweden: Metal workers' tradition 1986-1987. sign. 39/87. 
21 See Berg 1994, 131; Mörck 1991, 54; Arbetets etniska delning 1994, 13.

22 lacovetta 1997, 29

23 E.g. Lusto Finnish Forest History Museum: Interviews in Gothenburg.

24 Lusto Finnish Forest History Museum: Interviews in Gothenburg.

25 Arvastson 1987, 118; Arbetets etniska delning 1994, 11, The Archive of the Finnish Minority in Sweden: Metal workers' tradition 1986 - 1987. sing. 16/87; sign. 39/87; sign $65 / 87$; sign $73 / 87$.

26 See e.g. Radforth 1998; Lindström 1998

27 See Snellman 1996, 208.

28 E.g. Lusto Finnish Forest History Museum: Interviews in Gothenburg.

29 Lusto Finnish Forest History Museum: Interviews in Gothenburg.

30 See e.g. Karjalainen 1976. A comprehensive study has, by contrast, been made of Finnish women in domestic service in Canada. See Lindström-Best 1988.

31 Lusto Finnish Forest History Museum: Interviews in Gothenburg.

32 Lusto Finnish Forest History Museum: Interviews in Gothenburg.

33 Oulu Provincial Archives: Hanna Snellman's Archive. Interviews.

34 Lusto Finnish Forest History Museum: Interviews in Gothenburg.

35 Lusto Finnish Forest History Museum: Interviews in Gothenburg.

36 Oulu Provincial Archives: Hanna Snellman's Archive. Interviews; See Kinnunen \& Korvajärvi 1996, 9

37 Klippenstein 2000, 203; Linström 1998, 179-183.

38 See e.g. Koiranen 1966, 71-74; Jaakkola 1983, 101.

39 See e.g. Lusto Finnish Forest History Museum: Interviews in Gothenburg.

40 Korkiasaari 2000, 208-211.

41 Cavanaugh \& Warne 1993, 11

42 Dyck 1992, 189-191; lacovetta 1995, 155.

43 Dyck 1992, 173

44 Lainio \& Wande 1996, 360-370; Luokan kynnyksen yli 1993; Rodrigo Blomqvist 2002.

45 Österlund-Plözsch 2003, 77-78.

46 Lusto Finnish Forest History Museum: Interviews in Gothenburg.

47 Huttunen 2002, 28

48 Häyrynen 2004, 119
49 Lusto Finnish Forest History Museum: Interviews in Gothenburg.

50 Lusto Finnish Forest History Museum: Interviews in Gothenburg.

51 Lusto Finnish Forest History Museum: Interviews in Gothenburg. See also Brnic 2002.

52 Oulu Provincial Archives: Hanna Snellman's Archive. Interviews; Lusto Finnish Forest History Museum: Interviews in Gothenburg.

53 See Snellman 2003, 195-222.

54 Toukomaa 1973 
ORAL HISTORY MATERIAL

The Archives of the Finnish Minority in Sweden, Stockholm Metal workers' tradition 1986-1987

Oral History Collection

Lusto Finnish Forest History Museum, Punkahariu Interviews in Gothenburg (Mepe A02001)

Oulu Provincial Archive, Oulu Hanna Snellman's Archive

Interviews (uncatalogued collection)

\section{SOURCES}

Tradition Archive of Finnish Literature Society, Helsinki Lumberjack Traditions 1969 


\section{UNPUBLISHED SOURCES}

Church records of the community of Sodankylä Register of marriages 1881-1915

Correspondence with Dwight Gessie 1989. Parks and Recreation Department, the Corporation of the City of Thunder Bay, Canada.

Diaries and letters

Ulla's diary, Private Collection, Salla

Films

Two Lumberjacks. SF Suomen Filmiteollisuus 1954

Minnesota Historical Society, St. Paul

Roots: Timber. An unpublished paper.

Drake, Robert M. 1989: Wanigan report. An unpublished paper.

The National Board of Antiquities, Helsinki Collections of the Workers' Culture Project

Documentation of floating on the Kemi River in 1986/Hanna Snellman. Unpublished field work material

Oulu Provincial Archives

Juridical Archive of Rovaniemi

Kemijoki Floating Association Archive

Buildings owned by the Kemi River Floating Company in

1969

Files of the floating camps

Kemi River Floating Company Board of Management,

Meetings
Kemi Oy Archive

Berättelse öfver flottningen af stock i Kemi elf under femårsperioden 1901-05

Berättelse öfver travarubolaget Kemis verksamhet år 1895 Documents on the building of the telephone lines Linkola, Yrijo 1939: Kemi Oy 1893-1939. Unpublished manuscript (in Finnish)

Meinander, Nils 1952: Historiken av Ab Kemi Oy. An

unpublished manuscript

University of Helsinki

Department of Ethnology, Archive

Oral History Collections. Sign. 139

Snellman Hanna 1990: Kemijoen vesistön uittotukikohdat. Licentiate thesis. An unpublished paper

Department of Finnish, Archive Horila Tapio 1936: Suomalaista tukkilaissanastoa. Thesis. An unpublished paper

University of Turku

Department of Sociology

Niemelä Jukka 1982: Leivän isä vastaan Lapin jätkä. Sosiologinen tutkimus Kemiyhtiön metsä- ja vitto työläisten lakkoliikkeestä v. 1906. Thesis. An unpublished paper

Eenilä Jukka 1967: Suomen metsätyö ja metsätyöläiset 1880-1928. Licentiate thesis. An unpublished paper 
Ahnlund, Mats \& Brunnström, Lasse 1987: Från Dawson till Pullman. Nordamerikanska bolagsamhällen - en översikt. Bebyggelsehistorisk tidskrift 13/1987. Historiska institutionen.

Ahponen, Pirkkoliisa \& Järvelä, Marja 1983: Maalta kaupunkiin, pientilalta tehtaaseen. Tehdastyöläisten elämäntavan muutos. Porvoo: WSOY.

Ahrne, Göran \& Roman, Christine \& Franzén, Mats 2000: Det sociala landskapet. En sociologisk beskrivning av Sverige från 50-tal till 90-tal. Göteborg: Bokförlaget Korpen.

Ahvenainen, Jorma 1970: Rovaniemen historia II 1632-1960. Rovaniemi.

— 1984: Suomen sahateollisuuden historia. Porvoo: WSOY.

Alapuro, Risto \& Alestalo, Matti 1973: Konkreettinen sosiaalitutkimus. - Suomalaisen sosiologian juuret. Eds. Risto Alapuro \& MAtti Alestalo \& Elina Haavio-Mannila. Porvoo: WSOY.

Andersen, Sønnik 1932: Undersökelse av skogshytter og skogarbeidernes levevillkår. Oslo.

Andersson, Oscar 2003: Chicagoskolan. Institutionaliseringen, idétraditionen \& vetenskapenen. Lund monographs in social anthropology 11. Lund: Sociologiska institutionen, Lund universitet.

Anttila, Veikko 1974: Talonpojasta tuottajaksi. Suomen maatalouden udenaikaistuminen 1800-Iuvun lopulla ja 1900-Iuvun alkupuolella. Helsinki: Kirjayhtymä.

Apo, Satu 1984a: Kansankulttuurimme kaksi kuvaa. - Kotiseutu 1/1994. Suomen Kotiseutuliitto.

— 1984b: Ei unohdeta Ilmar Talvea. - Kotiseutu 3/1984. Suomen Kotiseutuliitto.

Applebaum, Herbert A. 1981: Royal Blue. The Culture of Construction Workers. New York: Holt, Rinehart and Winston.

Arbetets etniska delning. Studier från en svensk bilfabrik. Eds. Carl-Ukrik Schierup \& Sven Paulsson. Stockholm: Carlssons 1994.

Arvastson, Gösta 1987: Maskinmänniskan. Arbetets förvandlingar i 1900-talets storindustri. Göteborg: Bokförlaget Korpen. 
A:son Palmqvist, Lena 1984: Byggnadstraditioner i Minnesotas Svenskbygder. Kontinuitet och förnyelse. - Bebyggelsehistorisk tidskrift 8/1984. Historiska institutionen.

Bedal, Konrad 1976: Gefüge und Struktur. Zu Standort und Arbeitsweise volkskundlicher Hausforschung. - Zeitschrif für Volkskunde 1976/11. Waxmann Verlag.

Berg, Ejnar 1981: Kaserner, baracker och hyddor. Svenska soldatboningar under fyra århundraden. Armémusei skrifter 3. Stockholm: Almqvist \& Wiksell.

Berg, Magnus 1994: Seldas andra bröllop. Berättelser om hur det är: turkiska andragenerationsinvandrare, identitet, etnicitet, modernitet, etnologi. Skrifter från Etnologiska föreningen i Västsverige 18. Göteborg: Etnologiska föreningen Västsverige.

Bertaux, Daniel \& Bertaux-Wiame, Isabelle 1981: Life stories in the Bake's Srade. - Biography and Society: The life history approach in the social sciences. Ed. Daniel Bertaux. Sage Studies in International Sociology 23. Beverly Hills: Sage.

Biography and Society. The life history approach in the social sciences. Sage studies in international sociology 23. Ed. Daniel Bertaux. Beverly Hills: Sage 1981.

Blandsverige. Om kulturskillnader och kulturmöten. Eds. Åke Daun \& Billy Ehn. Stockholm: Calssons 1988.

Borda, Beatriz \& Lundin, Susanne 1986: Vem får grädden på tårtan? $0 \mathrm{~m}$ samhällets subtila maktstrukturer i Pierre Bourdieus sociologi. - Rig 3/1986. Föreningen för svensk kulturhistoria.

Bordegård, Lars-Erik 1978: Finländares och svenskars levnadsvillkor. En fallstudie från Virsbo samhälle i Västmanslands län. Forskningsprojektet Migrationen Finland-Sverige. Forskningsrapport 4. Stockholm: Nordiska Museet.

Brown, Nelson Courtland 1949: Logging. The Principles and Methods of Harvesting Timber in the United States and Canada. New York: John Wiley \& sons.

Brück, Ulla 1984: Historisk antropologi. - Rig 1/1983. Föreningen för svensk kulturhistoria.

Bryant, Ralph Clement 1923: Logging. The principles and general methods of operation in the United States. New York: John Wiley \& sons.
Calder, Jenny 1974: There must be a lone ranger: the American West in film and reality. New York: Taplinger Pub. Co.

Carlsson, Sten 1964: Norrman i Sverige 1814-1905. Historielärarnas förenings årskrift 1963-1964.

Cavanaugh, Catherine A. \& Warne, Randi R. 1993: Standing on New Ground. Women in Alberta. Edmonton: The University of Alberta Press.

Connerton, Paul 1989: How Societies Remember. Cambridge: Campridge University Press.

Dary, David 1981: Cowboy Culture. A Saga of Five Centuries. New York: Knopf.

Daun, Åke 2003: Med rörligt sökarljus. Den nya etnologins framväxt under 1960- och 1970-talen. En personlig tidsskildning. Eslöv: B. Östlings bokförlag symposion.

Dyck, Isabel 1992: Integrating Home and Wage Workplace. Women's Daily Lives in a Canadian Suburb. British Columbia Reconsidered. Eds. Gillian Greese \& Veronica StrongBoag. Vancouver: Press Gang Publishers.

Easterday, Lois \& Papademas, Diana \& Schorr, Laura \& Valentine, Catherine 1986: The Making of a Female Researcher: Role Problems in Fieldwork. - Field Research: A Sourcebook and Field Manual. Ed. Robert G. Burgess. London: Allen \& Unwin.

Edelsward, Lisa-Marlene 1991: Sauna as symbol. Society and Culture in Finland. American University Studies. Series XI Anthropology and Sociology 53. New York: Peter Lang.

Eenilä, Jukka 1965: Uitto ja vittotyöläiset Paimijoen vesistössä. Scripta Ethnolocia 2. Turku: Turun yliopisto.

Ehn, Billy 1989: Konfliktundvikande mellan svenskar och invandrare. Att leva med mångfalden. En antologi från diskriminerings utredningen. Lund: LiberFörlag.

Ehn, Billy \& Löfgren, Orvar 1982: Kulturanalys. Ett etnologiskt perspektiv. Lund: LiberFörlag.

Enbuske, Matti 1997: Rovaniemen historia vuoteen 1990. Jokivarsien kasvatit ja junantuomat. Rovaniemi: Rovaniemen kaupunki, maalaiskunta ja seurakunta.

Erixon, Sigurd 1956: Är de nordamerikanska timringstekniken överförd från Sverige? - Folk liv 1955-56. 
Fjellström, Phebe 1970: Swedish-American Colonization in the San Joaquin Valley in California. A Study of the Acculturation and Assimilation of an Immigrant Group. Studia Ethnographia Upsaliensia 33. Uppsala: Institut för allmen och jämförande etnografi.

Frykman, Jonas 1977: Horan i bondesamhället. Lund: Libe Läromedel.

— 1993: Horan i bondesamhället (2nd ed.). Stockholm: Carlssons.

— 1999: Nationella ord och handlingar. - Försvenskingen av Sverige. Det nationellas förvandlingar. Eds. Billy Ehn \& Jonas Frykman \& Orvar Löfgren. Stockholm: Natur och kultur.

Furnham, Adrian \& Bochner, Stephen 1994: Culture Shock. Psychological Reactions to Unfamiliar Environments. London \& New York: Methuen.

Gaunt, David 1991: Oral history och levnadsoden. - Icke skriftliga källor. Eds. Anders Brandström \& Sune Akerman. Forskningsrapporter från Historiska Insitutionen vid Umeå Universitet 7. Umeå: Umeå univeristet.

Gerholm, Lena (ed.) 1993: Etnologiska visioner. Femton forskare reflekterar kring sitt ämne. Stocholm: Carlssons.

Ginzburg, Carlo 1992: Clues, Myths, and the Historical Method. Baltimore: John Hopkins University Press.

Giesdal-Christensen, Anne-Louise 1979: Bostad och kommunikation. - Kulturell kommunikation. Eds. Nils-Arvid Bringeus \& Goran Rosander. Lund: Signum.

Gray, James H. 1971: Red Lights on the Prairies. Toronto: Macmillian of Canada.

Gudeman, Stephen 1986: Economics as culture. Models and metaphors of livelihood. International Library of Sociology. London: Routledge \& Kegan Paul.

Gullestad, Marianne 1984. Kitchen-table Society. A case study of the family life and friendships of young working-class mothers in urban Norway. Oslo: Universitets förlaget

Gustavsson, Anders 1980: Några trender inom västtysk etnologi under 1970-talet. Småskrifter från Etnologiska sällskapet i Lund. Lund: Signum.
— 1993: Att upptacka människor. - Etnologiska visioner. Femton forskare reflekterar kring sitt ämne. Ed. Lena Gerholm. Stockholm: Carlssons.

Haatanen, Pekka 1968: Suomen maalaisköyhälistö tutkimusten ja kaunokirjallisuuden valossa. Porvoo: WSOY

Hagberg, Jussi 1976: Jätkän kirous. Kuvaus kiveliönkiertäjän elämästä. Rovaniemi: Pohjoiset kirjailijat.

Hallberg, Margareta 2001: Etnologisk koreografi. Att följa ett ämne i rörelse. Nora: Nya Doxa.

Hansen, Kjell 1998: Välfärdens motsträviga utkant. Lokal praktik och statlig styrning i efferkrigstidens nordsvenska inland. Lund: Historiska Media.

Hareven, Tamara K. 1982: Family time and industrial time. The relationship between the family and work in a New England industrial community. Interdisciplinary perspectives on modern history. Eds. Robert Fogel \& Stephen Thernstrom. Cambridge: Cambridge University Press.

Heikinheimo, Lauri \& Ristimäki, Toini 1956: Metsä- ja uittotyövoiman määrä ja rakenne. Acta Forestalia Fennica 63. Helsinki: Suomen Metsätieteellinen Seura.

Heinonen, Jouko 1984: Rovaniemen markkinat. Lapin maakuntamuseon julkaisuja 1. Rovaniemi: Lapin maakuntamuseo.

Hellspong, Mats 1987: Fältgratt och khaki. Om 1900-talets svenska armeuniformer som tidsspegel. - Rig 2/1987. Föreningen för svensk kulturhistoria.

Hoikkala, Tommi 1999: Suuret ikäluokat ja työ. - Suomalaisen työn historiaa. Korvesta konttoriin. Ed. Raimo Parikka. Suomalaisen Kirjallisuuden Seuran Toimituksia 730. Helsinki: Suomalaisen Kirjallisuuden Seura.

Hormia, Osmo \& Launikari, Jaakko \& Lounela, Paavo \& Pöysälä, Martti \& Tammenoksa, Erkki 1972: Ruotsinsuomalaiset. Nykyhetki ja tulevaisuus. Porvoo \& Helsinki: WSOY.

Humphrey, Caroline 1974: Inside a Mongolian tent. - New Society 31 October 1974. New Society Publishers.

Hunnisett, Stanley E. 1989: Opportunities for Ethnology in Finnish Migration Research. Two Pilot Projects. - Migration 1/ 1984. The Institute of Migration. 
Huttunen, Leena 2002: Kotona, maanpaossa, matkalla. Kodin merkitykset maahanmuuttajien elämäkerroissa. Suomalaisen Kirjallisuuden Seuran Toimituksia 861. Helsinki: Suomalaisen Kirjallisuuden Seura.

Häkkinen, Antti 1995: Rahasta - vaan ei rakkaudesta. Prostituutio Helsingissä 1867-1939. Helsinki: Otava.

Härö, Merja 1984: Kasarmista omakotitaloon. Asunto-ongelmien ratkaisumalleja tyoväenasuntokysymyksen kaudella. Historiallinen Arkisto 81. Helsinki: Suomen Historiallinen Seura.

Häyrynen, Mauno 2004: Countryside Imagery in Finnish National Discourse. - European Rural landscapes: Persistence and Change in a Globalising Environment. Eds. Palang, H. et al. Norwell, MA: Kluwer Academic Publisher.

lacovetta, Franca 1995: Remaking Their Lives: Women, Immigrants, Survivors and Refugees. - A Diversity of Women. Ed. Joy Parr. Toronto: University of Toronto Press.

— 1997: The Writing of English Canadian Immigrant History Canada's Ethnic Group Series Booklet No. 22. Ottawa: Canadian Historical Association.

Immonen, Kari 1996: Paperiperheen neljä päivää. - Lääkari, lukkari, talonpoika, duunari. Lukuja suomalaisten historiaan. Ed. Vuokko Aromaa. Helsinki: Otava.

Ingold, Tim 1984: The Estimation of Work in a Northern Finnish Farming Community. - Family and Work in Rural Societies: Perspectives on Non-Wage Labour. Ed. Norman Long. London: Tavistock.

- 1988: Land, Labour and Livelihood in Salla, Northeastern Finland. - The Social Implications of Agrarian Change in Northern and Eastern Finland. Ed. Tim Ingold. Suomen antropologisen seuran toimituksia 22. Helsinki: Suomen Antropologinen Seura.

Isacson, Maths 1994: Vardagensekonomi. Hedemora: Gidlunds Förlag.

Itkonen, Martti 1976. Kemijoen Uittoyhdistys 1901-1976. Kemi: Kemijoen uittoyhdistys.

Jaakkola, Magdalena 1983: Ruotsinsuomalaisten etninen järjestäytyminen. Siirtolaistutkimuksia A 12. Turku: Siirtolaisuusinstituutti.
Jacobson, Maja 1993: Att klä sig - smak, stil och symbolik. Kultur och erfarenhet. Aktuella teman i svensk etnologi. Eds. Billy Ehn et. al. Stockholm: Carlssons.

Jansson, Sören 1984: Flottarkultur. - Strömkarlarna. En etnologisk skildring av flottare i Dalälvsområdet. Eds. Sven Rydberg et.al. Dalarnas fornminnes och hembygdsförbunds krifter 28. Falun: Dalarnas Museum.

Jensen, Vernon H. 1945: Lumber and Labor. Labor in Twentieth Century America. New York: Farrar \& Rinehart.

Johansson, Ella 1989: Beautiful Men, Fine Women and Good Workpeople: Gender and Skill in Northern Sweden, 18501950. - Gender \& History. Vol. 1, No. 2. Blackwell.

_ 1990: Free sons of the forest: Storytelling and the construction of identity among Swedish lumberiacks. - The Myths We Live By. Eds. Ralph Samuel \& Paul Thompson. History Workshop series. London: Routledge.

- 1994: Skogarnas fria soner. Maskulinitet och modernitet $\mathrm{i}$ norrlandskt skogsarbete. Nordiska Museets Handlingar 118. Stockholm: Nordiska Museet.

Jordan, Terry G. \& Kaups, Matti 1989: The American Backwoods Frontier. An Ethnic and Ecological Interpretation. Creating the North American Landscape. Baltimore: John Hopkins University Press.

Junttila, Juhani \& Pasanen, Juha \& Teppo, Jorma 1974: Tukkikämppiä ja ruukinpirttejä Lapin savotoilta ajalta 1880-1930. Oulun yliopiston arkkitehtiosaston rakennustaiteen historian laitoksella v. 1970-72 suoritettu erikoistyö. Rovaniemi: Lapin Metsämuseoyhdistys.

Kalela, Jorma 1984a: Muistietotutkimus ja historialiike. - Kotiseutu 1/1984. Suomen Kotiseutuliitto.

— 1984b: Mitä on kansanomainen historia? - Kotiseutu 4/1984. Suomen Kotiseutuliitto.

— 1991: En historikers händelse. Kulturella mönster och samhälliga förhållanden i källornas läsart. - Icke skriftliga källor. Forskningsrapporter från Historiska Institutionen vid Umeå Universitet 7. Eds. Anders Brändström \& Sune Akerman. Umeå: Umeå universitet.

Kalela, Jorma \& Manninen, Pauli 1985: Mitä on oral history? Paul Thompsonin haastattelu. - Sosiologia 3/1985. The Westermarck society ry. 
Karjalainen, Pirkko 1976: Kotiapulaiset ja heidän työnantajansa. Domestic servants and their employers. Suomen virallinen tilasto 32, sosiaalisia erikoistutkimuksia 45. Helsinki: Sosiaali- ja terveysministeriö.

Karonen, Vesa 1995: Kuinka Haanpäästa tuli Haanpää? - Hiidenkivi 5. Kotimaisten kielten tutkimuskeskus: Suomalaisen Kirjallisuuden Seura: Suomen Kotiseutuliitto.

Kettunen-Hujanen, Eija 2000: Elämän pakkoraossa vai matkalla vaurauteen? Savosta, Pohjois-Karjalasta ja Kainuusta 1918-1930 muuttaneiden siirtolaisten sopeutuminen Kanadaan. Bibliotheca Historica 58. Helsinki: Suomalaisen Kirjallisuuden Seura.

Kilpi, Volter 1989: Pitäjän pienempiä. Keuruu: Gummerus.

Kinnunen, Merja \& Korvajärvi, Päivi 1996: Johdanto: Naiset ja miehet työelämässä. - Työelämän sukupuolistavat käytännöt. Eds. Merja Kinnunen \& Päivi Korvajärvi. Tampere.

Klintberg, Bengt af 1989: Etnocentriska sägner. - Blandsverige. Eds. Åke Daun \& Billy Ehn. Stockholm: Carlssons.

Klippenstein, Frieda Esau 2000: Scattered but Not Lost. Mennonite Domestic Servants in Winnipeg, 1920s-50s. - Telling Tales. Essays in Western Women's History. Eds. Catherine A. Cavanaugh \& Randi R. Warne. Vancouver: University of British Columbia Press.

Knocke, Wuokko 1986: Indvanrade kvinnor i lönearbete och fack. En studie om kvinnor från fyra länder inom Kommunal- och Fabriksarbetareförbundets avtalsomräde. Forskningsrapport 53. Stockholm: Arbetslivscentrum.

Koiranen, Vilho A. 1966: Suomalaisten siirtolaisten sulautuminen Ruotsissa. Sosiologinen tutkimus Ruotsiin vuosina 1945-1959 muuttaneiden suomenkielisten siirtolaisten kulttuurin muuttumisesta. Helsinki: WSOY.

Korhonen, Teppo 1985: Über einige Tragegerate aus Leder und Staff. - Suomen Museo 1985. Suomen Muinaismuistoyhdistys.

Korkiasaari, Jouni 2000: Suomalaiset Ruotsissa 1940-luvulta 2000-Iuvulle. - Suomalaiset Ruotsissa. Suomalaisen siirtolaisuuden historia 3. Eds. Jouni Korkiasaari \& Kari Tarkiainen. Turku: Siirtolaisuusinstituutti.
Kortfattad handledning med ritningar och beskrivningar för uppförande å skogarna av skogstugor, skogs- och flottningskojor med flera dylika bostäder åt arbetare med flera inom skogavverknings-, flottnings- och kolningsverksamhet enligt särskilt Kungl. maj:ts uppdrag utgiven av Kungl. domänstyrelsen i samråd med Kungl. socialstyrelsen. Stockholm 1921.

Kortteinen, Matti 1982: Lähiö. Tutkimus elämäntapojen muutoksesta. Helsinki: Otava.

Kuosmanen, Jari 2001: Finnkampen. En studie av finska mäns liv och sociala karriärer i Sverige. Skriftserien nr 2001:2. Institutionen för socialt arbete vid Göteborgs universitet. Hedemora: Gidlund.

Kuusanmäki, Lauri 1966: Pitäjän itsehallinto. Eripainos. - Hämeen historia 3:1. Hämeenlinna: Karisto.

Lainio, Jarmo \& Wande, Erling 1996: Finskan i utbildningsväsendet och sverigefinnarnas utbildning i Sverige. Finnarnas historia i Sverige 3. Tiden efter 1945. Ed. Jarmo Lainio. Nordiska Museets Handlingar 122. Helsinki: Suomen Historiallinen Seura.

Lainio, Jussi 1981: Lapin tarinoita. Lapin saria. Porvoo: WSOY.

Lehonkoski, Pekka 1987: W. Gutzeit \& Co:n tulo Saimaalle. Tukkimetsiä ja höyrylaivoja. Vuosisata Enso-Gutzeit Oy:n puunhankinta ja kuljetusta Saimaan alueella. Imatra: Enso-Gutzeit.

Lehtonen, Juhani U. E. 1972: U. T. Sirelius ja kansatiede. Kansatieteellinen Arkisto 23. Helsinki: Suomen Muinaismuistoyhdistys.

- 1982: Kaupungistuva kansankulttuuri. Suomen kulttuurihistoria 3. Porvoo:WSOY.

_ 1994: Valkoinen turkislakki. - Suomen Museo 1993. Suomen Muinaismuistoyhdistys.

— 1995: Abschied von der Ethnographic? Congressus Octavus Internationalis Fenno-ugristarum 10.-15.8.1995. I. Orationes plenariae et conspectus quinquennales. Jyväskylä.

— 2004: Kustaa Vilkuna - ein finnischer Volkskundler zwischen Berlin und Moskau. - Ethnologia Fennica. Finnish Studies in Ethnology, vol. 31. Ethnos ry. 
Leimu, Tuula 1976: Suomen teollisuustyöväestön työvaatteista. - Sananjalka 18. Suomen kielen seura.

— 1977: Tehdastyöläisten työpaikkaruokailusta. - Sananjalka 19. Suomen kielen seura.

Leiniö, Tarja-Liisa 1979: Finska invandrare i Sverige. Stockholm: Institutet för forskning.

Lento, Reino 1956: Väestö ja hyvinvointi. Johdatusta väestötieteeseen. Porvoo: WSOY.

Leutschaft, Kurt 1927: Waldarbeiterwohnungs- und Siedlungsfrage. Dresden.

Lindström, Varpu 1998: I Won '† Be a Slave! Finnish Domestics in Canada. - A Nation of Immigrants. Women, Workers, and Communities in Canadian History, 1840s-1960s. Eds. Franca lacovetta \& Paula Draper \&Robert Ventresca. Toronto: University of Toronto Press.

Liungmark, Lars 1991: Clifford Sifton + Nikolaj Bobrikoff $=$ Finns in Alberta. - Migration 1/1991. The Institute of Migration.

Londos, Eva 1993: Uppåt väggarna i svenska hem. En etnologisk studie av bildbruk. Stockholm: Carlssons.

Lundin, Susanne 1991: Bokstäverna som skapar världen. - Häften för kritiska studier 1991/1. Föreningen Häften för kritiska studier.

Luokan kynnyksen yli. Ruotsinsuomalaiset kirijoittavat kouluhistoriaa. Eds. Vuonokari, Erkki \& Pelkonen, Juhamatti Tukholma: Ruotsinsuomalaisten arkisto 1993

Löfgren, Orvar 1982: Kulturbygge och kulturkonfrontation. - Kultur och medvetande. En tvärvetenskaplig analys. Eds. Ulf Hannerz \& Rita Lilieström \& Orvar Löfgren. Stockholm: Akademilitteratur.

— 1996: Ett ämne välier väg. - Vardagslivets etnologi. Reflektioner kring en kulturvetenskap Eds. Billy Ehn \& Orvar Löfgren. Stockholm: Natur och kultur.

— 1999: Nationella arenor. De nationellas förvanklingar. Eds. Billy Ehn \& Jonas Frykman \& Orvar Löfgren. Stockholm Natur och kultur.

Lönnqvist, Bo 1989: Minne och glömska. Om etnologins identitet. - Kansa kuvastimessa. Etnisyys ja identiteetti. Tietolipas 114. Eds. Teppo Korhonen \& Matti Räsanen. Helsinki: Suomalaisen Kirjallisuuden Seura
Löytönen, Markku 1999. Ihmiset maisemassa. - Suomi: maa, kansa, kulttuurit. Eds. Markku Löytönen \& Laura Kolbe. Suomalaisen Kirjallisuuden Seuran Toimituksia 753. Helsinki: Suomalaisen Kirjallisuuden Seura.

Mahilainen, Seija 1987: Lämpimän uunin päällä. - Hitsikissa hiipii uuniin. Ruotsinsuomalaisten metallityöläisten kertomuksia pakkosulatuksen vuosilta. Eds. Erkki Vuonokari \& Juhamatti Pelkonen. Tukholma: Ruotsinsuomalaisten arkisto.

Massa, Ilmo 1983: Ihminen ja Lapin luonto. Lapin luonnonkäytön historiaa. Suomen antropologisen seuran toimituksia 12. Helsinki: Suomen antropologinen seura.

Material Anthropology: Contemporary Approaches to Material Culture. Eds. Barrie Reynolds \& Margaret A. Stott. Lanham: Universtiy Press of America 1987.

Metsäammattilaiset metsätalouden murroksessa. Metsäperinteen tallennushanke 1999-2002. Eds. Hanna Snellman \& Katri Kaunisto \& Leena Paaskoski. Helsinki: Metsämiesten Säätiö 2002.

Miller, Robert L. 2000: Researching Life Stories and Family Histories. Introducing qualitative methods. London: Sage.

Mäkilä, Matti 1987: Uiton muuttuminen vuosien saatossa. Lapin Metsämuseoyhdistys ry:n julkaisusarja n:0 4. Rovaniemi: Lapin Metsämuseoyhdistys.

Möller, Yngve 1986: Östen Undén. En biografi. Stockholm: Nostedt.

Mörck, Magnus 1991: Storstadens livstilar och boendekarriärer. En etnologisk intervjuundersökning från 80 -talets Göterborg. - Skrifter från Etnologiska föreningen i Västsverige 9. Göteborg: Etnologiska föreningen i Västsverige.

Mørkyed, Oddvar 1978: Litt om de gamle skogstuene i Namdalen. - Årbok för Namdalen. Namdal historielag.

Nason, James D. 1987: The Determination of Significance: Curatorial Research and private collections. - Material Anthropology. Contemporary Approaches to Material Culture. Eds. Barrie Reynolds \& Margaret A. Stott. Lanham: Universtity Press of America.

Niemi [Nurmi], Virpi 1970: Uittotöistä ja vittajista Torniojoen latvavesillä. - Torniolaakson vuosikirja 1970. Tornionlaakson neuvosto. 
Nilson, Allan T. 1975: New-Sweden, Maine. Förändringar och karateristiska hos svenskattlingar under jämförelse med några andra etniska grupper i Nordost Amerika. - Unda Maris 1973-1974.

Nilsson, Bo G. 1999: Berättelsen om det gamla klassamhället. Metod och minne. Etnologiska tolkningar och rekonstruktioner. Eds. Magnus Berbqvist \& Birgitta Svensson. Lund Studenlitteratur.

Nurmi, Virpi 1989: Lasinvalmistajat ja lasinvalmistus Suomessa 1900-luvun alkupuolella. Kansatieteellinen Arkisto 36 Helsinki: Suomen Muinaismuistoyhdistys.

Nylen, Anna-Maja 1962: Varför klär vi oss? Kring draktens roll förr och nu. Västerås: ICA-förlaget.

Paasio, Yriö 1951: lijoen vittoyhdistys wv. 1915-1950. lijoki: lijoen Uittoyhdistys.

Pelkonen, Juhani 1989: Nuortin konesavotta 1913-1916. Lapin Metsämuseoyhdistys ry:n julkaisusaria n:0 5. Rovaniemi Lapin Metsämuseoyhdistys.

Peltonen, Matti 1991: Uiton historia. Tukinuitosta Suomessa 1800luvun puolivälistä 1980-luvulle. The History of Timber Floating in Finland. Tekniikan museon julkaisuja 6. Helsinki: Tekniikan museo.

- 1997: Kerta kiellon päälle. Suomalainen kieltolakimentaliteetti. Vuoden 1733 juopumusasetuksesta kieltolain kumoamiseen 1932. Hanki ja jää. Helsinki: Tammi.

Perä-Pohjalainen 1887, 1889, 1904.

Peterson, Gunilla 1993: Föremål och språk som symboler i en arbetarkultur. - Rig 4/1993. Föreningen för svensk kulturhistoria.

Pulma, Panu 1987: Suomen lastensuojelun historia. Helsinki: Lastensuojelun keskusliitto.

Purhonen, Elias J. 1960: Oulujoen Uittoyhdistys 1910-1960. Katsaus yhteisuiton 50-vuotistaipaleelle. Kajaani: Oulujoen Uittoyhdistys.

Pälsi, Sakari 1923: Tukkimetsistä ja uittopuroilta. Helsinki: Otava.
Pöysä, Jyrki 1997: Jätkän synty. Tutkimus sosiaalisen kategorian muotoutumisesta suomalaisessa kulttuurissa ja itäsuomalaisessa metsätyöperinteessa. Suomalaisen Kirjallisuuden Seuran Toimituksia 669. Helsinki: Suomalaisen Kirjallisuuden Seura.

Radforth, Ian 1998: Finnish Radicalism and Labour Activism in the Northern Ontario Woods. A Nation of Immigrants. Women, Workers, and Communities in Canadian History, 1840s1960s. Eds. Franca lacovetta \& Paula Draper \& Robert Ventresca. Toronto: University of Toronto Press.

Rannikko, Pertti 1999: Savottojen ja väestökadon Suomi. - Suomi: Maa, kansa, kulttuurit. Eds. Markku Löytönen \& Laura Kolbe. Helsinki: Suomalaisen Kirjallisuuden Seura.

Rapoport, Amos 1976: Sociocultural Aspects of Man-Environment Studies. - The Mutual Interaction of People and Their Built Environment. A cross-cultural perspective. World anthropology. Ed. Amos Rapoport. The Hague: Mouton.

— 1990: Systems of activities and systems of settings. - Domestic architecture and the use of space. An interdisciplinary crosscultural study. New directions in archaeology. Ed. Susan Kent. Cambridge: Cambridge University Press.

Rehnberg, Mats 1953: Arbetsvandringar från Småland. - Nordiska Museets och Skansens Årsbok 1953. Nordiska Museet.

Reinans, Sven Alur 1996: Den finländska befolkningen i Sverige - en statistisk-demografisk beskrivning. - Finnarnas historia i Sverige 3. Ed. Jarmo Lainio. Nordiska Museets Handlingar 122. Helsinki: Suomen Historiallinen Seura.

Rodrigo Blomqvist, Paula 2002: Från assimilation till separation. Den finska invandrargruppens krav på finskpråkig skolundervisning. Förvaltningshögskolans rapporter 47. Göteborg: Göteborgs universitet.

Roinila, Mika 1992: The Atlantic Finns; A Forgotten Ethnic Minority. - Migration I/1992. The Institute of Migration.

Ropponen, Jari 1985: Pohjois-Karjalan Uittoyhdistys 1886-1986. Joensuv: Pohjois-Karjalan Uittoyhdistys.

Rosander, Göran 1990: Fritidshusens symboliska gestaltning. Människor \& Föremål. Eds. Alf Arvidsson \& Kurt Genrup \& Roger Jacobsson \& Britta Lundgren \& Inger Lovgröna. Umeå: Ełnologiska institutionen vid Umeå universitet \& Kungl. Skytteanska Samfundet i Umeå. 
Rosengren, Annette 1975: Memma och kalakukko. Rapport om mathållning hos finländarna i Virsbo. Forskningsprojektet Migrationen mellan Finland och Sverige efter andra världskriget. Forskningsrapport 1. Stockholm: Nordiska Museet.

Roudasmaa, Stig 1986: Sotilasvirkapuvut 1918. Sotahistoriallinen Aikakauskirja 5. Helsinki: Sotahistoriallinen Seura \& sotatieteen laitos.

Ruotsin suomalaiset. Tutkimuksia, puheenvuoroja, kannanottoja kerhotoiminnasta. Stockholm: Tiden 1972.

Salmi, Minna 1996: Työelämän ja perhe-elämän yhdistämisen palapelit. - Työelämän sukupuolistavat käytännöt. Eds. Merja Kinnunen \& Päivi Korvajärvi. Tampere: Vastapaino.

Sariola, Sakari 1954: Lappi ja väkijuomat. Väkijuomakysymyksen tutkimussäätiön julkaisuja 1. Helsinki: Väkijuomakysymyksen tutkimussäätiö.

Sejersted, Francis 1980: Veien mot ost. - Vandringer. Festskrift till Ingrid Semmingsen på 70-arsdagen 29. mars 1980. Eds. Sivert Långholm \& Francis Sejersted. Oslo.

Siirtolaisuuden ja maassamuuton tutkimus. Muuttoliikkeiden pääpiirteet sekä selvitys tutkimustilanteesta ja tarpeesta. Siirtolaisuusinstituutin tutkimuksia no 21. Turku: Siirtolaisuusinstituutti 1984.

Siivonen, Katriina 1993: Ihmisen ulkoasujen viestit ja niiden tulkinta. - Sananjalka 35. Suomen kielen seura.

Silvasti, Tiina 2001: Talonpojan elämä. Tutkimus elämäntapaa jäsentävistä kulttuurisista malleista. Suomalaisen Kirjallisuuden Seuran Toimituksia 821. Helsinki: Suomalaisen Kirjallisuuden Seura.

Sirelius, U. T. 1906: Über die Sperffischerei bei den finnischugrischen Völkern. Travaux ethnographiques 3. Helsinki: Société finno-ougrienne.

Skogarbetarnas levnads- och arbetarförfôllanden i Värmland, Dalarna och Norrland av K. Socialstyrelsen. Stockholm 1916.

Snellman, G.R. 1914: Tutkimus Suomen sahateollisuudesta sekä sen yhteyteen kuuluvista metsänhakkuusta, lauttauksesta ja lastauksesta. - Työtilastoa 16. Helsinki: Teollisuushallitus.
Snellman Hanna 1988: Uittotyöväen elämää Suvannon kylassä ja Kitisenjoella 1920-1950-luvuilla. Lapin Metsämuseoyhdistys r.y:n julkaisusarja n:0 4. Rovaniemi: Lapin Metsämuseoyhdistys.

— 1989: Lumberiacks in Finnish Lapland. Reality and Romance as Historical Portrayals. - International Journal of Oral History 10, No. 2, June 1989. Meckler Corporation.

- 1990: The Uitto-6 at the Forestry Museum of Lapland, Rovaniemi. - The Maritime Museum of Finland. Annual Report 1989-1990. Helsinki: National Board of Antiquities.

- 1992: Floating Workers' dwellings in Finnisf Lapland. Ethnologia Fennica. Finnish Studies in Ethnology 19/1991. Ethnos ry.

— 1996: Tukkilaisen tulo ja lähtö. Kansatieteellinen tutkimus Kemijoen metsä- ja vittotyöstä. Scripta Historica 25. Oulu: Pohjoinen.

— 1999 Kansatieteilijä lapsuutensa maisemissa. - Tunturista tupaan. Pohjoiset identiteetit ja mentaliteetit osa 2. Eds. Maria Tuominen \& Seija Tuulentie \& Veli-Pekka Lehtola \& Mervi Autti. Lapin yliopiston taiteiden tiedekunnan julkaisuja C, katsauksia ja puheenvuoroja 17. Lapin yliopiston yhteiskuntatieteellisiä julkaisuja C, katsauksia ja puheenvuoroja 33. Inari: Kustannus-Puntsi.

- 2002: Vivencias de la emigración en Escandinavia. Historia, Antropologia y Fuentes Orales 28 Escenarios Migratorios. Barcelona.

— 2003: Sallan suurin kylä - Göteborg. Tutkimus Ruotsin lappilaisista. Suomalaisen Kirjallisuuden Seuran Toimituksia 927. Helsinki: Suomalaisen Kirjallisuuden Seura.

- 2005: Women working Their Way through Logging Camps. The North Calotte. Perspectives on the Histories and Cultures of Northernmost Europe. Eds. Maria Lähteenmäki \& Päivi Maria Pihlaja. Publications of the Department of History. University of Helsinki 18. Inari: Kustannus-Puntsi.

Sohlman, S.A. 1927: Metsä- ja uittotyömiesten asumuksista. Metsätaloudellinen aikakauskirja 5/1927. Suomen metsänhoitoyhdistys : Yksityismetsänhoitajayhdistys : Suomen vittajainyhdistys.

Sörlin, Sverker 1981: Flottning i Västerbotten. - Västerbotten 3/ 81. Västerbottens läns hembygdsförening. 
Steen, Immanuel 1980: Finska invandrarungdomar i Finnspång och Västerås. Enkätundersökning av grundskolans årskurs 4 och 9 samt förvärvsarbetande ungdomar i åldern 20-25 år. Stockholm: Statens ungdomsråd.

Suojanen, Päivikki 1996: Home as Verbal and Visual Discourse. Report on Stories Told by Finnish Americans. Arv. Nordic Yearbook of Folklore 1996. Kungliga Gustav Adolfs Akademien.

Suomalainen Ruotsissa. Selostus ulkomaalaisten oikeuksista ja velvollisuuksista. Stockholm: Invandrarverk 1969 \& 1979.

Suomen Asetuskokoelma 1928. Helsinki.

Suomen vapaussota kuvissa I-II. Eds. Mauri Malmberg \& Hugo Österman \& M. Kivilinna \& H.S. Viheriuuri \& Yrïö Ylänne. S.I: Isänmaan kirja 1984.

Suomen Virallinen Tilasto XXXII. Sosiaalisia erikoistutkimuksia IV. Tutkimus metsä- ja vittotyöntekijäin oloista keväällä 1921. Helsinki: Sosiaalihallitus 1923.

Suutari, Pekka 2000: Götaioen jenkka. Tanssimusiikki ruotsinsuomalaisen identiteetin rakentajana. Suomen etnomusikologisen seuran julkaisuja 7. Ruotsinsuomalaisten arkiston julkaisuja 4. Tukholma: Ruotsinsuomalaisten arkisto.

Szabó, Matias 1989: Vägen mot medborgarskap. Blandsverige. - Kulturskillnaden och kulturmöten. Eds. Åke Daun \& Billy Ehn. Stockholm: Carlssons.

Talve, Ilmar 1961: Satakunnan vittotyöläisistä ennen 1920-Iukua. - Scripta Ethnologia. Turku: Turun yliopiston kansatieteen laitos.

— 1963: Suomalainen kansatiede. - Sananjalka 5. Suomen kielen seura.

- 1978: Skogavverkningarna i Finland under 1800-talet. Förutsättningar och inledande skede. - Budkavlen 1977 1978. Etnologiska och Folkloristiska institutionerna vid Abo Akademi.

— 1983: Suomen kansankulttuuri teollistumiskaudella. - Suomen kulttuurihistoria II. Porvoo: WSOY.
- 1990: Suomen kansankulttuuri. Suomalaisen Kiriallisuuden Seuran Toimituksia 514. Helsinki: Suomalaisen Kirjallisuuden Seura.

— 2004: Kolme kotimaata. Omaelämäkerta. Turku: Kiria-Aurora.

Tammenoksa, Erkki 1972: Ruotsinsuomalaisten poliittinen toiminta. - Ruotsinsuomalaiset. Tutkimuksia, puheenvuoroja, kannanottoja. Ed. Erkki Tammenoksa. Tukholma: Tukholman suomenkielisen sosiaalidemokraattisen ammattiyhdistysväen kerho.

Tema invandrare. Levnadsförhållanden. Rapport 38. Sveriges officiella statistik. Stockholm: Statistiska Centralbyrån 1984.

Teräs, Kari 2001: Arjessa ja liikkeessä. Verkostonäkökulma modernisoituviin työelämän suhteisiin 1880-1920. Bibliotheca Historica 96. Helsinki: Suomalaisen Kirjallisuuden Seura.

Toukomaa, Pertti 1973: Korutonta kertomaa. Suomalaisperheet ruotsalaisessa teollisuusyhdyskunnassa. Tampereen yliopiston sosiologian ja sosiaalipsykologian laitoksen tutkimuksia 1. Tampere: Tampereen yliopisto.

Tuomi-Nikula, Outi 1989: Saksansuomalaiset: tutkimus syntyperäisten suomalaisten akkulturaatiosta Saksan liittotasavallassa ja Länsi-Berliinissa. Suomi 148. Helsinki: Suomalaisen Kirjallisuuden Seura.

Tyrfelt, Annika 1975: Aldrig blir den burden jungfru mer, aldrig bär hon krona... Rapport om finländska invandrares högtidsseder i Virsbo. Forskningsprojektet Migrationen mellan Finland och Sverige efter andra världskriget. Forskningsrapport. Stockholm: Nordiska Museet.

Valonen, Niilo 1952: Geflechte und andere Arbeiten aus Birkenrindenstreifen unter besonderer Berücksichtigung finnischer Tradition. Kansatieteellinen Arkisto 9. Helsinki: Suomen Muinaismuistoyhdistys.

Van Maanen, John 1988: Tales of the Field. On Writing Ethnography. Chicago \& London: The University of Chicago Press.

Velure, Magne 1975: Kniv, sprit och sisu. En preliminary rapport om stereotypisering av finnar i Sverige. Forskningsprojektet Migrationen mellan Finland och Sverige efter andra världskriget. Forskningsrapport 3. Stockholm: Nordiska Museet. 
Vilkuna, Kustaa 1974: Lohi. Kemijoen ja sen lähialueen lohenkalastuksen historia. Helsinki: Otava.

Wackerman, A. E. 1949: Harvesting Timber Crops. New York: McGraw-Hill.

Waterson, Roxana 1991: The living house. An Anthropology of Architecture in South-East Asia. Oxford: Oxford University Press.

Werner-Hansen, Georg 1970: Nordmenn i Østerled. Om nordmennes virksomhet I skogbruk, trelasthandel og treföredling I Finnland. Oslo: Landbruksförlaget.

Wolf-Knuts, Ulrika 2000: Ett bättre liv. Finlandssvenskar i Sydafrika - om emigration, minnen, hemlängtan och nostalgi. Migrationsstudier B 4. Åbo: Institute of Migration.

Women in the Field. Anthropological Experiences. Ed. Peggy Golde. Berkley: University of California Press 1986.

Wright, Will 1977: Six guns \& Society. A Structual Study of the Western. Berkley: University of California Press.

Ylinen, Raimo 1980: Savon Uittoyhdistys 1930-1980. Kuopio: Savon Uittoyhdistys.

Ylärakkola, Arvo 1972: Vähemmistöpuoluehanke savuna ilmaan. - Ruotsinsuomalaiset. Tutkimuksia, puheenvuoroja, kannanottoja. Ed. Erkki Tammenoksa. Tukholma: Tukholman suomenkielisen sosiaalidemokraattisen ammattiyhdistysväen kerho.

Yocom, Margaret M. 1990: Fieldwork, Gender and Transformation: The Second Way of Knowing. - Southern Folklore. Vol. 47, nr. 1. Ed. Camilla Collins.

Ågren, Marja 2002: Vad sags om finskhet? - Nordiga länder kulturvetenskapliga perspektiv. Eds. Magnus Berg \& Riina Reinvelt \& Line Alice Ytrehus. Skrifter från Etnologiska föreningen i Västsverige 38. Göteborg: Etnologiska föreningen i Västersverige.

Åström, Anna-Maria 1993: 'Sockenboarne'. Herrgårdskultur i Savolax 1790 - 1850. Folklivsstudier 19. Skrifter utgivna av Svenska litteratursällskapet i Finland 585. Helsingfors: Svenska Litteratursällskapet i Finland.

Österlund-Pötzsch, Susanne 2003: American Plus. Etnisk identitet hos finlandsvenska ättlingar i Nordamerika. Skrifter utgivna av Svenska Litteratursällskapet i Finland nr. 658. Helsingfors: Svenska Litteratursällskapet i Finland. 




\section{WWW.puntsi.fi}

books from the northernmost north

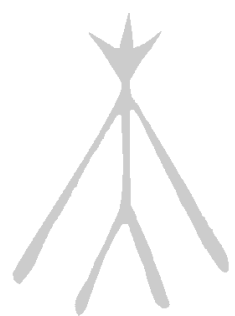

